\title{
"AMBIENT NOISE MEASUREMENTS FOR PRELIMINARY MICROZONING STUDIES IN THE CITY OF MESSINA, SICILY,
}

\author{
Silvia Scolaro ${ }^{1}$, Paolo Pino ${ }^{1}$, Sebastiano D’Amico², Barbara Orecchio ${ }^{1}$, Debora Presti ${ }^{1}$, \\ Antonino Torre ${ }^{1}$, Cristina Totaro ${ }^{1}$, Daniela Farrugia ${ }^{2}$, Giancarlo Neri ${ }^{1}$ \\ ${ }^{(1)}$ Department of Mathematics, Computer Sciences, Physics, and Earth Sciences, University of Messina, Messina, Italy \\ ${ }^{(2)}$ Department of Geosciences, University of Malta, Malta
}

Article history

Receveid November 26, 2016; accepted September 5, 2017.

Subject classification:

Ambient noise; H/V; Site frequencies.

\begin{abstract}
On December $28^{\text {th }} 1908$ the city of Messina was destroyed by one of the most catastrophic Italian earthquakes of the last centuries $\left(\mathrm{M}_{\mathrm{w}}=7.1, \mathrm{I}=\mathrm{XI}\right)$ which caused more than 60000 deaths and destruction in many localities of Sicily and Calabria. In this study we present the results of more than 100 seismic ambient noise measurements carried out in the framework of the first massive seismic site response survey performed in the city of Messina. Starting from geological information and historical reports reconstructing the damage scenario of the 1908 event, we have identified several sites particularly interesting for seismic response investigations. This extensive survey allowed us to evaluate the fundamental resonance frequency for each investigated site and to identify the areas prone to site amplification. Measurements have been performed by using 3-component velocimeter, Micromed Tromino, and the collected dataset has been processed by applying the Horizontal-to-Vertical Spectral Ratio technique. For each investigated site we provide the fundamental resonance frequency and a preliminary information on the metamorphic bedrock depth. The massive dataset collected and the results obtained will be useful for the seismic microzonation of the urban territory of Messina.
\end{abstract}

\section{INTRODUCTION}

The Messina Straits (Southern Italy) is one of the most seismically active areas of the Mediterranean (see http://emidius.mi.ingv.it/NT) and the December 28th 1908 earthquake $(\mathrm{Mw}=7.1, \mathrm{I}=\mathrm{XI})$, with the related tsunami (run-up height up to $10 \mathrm{~m}$ ) is one of the strongest events occurred in Italy during last centuries (Figure 1). The 1908 earthquake caused more than 60000 casualties and destroyed many localities of Sicily and Calabria [Mercalli, 1909; Baratta, 1910]. Damage in Messina and Reggio Calabria was exacerbated by the poor quality of construction and building materials, as well as by the occurrence of significant earthquakes during the preceding decades (1894, 1905, 1907). Extensive information concerning the damage level in the different areas of Messina are reported in Baratta [1910], who also estimated that about $98 \%$ of the buildings where heavily damaged or needed to be demolished. As regards environmental effects, no surface breaks directly related with the earthquake fault was reported, but several secondary surface effects were observed both in Sicily and Calabria. Variations in the water level in pools and wells, ground fractures, and many landslides and rockfalls were observed over a large region encompassing the intensity X and XI areas and significant subsidence occurred on both sides of the Straits [Pino et al., 2009].

The analysis of the effects of past earthquakes on the cities helps to identify most affected areas. In fact, it is possible to study geological and anthropic features that influence the intensity of damage so improving seismic prevention strategy. The dynamic ground shaking is one of more important factors for the analysis of the local seismic hazard. The effects of seismic motion can depend largely on local geology therefore the investiga- 


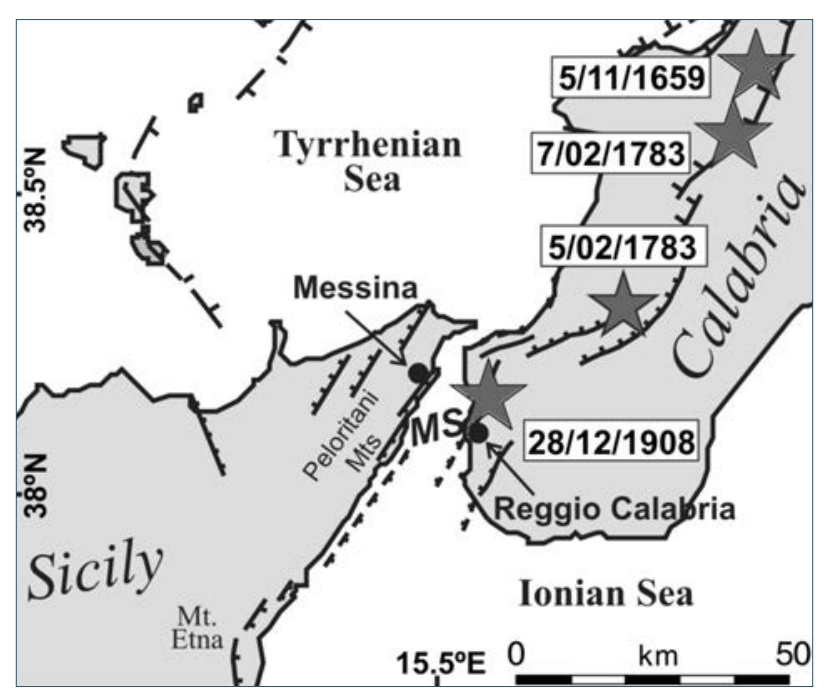

FIGURE 1. The figure shows the Messina Straits (MS) area and the principal fault systems: hatched, normal faulting [Ghisetti, 1992; Bonini et al., 2011; Doglioni et al., 2012]. Stars indicate the historical earthquakes for the study area with $\mathrm{Mw} \geq 6.5$ (http://doi.org/10.6092/INGV.IT-CPTI11).

tion of the local ground condition is of primary interest for site-specific hazard and risk assessment. A quick estimate of the surface geology effects on seismic motion is performed in this study by the Horizontal-to-Vertical noise Spectral Ratio (HVSR or H/V) method [Lermo and Chavez-Garcia, 1993; Konno and Ohmachi, 1998; Bard, 1999; Bonnefoy-Claudet, 2006a; D’Amico et al., 2008, Castellaro and Mulargia, 2009; Vella et al., 2013]. This technique relies on the calculation of the Fourier amplitude spectral ratio between the horizontal to vertical components of the seismic noise recorded with a single three component seismic station [Nogoshi and Igarashi, 1971; Nakamura, 1989; Bonnefoy-Claudet, 2006a and 2006b]. The power spectra of the components of the seismic noise are affected by noise source characteristics and by geothecnical parameters of the subsoil [Nogoshi and Igarashi, 1971; Nakamura, 1989]. The basic hypothesis for using seismic ambient noise is that the resonance of a soft layer corresponds to the fundamental mode of Rayleigh waves, which is associated with an inversion of the direction of Rayleigh wave rotation [Nogoshi and Igarashi, 1971; Lachet and Bard, 1994; Scherbaum et al., 2003]. Thus, the spectral ratio can reveal the presence of amplification peaks due to impedance contrasts between sedimentary layers, and it provides a first estimate of the fundamental resonance frequency of the site.

At present, several seismic site response studies have been performed in Eastern Sicily [e.g. Gresta et al., 2004; Rigano et al., 2005; Panzera et al., 2011, 2016; Di Stefano et al., 2014, Arancio et al., 1986; De Rose et al., 2012; Pino et al., 2017], but only few analyses regard the city of Messina [Arancio et al., 1986; De Rose et al., 2012]. In this study, we focused on the presentation of the results of an extensive survey of seismic noise measurements in Messina. The main aim is to investigate the fundamental resonance frequencies that characterize areas of particular interest for the site effect investigation and the large amount of collected data allowed us to obtain a detailed mapping of the site frequencies within the urban areas.

\section{GEOLOGIC SETTING}

The Messina Straits is a very narrow graben structure crosscutting with a NNE-SSW trend the southern segment of the Calabrian Arc (Figure 1). It is located between the faster SE retreating Ionian slab beneath Calabria and the Sicilian continental lithosphere in compression along the Tyrrhenian offshore of Sicily [Ghisetti, 1992; Tortorici et al., 1995; Neri et al., 2004 and 2005]. Being a transfer zone between these two geodynamic settings, the Messina Straits is characterized by a complex network of normal and transtensional faults [Ghisetti, 1992; Neri et al., 2005; Doglioni et al., 2012] related to the opening of the Straits [Bonini et al., 2011] and controlling the landform shaping. A particular aspect of this area are isolated hills and NW-SE elongated hilly ranges with steep slopes, tectonically structured in a semi-graben down faulted seaward. The hills are surrounded by flood plains and coastal esplanade where the center of Messina city lies while several villages are scattered on the top of the hills. We report the geological map of Messina indicating the investigation-sectors (red boxes) and the relative geological cross-sections available from the literature [Figure 2; Gargano et al., 1994]. In the survey area widespread outcrop paleozoic highgrade metamorphic rocks (Aspromonte Nappe, Auct.) unconformably overlaid by scattered heterogeneous and discontinuous sedimentary succession Middle-Upper Miocene-Middle Pleistocene in age (Figure 2). On the metamorphic bedrock sporadically overlies the oldest sedimentary sequence of this region, Middle-Upper Miocene San Pier Niceto Formation (Auct.), consisting of a massive, well compacted and weakly cemented silty-sandy conglomeratic and arenites up to $150 \mathrm{~m}$ thickness. We can also find above metamorphic rocks the coarse sands and gravels of Middle Pleistocene Messina Formation (a granular formation, coarser and denser, predominantly gravelly interfingered with lenses of pebbles) with highly variable thicknesses that can reach up to 250 meters in the northern part of Messina (Figure 2). A few tens of meters of messinian limestones and tender whitish marly limestone (Trubi Formation, 


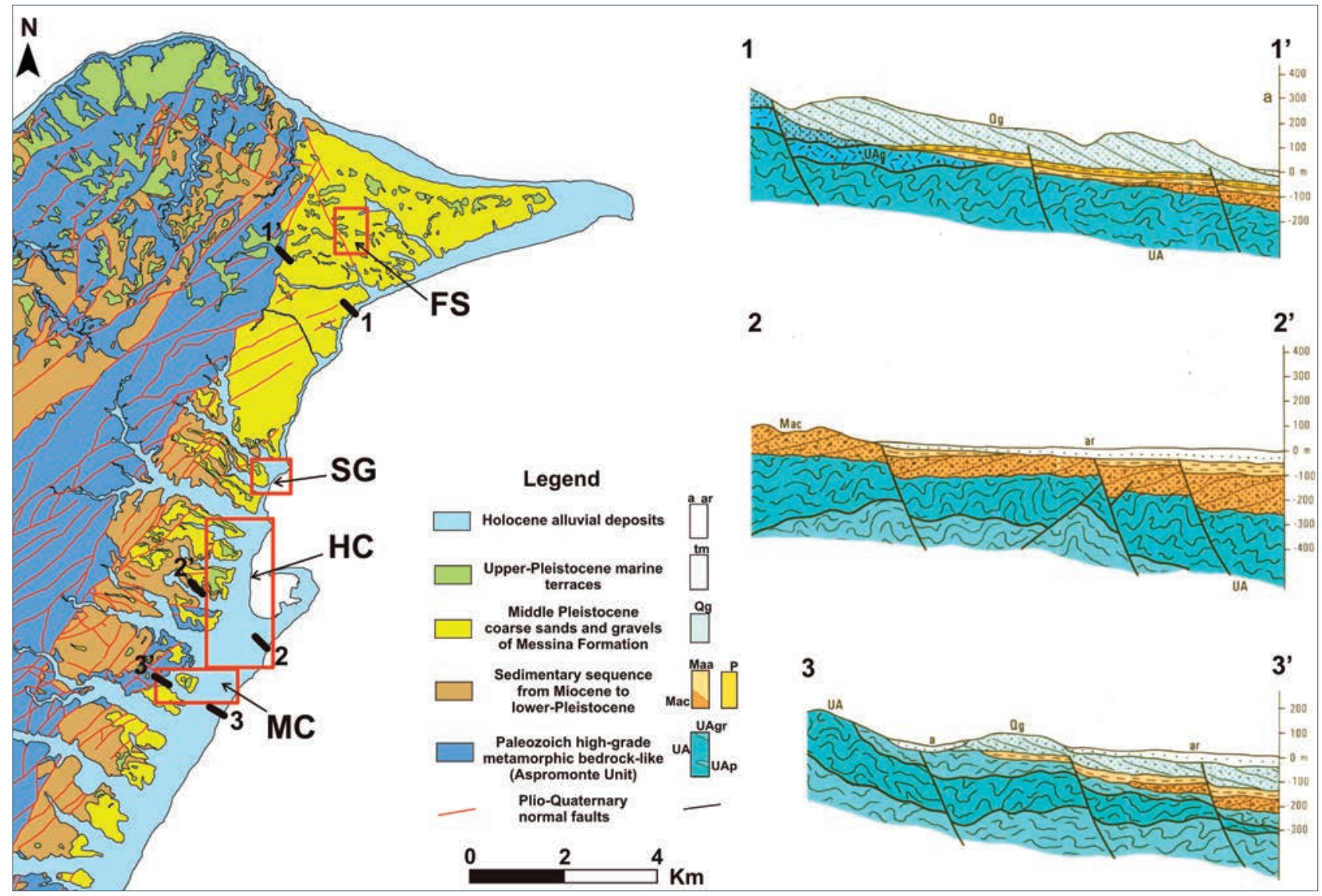

FIGURE 2. Geological and structural map of Messina region [left panel, modified from Gargano et., 1994]. The red boxes identify the areas under investigation: Faro Superiore (FS), Salvatore dei Greci (SG), Historic Centre (HC), Monumental Cemetery (MC). The geological cross-sections available for the investigated areas are reported in the right panel [modified from Gargano et al. 1994]. No cross-section is available for the SG sector.

Auct), sometimes overlapped by Plio-Pleistocene calcarenitic units, sporadically outcrop between both geological sedimentary formations previously described.

\section{METHODS}

An extensive survey of seismic noise recordings was carried out in the urban territory of Messina by applying the Horizontal-to-Vertical Spectral Ratios technique [Nogoshi and Igarashi, 1971; Nakamura, 1989] to assess the fundamental resonance frequencies. The HVSR technique consists in estimating the ratio of horizontal and vertical components of the ambient noise recorded at the surface. This spectral ratio exhibits a peak corresponding to the fundamental frequency of a site [Bonnefoy-Claudet et al., 2006a and 2006b] and this peak is more accentuated when a sharp impedance contrast exists between the bedrock and upper layers [Field and Jacob, 1993; Lachet and Bard, 1994; Bard, 1999; Mucciarelli and Gallipoli, 2001; Malischewsky and Scherbaum, 2004]. H/V spectral ratio without clear and statistically significant peaks [i.e. peak amplification smaller than 2 unit; Bard, 2005; Vella et al., 2013] was interpreted as indicative of subsurface structures devoid of impedance contrasts at depth. The ambient noise wavefield is a combination of both body and surface waves and the resonance peak can be interpreted both in terms of SH resonance in superficial layers and ellipticity if Rayleigh surface waves predominate [Fäh et al., 2001; Scherbaum et al., 2003; Bonnefoy-Claudet et al., 2006a]. Also, the final H/V curve contains useful information about the relationship between the shearwave velocity profile of the sediments and their thickness [Fäh et al., 2003; Castellaro and Mulargia, 2009; Parolai, 2012].

According to the historical information reported by Baratta [1910], we have identified several sites particularly interesting for the site effect investigation and more than 100 single-points measurements were sampled. In our survey single-station measurements were performed by a 3-component digital seismograph Micromed Tromino (www.tromino.eu). At each site we recorded seismic noise for 20 minutes with a sampling rate of 256 $\mathrm{Hz}$. Data analysis of single-station measurements was performed using the Grilla software (www.tromino.eu). Following the SESAME criteria [Bard, 2005], each record 
was divided into non-overlapping time windows $20 \mathrm{~s}$ long. The Fourier spectrum of each time window was calculated and smoothed through a triangular window with frequency dependent half-width (5\% of central frequency). The H/V spectral components ratio was computed for each frequency by averaging the horizontal spectra using the geometrical mean and dividing by the vertical spectrum for each time window. Before interpreting the resulting curves, we identified and discarded eventual spurious noise windows associated to very close sources (e.g. due to impulsive or strongly localized anthropic sources) thus minimizing the standard deviation. The analyses were limited to the frequency range $0.1-20 \mathrm{~Hz}$ which is the frequency range of interest for seismic microzonation and earthquake engineering. In general, if final curves show a single peak, the corresponding frequency $\mathrm{F}_{0}$ is considered as the fundamental resonance frequency at the site. If another peak is present, it is interpreted as a resonance frequency due to a shallower impedance contrast.

\section{RESULTS AND DISCUSSIONS}

Single-station measurements were carried out in four sectors (Figure 2) named Faro Superiore (FS), Salvatore dei Greci (SG), Historic Center (HC), and the Monumental Cemetery (MC). These sectors are representative of different level of damages after the 1908 earthquake including, according to the information collected by Baratta [1910], some of the more (Faro Superiore, Historic Center) and the less (Salvatore dei Greci, Monumental Cemetery) damaged areas of the city. The geological map (Figure 2) shows that sectors SG, HC, MC are mostly located on Holocene alluvial deposits of coastal and fluvial plains while preHolocene substratum outcrops only in the hilly zones (FS sector in Figure 2). For each study area we have grouped the H/V curves to identify the characteristic frequency distribution (Figures 3 to 6), while all the individual curves with the relative standard deviation are reported in the supplementary material.

Faro Superiore (FS, Figure 2) lies in a flat and wide top of a hill made by more than $200 \mathrm{~m}$ [Gargano et al., 1994] of thick gravels and sands of the Messina Formation. In this area and in the surroundings, no other geological formation outcrops and the metamorphic bedrock is localized up to a depth of about 400-500 m depth [Gargano et al., 1994]. We have performed ambient noise singlestation measurements scattered in the whole area (Figure 3a). All the $\mathrm{H} / \mathrm{V}$ results show only a single peak at about $0.4 \mathrm{~Hz}$ that might correspond to a very deep impedance

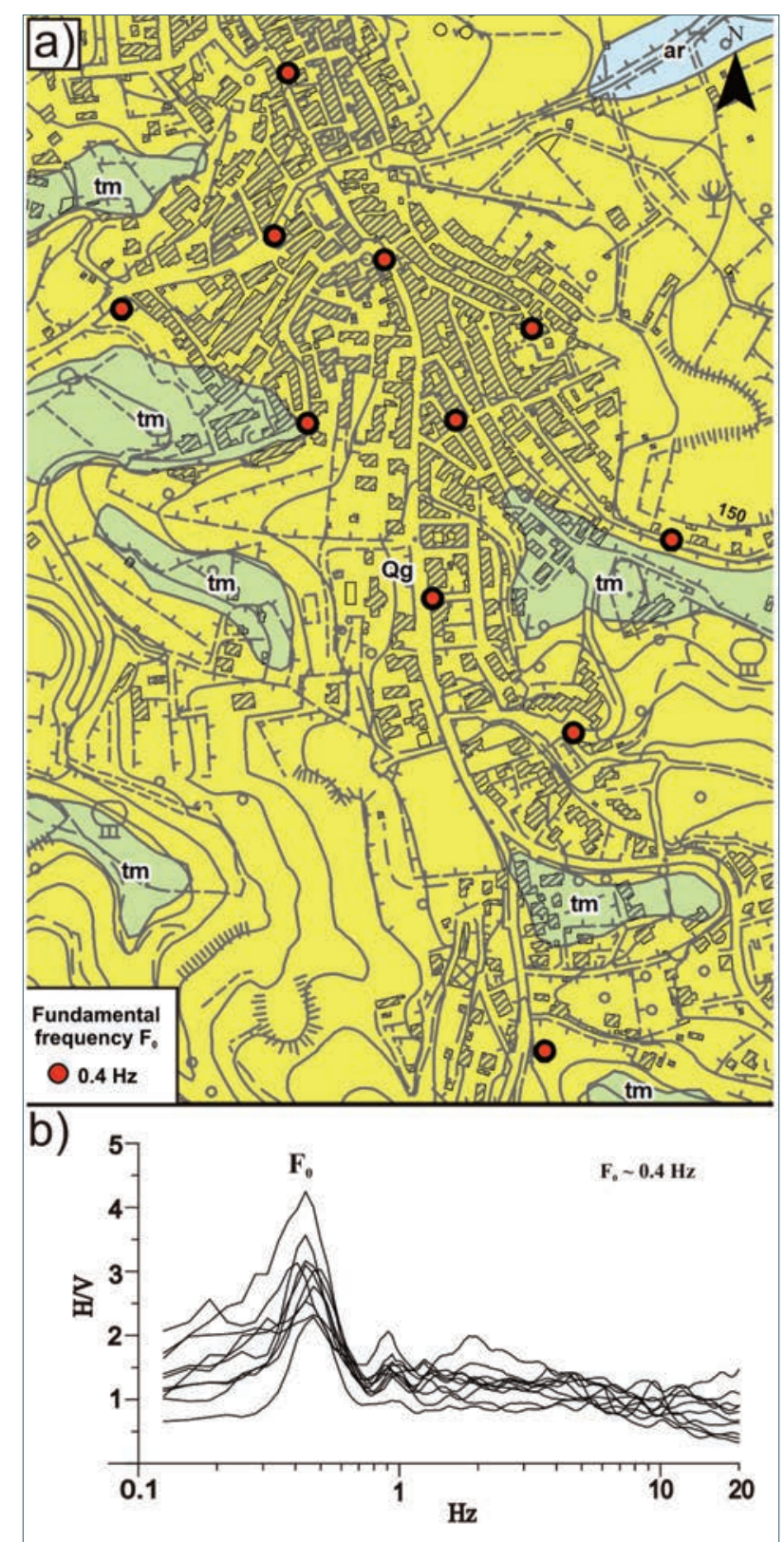

FIGURE 3. a) Geological base map of Faro Superiore (FS) showing the location of the seismic noise acquisition points (red dots). For geologic details see Figure 2. b) The panel reports the H/V curves obtained in the FS area. A fundamental frequency peak at about $0.4 \mathrm{~Hz}$ is present at all investigated sites.

contrast (Figure 3b), possibly the seismic bedrock.

Several alluvial fans are present along the coastline near the Salvatore dei Greci area (SG, Figure 2) and put down by the lateral torrents that flow from the Peloritani Mts. flanks. In general, they are composed of heterogeneous grain sizes (commonly sands, gravels and boulders). Within the alluvial formation a water table is located in variable depth, from a few meters nearby the coastline to about 25 meters more in the hinterland. Underlying to the alluvial deposits there are gravels and 

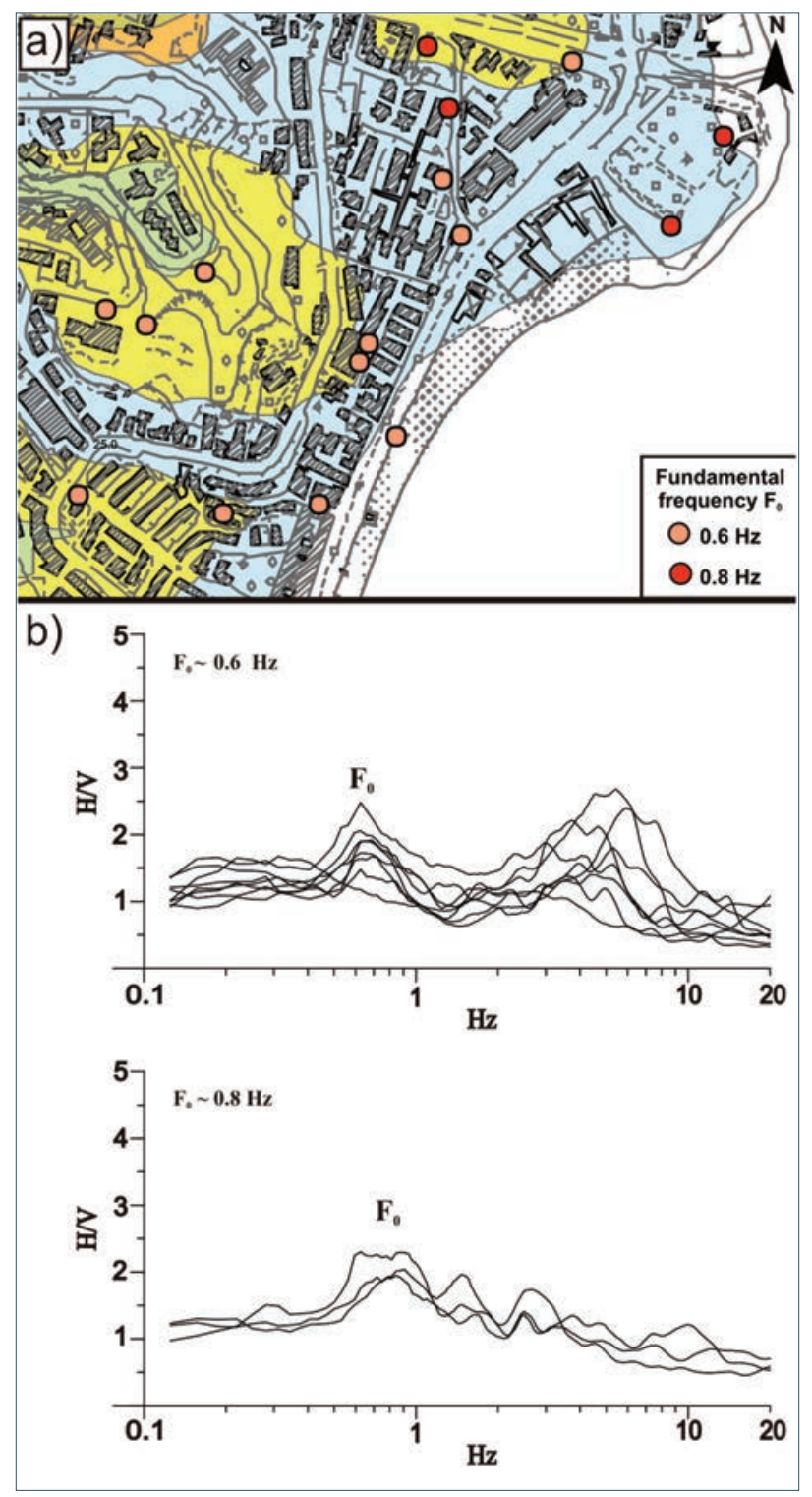

FIGURE 4. a) Geological base map of Salvatore dei Greci (SG) showing the location of HVSR measurement points (red and orange dots). For geologic details see Figure 2. b) Examples of different $\mathrm{H} / \mathrm{V}$ curves obtained in the investigated area. We observed curves characterized by a bimodal behavior with a low $\mathrm{F}_{0}$ at about $0.6 \mathrm{~Hz}$ and peaks at frequencies higher than 3.0 $\mathrm{Hz}$ (top plot), and curves with $\mathrm{F}_{0}$ peaks at about $0.8 \mathrm{~Hz}$ (bottom panel).

sands of Messina Formation with thicknesses in the range 60-100 meters. Figure 4 shows the location of the seismic noise acquisition points (plot a) in the SG sector and the corresponding $\mathrm{H} / \mathrm{V}$ results (plot b). We can distinguish two categories of H/V curves: the first group is characterized by a bimodal behavior with a low fundamental frequency $\left(\mathrm{F}_{0}\right)$ at about $0.6 \mathrm{~Hz}$ and peaks at frequencies higher than $3.0 \mathrm{~Hz}$, having amplitude that in both cases just reach 2 units; the second group shows only the fundamental frequency $\left(\mathrm{F}_{0}\right)$ peaks at about $0.8 \mathrm{~Hz}$ with am- plitude that just reach 2 units. The frequency values $\mathrm{F}_{0}$ can be associated to the resonance frequency of the deep bedrock while the higher frequency peaks, where present, are associated with shallow impedance contrasts most probably related to soft sediment deposits.

In the Historic Center of Messina (HC, Figure 2) the geological architecture is similar to Salvatore dei Greci area. Figure 5 shows the seismic noise acquisition points (plot a) and the corresponding $\mathrm{H} / \mathrm{V}$ results (plot b). The sample points display resonant frequencies in the range 0.6 - $2 \mathrm{~Hz}$. In particular, we may distinguish three main groups of $\mathrm{H} / \mathrm{V}$ curves characterized by frequency peaks at about $0.6 \mathrm{~Hz}, 1.0 \mathrm{~Hz}$ and $2.0 \mathrm{~Hz}$, respectively (Figure 5b). Along the investigated area we observe that the fundamental frequency value increase and then decrease progressively moving from North to South. The general features of the reconstructed bedrock portion are compatible with the geological data and to results obtained by De Rose et al. [2012].

The interpretative geological section reported in Figure 2 shows, in Monumental Cemetery area, a general architecture of buried staircase geological formations and NNE-SSW trending normal faults downing seaward. Moving towards the sea, a metamorphic bedrock-like lies at progressively greater depths (up to $230 \mathrm{~m}$ above ground level) preceded by a well-consolidated sedimentary sequence of late Miocene-Pleistocene (Figure 2). Figure 6 shows the seismic noise acquisition points in the MC area (plot a) and the related H/V curves (plot b). We differentiate three main groups of $\mathrm{H} / \mathrm{V}$ results: the first group shows a bimodal behavior with a fundamental frequency $\mathrm{F}_{0}$ at about $0.6 \mathrm{~Hz}$ (amplitude greater than 3 units), and peaks at frequency higher than $1.0 \mathrm{~Hz}$ (amplitude greater than 2 units); the second and third group show only one peak with amplitude greater than 2 units at about $1.0 \mathrm{~Hz}$ and $2.0 \mathrm{~Hz}$, respectively. Moving from east to west, away from the coastline, the fundamental frequency $\left(\mathrm{F}_{0}\right)$ increase progressively highlighting the depth variation of the seismic reflector (Figure 6). Preliminary array measurements using joint inversion of surface wave dispersion and H/V curves [Figure 6c; details on method and procedures are given in Picozzi and Albarello, 2007; Farrugia et al., 2016 and references therein] confirm the depth of main reflectors as shown in figure $6 b$.

\section{CONCLUSIONS}

In almost all the HVSR measurements carried out in the city of Messina, fundamental frequencies $\left(\mathrm{F}_{0}\right)$ associated to deep reflectors are evident in the range $0.4-2$ 


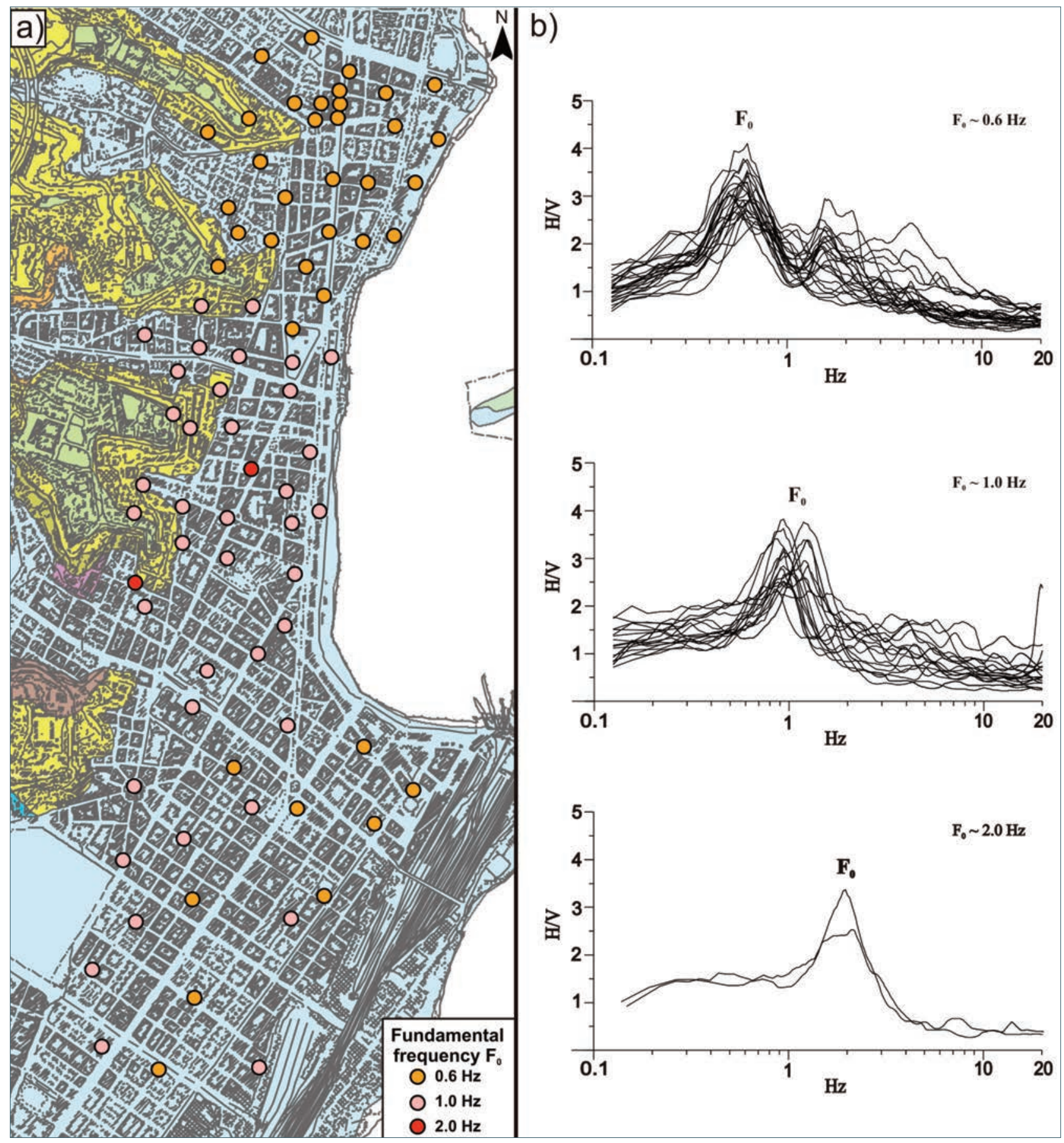

FIGURE 5. a) Geological base map of the Historic Center (HC) showing the location of HVSR measurement points (colored dots). For geologic details see Figure 2. From North to South the sample points exhibit $\mathrm{F}_{0}$ frequencies in the range $0.6-2 \mathrm{~Hz}$. b) Examples of different $\mathrm{H} / \mathrm{V}$ curves obtained in the investigated area. Plots from top to bottom show curves with peaks at about $0.6 \mathrm{~Hz}, 1.0 \mathrm{~Hz}$ and $2.0 \mathrm{~Hz}$ respectively.

Hz. However, in several sites significant high-frequency peaks related to shallow sediment coverage are also observed. Combining our results with geological information available for the study area we can preliminarily state that frequency variation of fundamental peaks can be associated to the variable depth of seismic bedrock.

This work furnishes an extensive collection of seismic noise data useful for the seismic microzonation of the urban territory of Messina. The seismic microzonation of a territory aims to identify which geological and geomorphological conditions may affect the characteristics of the seismic motion and produce site effects. Also, the evaluation of the local site response in an urban area as Messina is one of the main goals for city planning 

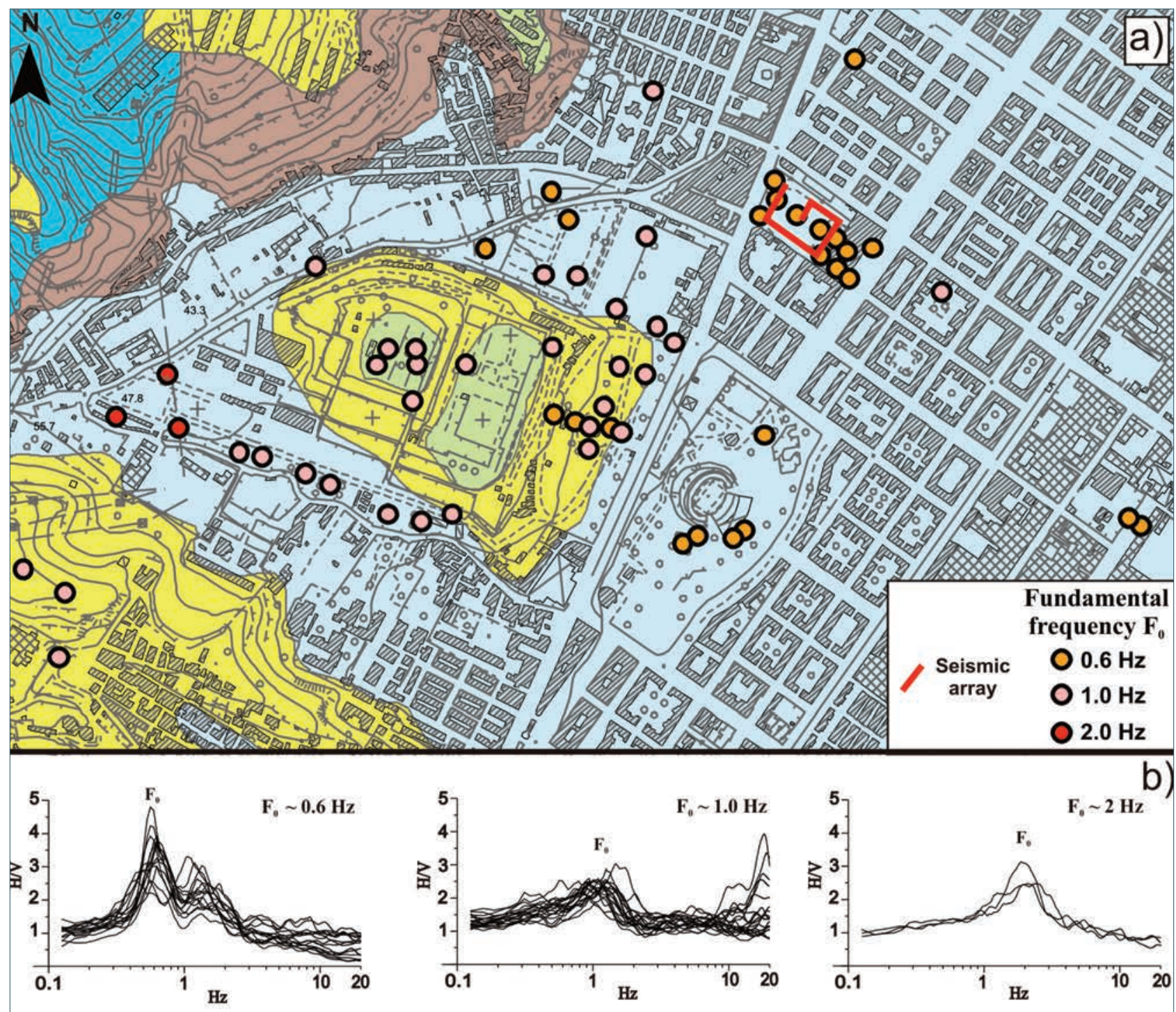

c)
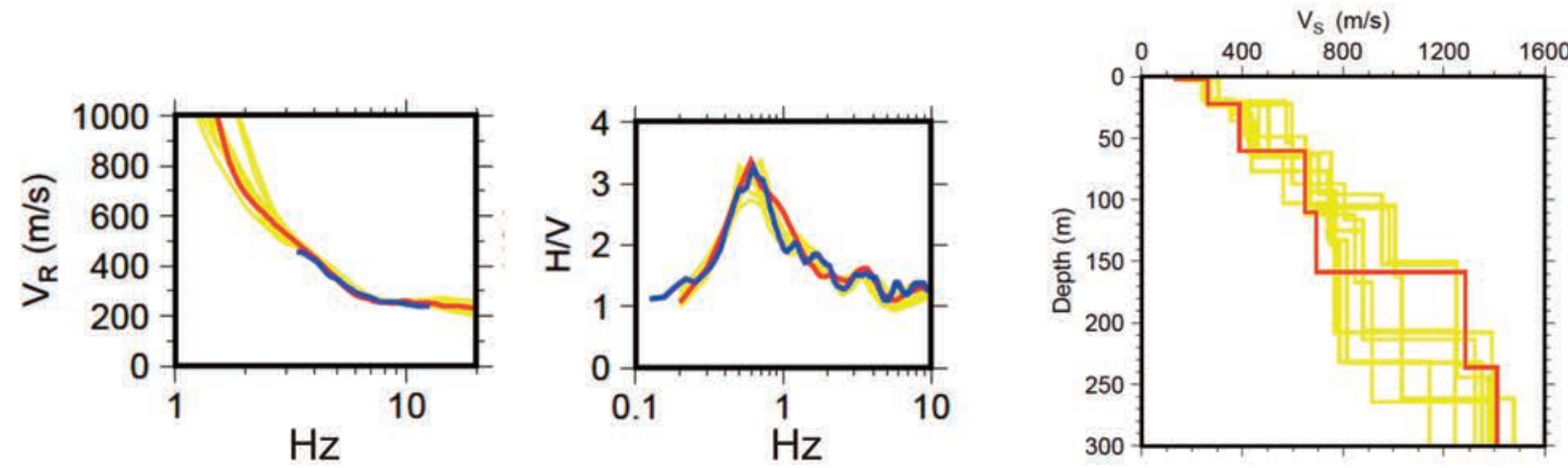

FIGURE 6. a) Geological base map of the Monumental Cemetery area (MC) showing the location of HVSR measurement points (colored dots). For geologic details see Figure 2. b) Examples of different H/V curves obtained in the investigated area. The first group (left plot) shows a fundamental peak at about $0.6 \mathrm{~Hz}$ and peaks with amplitude greater than 2 at frequencies higher than $1.0 \mathrm{~Hz}$, the second (central plot) and third group (right plot) show only fundamental peaks at about $1.0 \mathrm{~Hz}$ and $2.0 \mathrm{~Hz}$, respectively. c) Results of preliminary array measurements performed in the investigated sector. The left and central panels show the effective dispersion and H/V curves (blue and red indicate the experimental and the best-fitting theoretical ones, respectively). The right panel reports the $1 \mathrm{D}$ velocity profiles obtained by the joint inversion (the red profile represents the one with the lowest misfit). 
aimed at mitigating the potentially high seismic risk. For this purpose, the seismic noise HVSR technique has proven suitable to identify areas subject to amplification effects and to delineate the geometry of the sedimentary layers. The huge number of seismic noise data collected and analyzed in the study areas of Messina combined with geological and lithological available information have allowed us to furnish first insights of possible areas prone to seismic amplification.

Acknowledgements. We thank the Associated Editor M. Mattia and two anonymous reviewers for their critical reviews and constructive comments. This research has benefited from funding provided by PO-FESR 2007/2013 Project 'Attività di sviluppo sperimentale finalizzata alla riduzione del rischio sismico nella Sicilia Orientale'.

\section{DATA AND SHARING RESOURCES}

http://emidius.mi.ingv.it/NT

\section{REFERENCES}

Arancio, S. and Lombardo, G. (1986). Elementi di microzonazione sismica dell'area dello Stretto di Messina. Bollettino della Societa Geologica Italiana, 105(12), 87-98.

Baratta, M. (1910), La catastrofe sismica Calabro messinese (28 dicembre 1908). Società geografica italiana.

Bard, P. Y. (2005) Guidelines for the implementation of the $\mathrm{H} / \mathrm{V}$ spectral ratio technique on ambient vibrations: measurements, processing, and interpretations. SESAME European research project. WP12, deliverable D23.12, 2004; available at: http://sesame-fp5.obs. Ujf-grenoble.fr/Deliverables2004.

Bard, P. Y. (1999). Microtremor measurements: a tool for site effect estimation. The effects of surface geology on seismic motion, 3, 1251-1279.

Bonnefoy-Claudet, S., Cotton, F., and Bard, P. Y. (2006a). The nature of noise wavefield and its applications for site effects studies: a literature review; EarthScience Reviews, 79(3), 205-227.

Bonnefoy-Claudet, S., Cornou, C., Bard, P. Y., Cotton, F., Moczo, P., Kristek, J., Fäh, D. (2006b). H/V ratio: a tool for site effects evaluation. Results from 1-D noise simulations, Geophys. J. Int., 167(2), 827-837.

Bonini, L., Di Bucci, D., Toscani, G., Seno, S., Valensise, G. (2011). Reconciling deep seismogenic and shallow active faults through analogue modeling: the case of the Messina Straits (southern ltaly), J. Geol. Soc.,
168(1), 191-199.

Castellaro, S., and Mulargia, F. (2009). The effect of velocity inversions on H/V, Pure Appl. Geophys., 166(4), 567-592.

D’Amico, V., Picozzi M., Baliva F., Albarello D. (2008). Ambient noise measurements for preliminary site-effects characterization in the urban area of Florence, 1taly, Bull. Seism. Soc. Am., 98.3, 1373-1388.

De Rose, C., Guerra, 1., Gervasi, A., Tafaro, A. F., \& Mucciarelli, M. (2012). Site effect in Messina and Reggio Calabria Area using HVSR technique. Rendiconti online della società geologica italiana.

Di Stefano P., Luzio D., Renda P., Martorana R., Capizzi P., D’Alessandro A., Messina N., Napoli G., Todaro S., Zarcone, G. (2014). Integration of HVSR measures and stratigraphic constraints for seismic microzonation studies: the case of Oliveri (ME). Natural Hazards and Earth System Sciences Discussions, 2(4), 2597-2637.

Doglioni, C., Ligi, M., Scrocca, D., Bigi, S., Bortoluzzi, G., Carminati, E., Riguzzi, F. (2012). The tectonic puzzle of the Messina area (Southern ltaly): Insights from new seismic reflection data. Scientific reports, 2.

Fäh D., Kind F., Giardini D. (2001) A theoretical investigation of average H/V ratios, Geophys. J. Int., 145, 535-549.

Fäh, D., Kind, F., Giardini, D. (2003). Inversion of local Swave velocity structures from average $\mathrm{H} / \mathrm{V}$ ratios, and their use for the estimation of site-effects. J. Seismol., 7, 449-467.

Farrugia F., Paolucci E., D’Amico S., Galea P., (2016). Inversion of surface-wave data for subsurface shearwave velocity profiles characterised by a thick buried low-velocity layer. Geophysical Journal International, 206, 1221-1231, doi:10.1093/gji/ggw204

Field, E., and Jacob, K. H. (1993). The theoretical response of sedimentary layers to ambient seismic noise. Geophys. Res. Lett.,. 20, 24, 2925-2928.

Gargano, C. (1994). Carta geologica di Messina e del settore nord-orientale dei Monti Peloritani. Dir. F. Lentini, scala, 1(25.000).

Ghisetti, F. (1992). Fault parameters in the Messina Strait (southern ltaly) and relations with the seismogenic source, Tectonophysics, 210(1), 117-133.

Gresta S., Langer H., Mucciarelli M., Gallipoli M. R., Imposa S., Lettica J., Monaco C. (2004). The site response in the city of Ragusa-lbla (Sicily) by using microtremors and strong ground motion simulations. In Risk Analysis IV, edited by CA Brebbia, Wessex Institute of Technology UK, 93-101, doi:10.2495/RISK040091

Konno, K., and Ohmachi, T. (1998). Ground-motion char- 
acteristics estimated from spectral ratio between horizontal and vertical components of microtremor. Bull. Seism. Soc. Am., 88(1), 228-241.

Lachet, C. and Bard, P. Y. (1994). Numerical and Theoretical Investigations on the Possibilities and Limitations of Nakamura's Technique, J. Phys. Earth, 42(5), 377-397.

Lermo, J., and Chávez-García, F. J. (1993). Site effect evaluation using spectral ratios with only one station, Bull. Seism. Soc. Am., 83(5), 1574-1594.

Malischewky P.G. and Scherbaum F. (2004). Love's formula and $\mathrm{H} / \mathrm{V}$ ratio (ellipticity) of Rayleigh waves, Wave Motion, 40, 57-67.

Mercalli, G. (1909). Contributo allo studio del terremoto calabro-messinese del 28 dicembre 1908. Cooperativa tipografica.

Mucciarelli, M., and Gallipoli, M. R. (2001). A critical review of 10 years of microtremor HVSR technique, Boll. Geof. Teor. Appl, 42(3-4), 255-266.

Nakamura, Y. (1989). A method for dynamic characteristics estimation of subsurface using microtremor on the ground surface, Quarterly Report Railway Tech. Res. Inst., 30(1), 25-30.

Neri, G., Barberi, G., Oliva, G., \&t Orecchio, B. (2004). Tectonic stress and seismogenic faulting in the area of the 1908 Messina earthquake, south ltaly, Geophys. Res. Lett., 31(10).

Neri, G., Barberi, G., Oliva, G., Orecchio, B. (2005). Spatial variations of seismogenic stress orientations in Sicily, south Italy, Phys. Earth Planet. In., 148(2), 175-191.

Nogoshi, M. and T. Igarashi (1971). On the amplitude characteristics of microtremor (part 2), J. Seismol. Soc. Japan, 24, 26-40.

Panzera, F., Rigano, R., Lombardo, G., Cara, F., Di Giulio, G., \&t Rovelli, A. (2011). The role of alternating outcrops of sediments and basaltic lavas on seismic urban scenario: the study case of Catania, Italy. Bulletin of Earthquake Engineering, 9(2), 411-439.

Panzera, F., D’Amico, S., Lombardo, G., \&t Longo, E. (2016). Evaluation of building fundamental periods and effects of local geology on ground motion parameters in the Siracusa area, Italy. Journal of Seismology, 20(3), 1001-1019.

Parolai, S. (2012). Investigation of site response in urban areas by using earthquake data and seismic noise. New manual of seismological observatory practice, 2, 1-38.

Picozzi, M., and Albarello, D. (2007). Combining genetic and linearized algorithms for a two-step joint inversion of Rayleigh wave dispersion and H/V spectral ratio curves, Geophys J. Int., 169(1), 189-200.

Pino, N. A., Piatanesi, A., Valensise, G., Et Boschi, E.
(2009). The 28 December 1908 Messina Straits earthquake (Mw 7.1): a great earthquake throughout a century of seismology. Seismological Research Letters, 80(2), 243-259.

Pino P., D’Amico S., Orecchio B., Presti D., Scolaro S., Torre A., Totaro C., Farrugia D., \&t Neri G. (2018). Integration of geological and geophysical data for re-evaluation of local seismic hazard and shallow geological structure: the case study of Rometta, Sicily. Accepted for publication, Annals of Geophysics.

Rigano R. and Lombardo G. (2005). Effects of lithological features and tectonic structures in the evaluation of local seismic response: an example from the $\mathrm{Hy}$ blean Plateau (Eastern Sicily). Geologica Carpathica-Bratislava-, 56(4), 297.

Scherbaum, F., Hinzen, K.G., Ohrnberger, M. (2003). Determination of shallow shear wave velocity profiles in the Cologne, Germany area using ambient vibrations, Geophys J. Int., 152, 597-612.

Tortorici, L., C. Monaco, C. Tansi, and O. Cocina (1995), Recent and active tectonics in the Calabrian Arc (southern ltaly), Tectonophysics, 243, 37-55.

Vella A., Galea P., D’Amico S., 2013. Site frequency response characterisation of the Maltese islands based on ambient noise $\mathrm{H} / \mathrm{V}$ ratios. Engineering Geology. 163, 89-100, doi:10.1016/j.enggeo.2013.06.006.

*CORRESPONDING AUTHOR: Silvia SCOLARO,

Department of Mathematics, Computer Sciences, Physics and Earth Sciences University of Messina, Messina, Italy email: silscolaro@unime.it

(c) 2018 the Istituto Nazionale di Geofisica e Vulcanologia. All rights reserved. 
Supplemental Material for

AMBIENT NOISE MEASUREMENTS FOR PRELIMINARY

MICROZONING STUDIES IN THE CITY OF MESSINA,

SICILY

Silvia Scolaro', Paolo Pino ${ }^{1}$, Sebastiano D'Amico ${ }^{2}$, Barbara Orecchio ${ }^{1}$,

Debora Presti ${ }^{1}$, Antonino Torre ${ }^{1}$, Cristina Totaro ${ }^{1}$, Daniela Farrugia ${ }^{2}$, Giancarlo Neri ${ }^{1}$

${ }^{(1)}$ Department of Mathematics, Computer Sciences, Physics, and Earth Sciences, University

of Messina, Messina, Italy

${ }^{(2)}$ Department of Geosciences, University of Malta, Malta

INTRODUCTION

The auxiliary material includes one hundred sixty-seven plots (see

Figures S1-S8). These provide the complete set of HVSR curves

obtained in the present study.

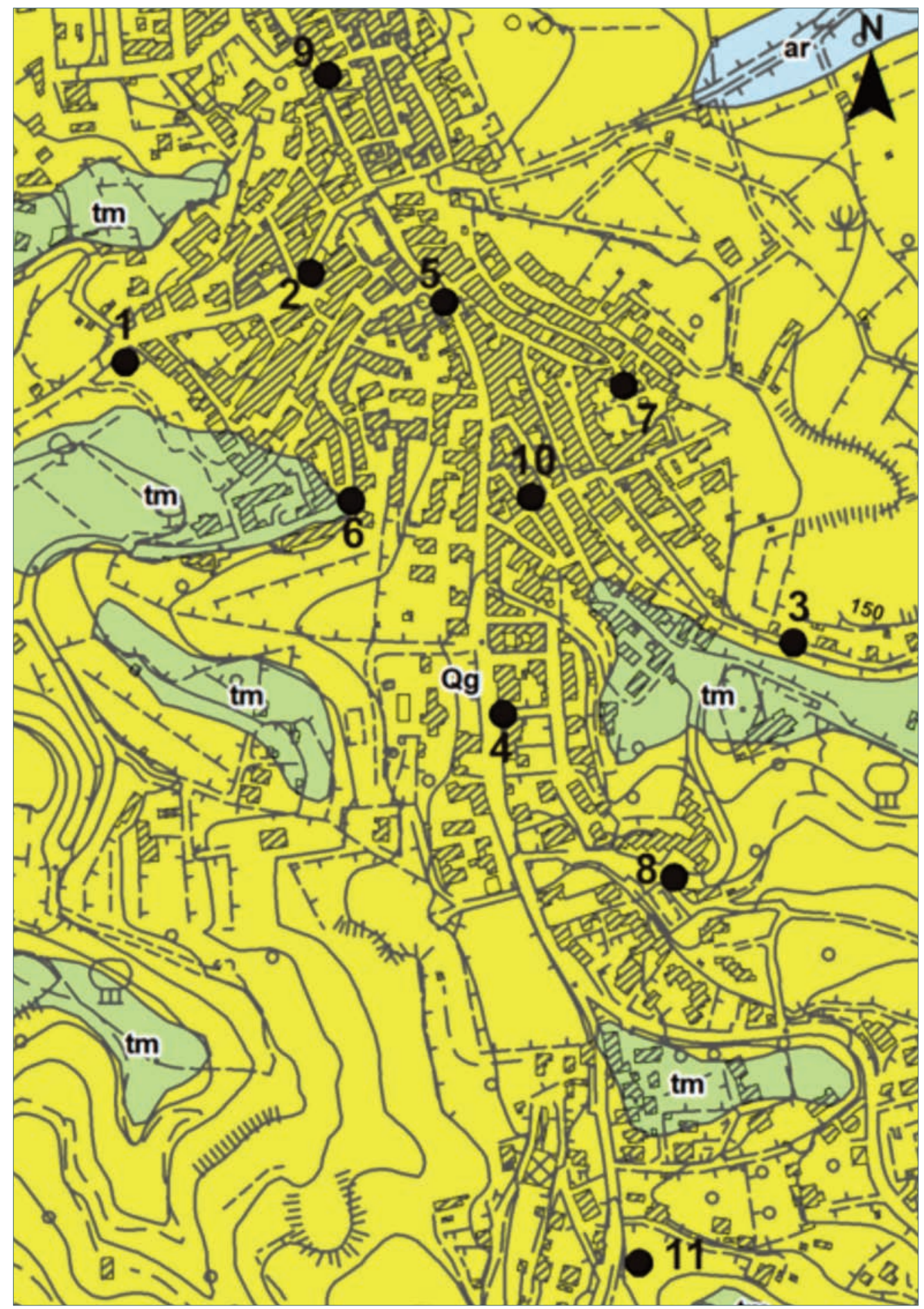

FIGURE S1. HVSR measurement points in the Faro Superiore area. 

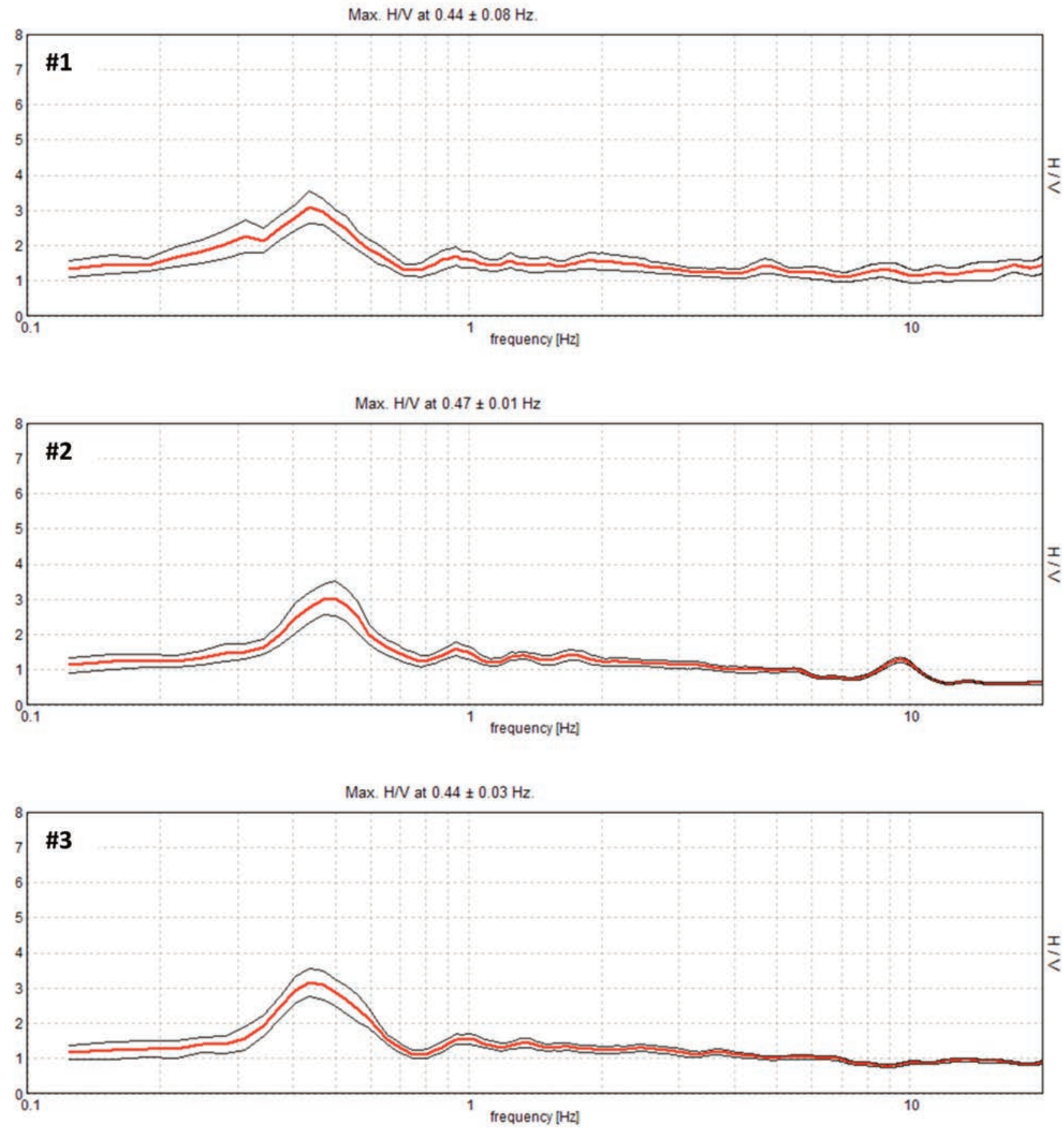

FIGURE S2. HVSR curves for the Faro Superiore area (\#11). Red curve = mean spectral ratio, black curves = standard deviation . 

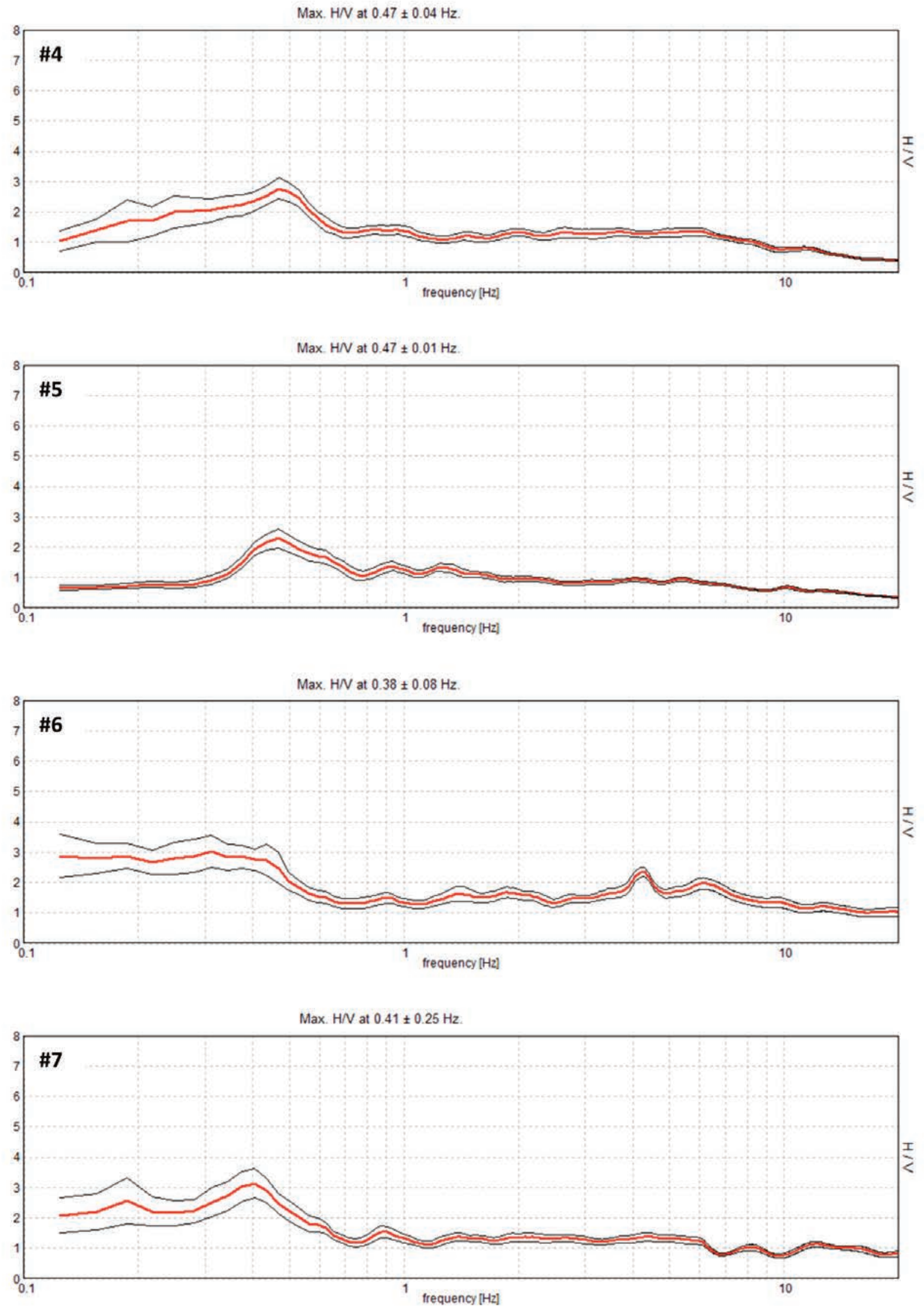

FIGURE S2. HVSR curves for the Faro Superiore area (\#11). Red curve = mean spectral ratio, black curves = standard deviation. 

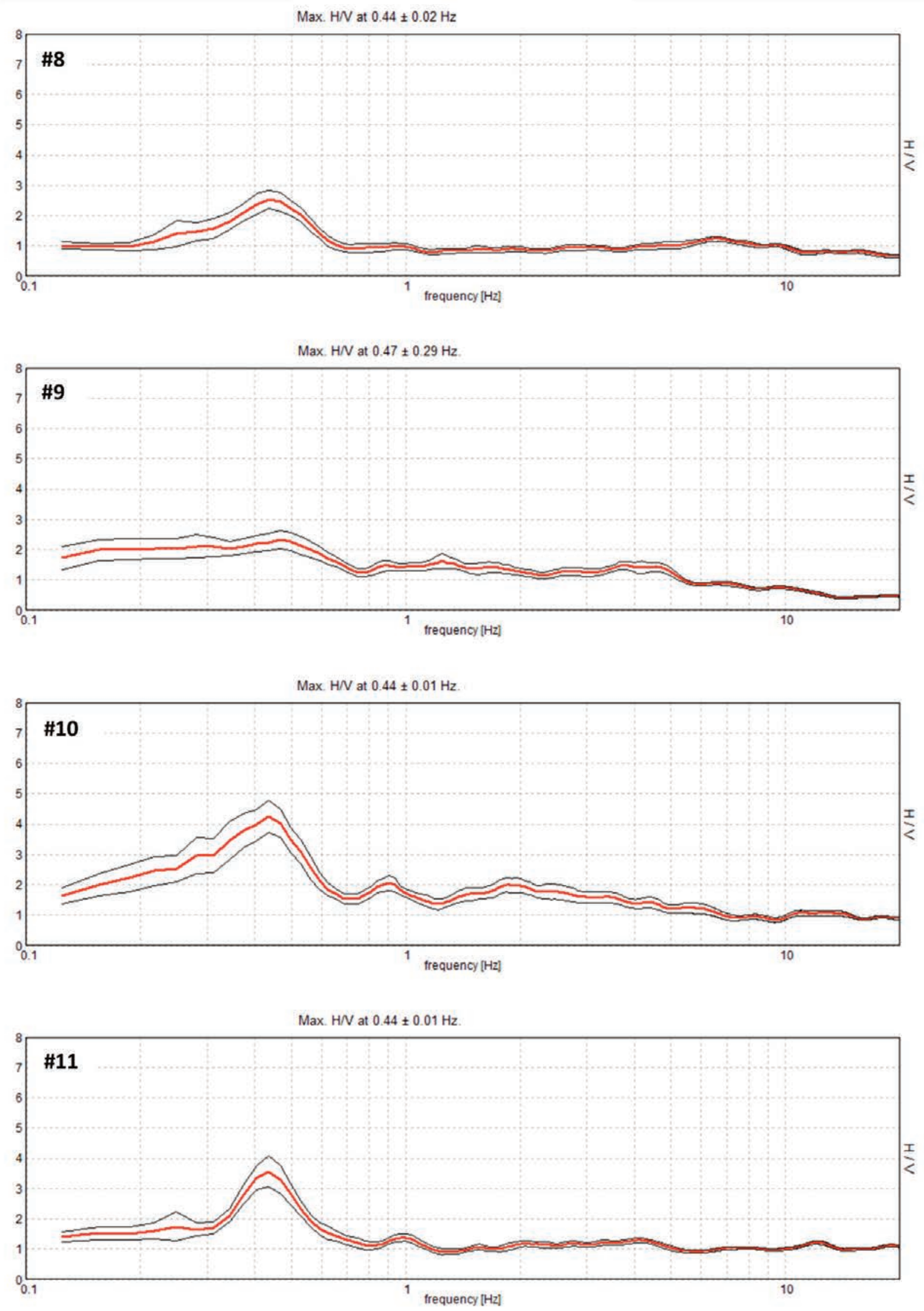

FIGURE S2. HVSR curves for the Faro Superiore area (\#11). Red curve = mean spectral ratio, black curves = standard deviation. 


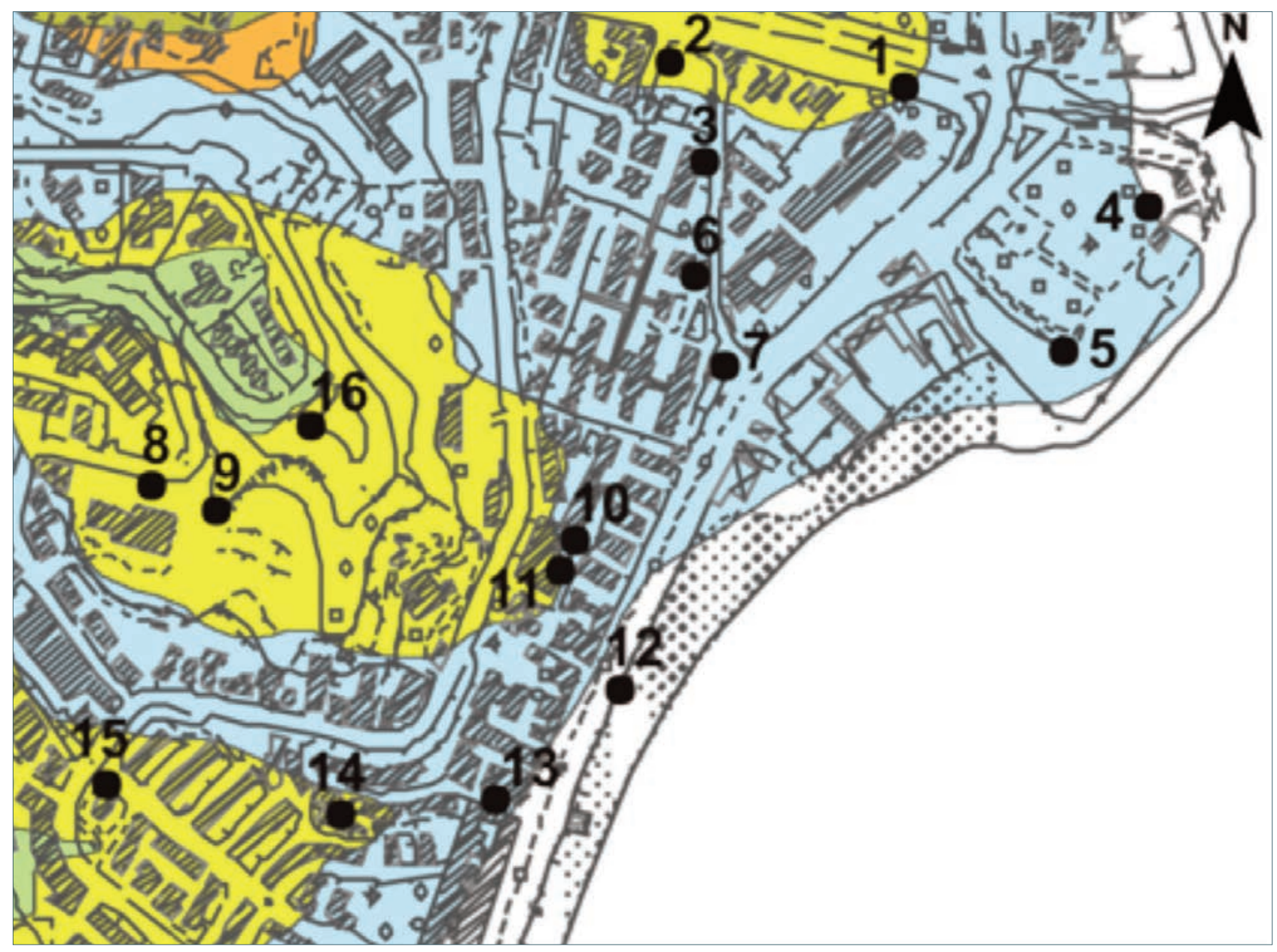

FIGURE S3. HVSR measurement points in the Salvatore dei Greci sector. 

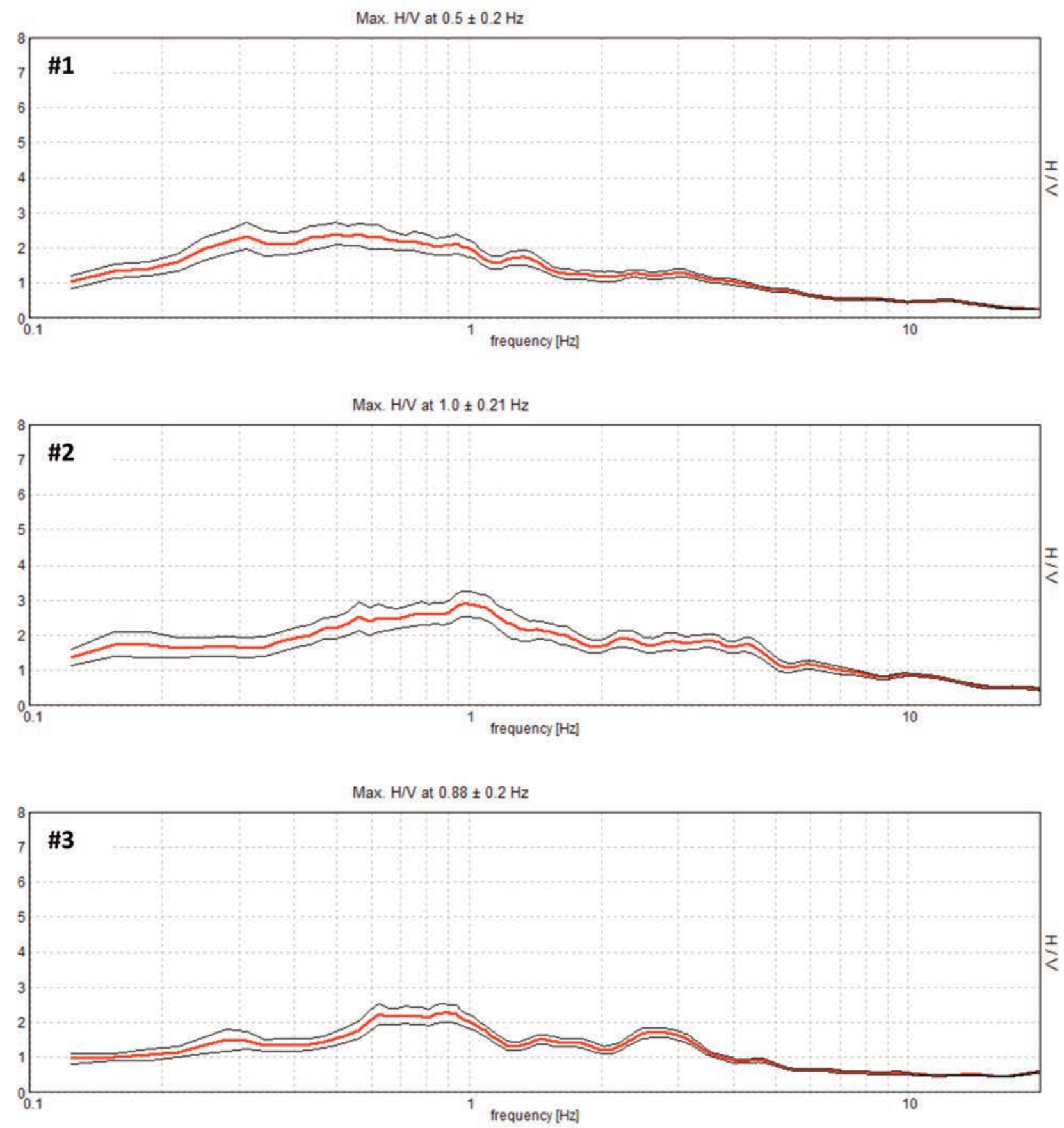

FIGURE S4. HVSR curves for the Salvatore dei Greci area (\#16). Red curve = mean spectral ratio, black curves = standard deviation. 

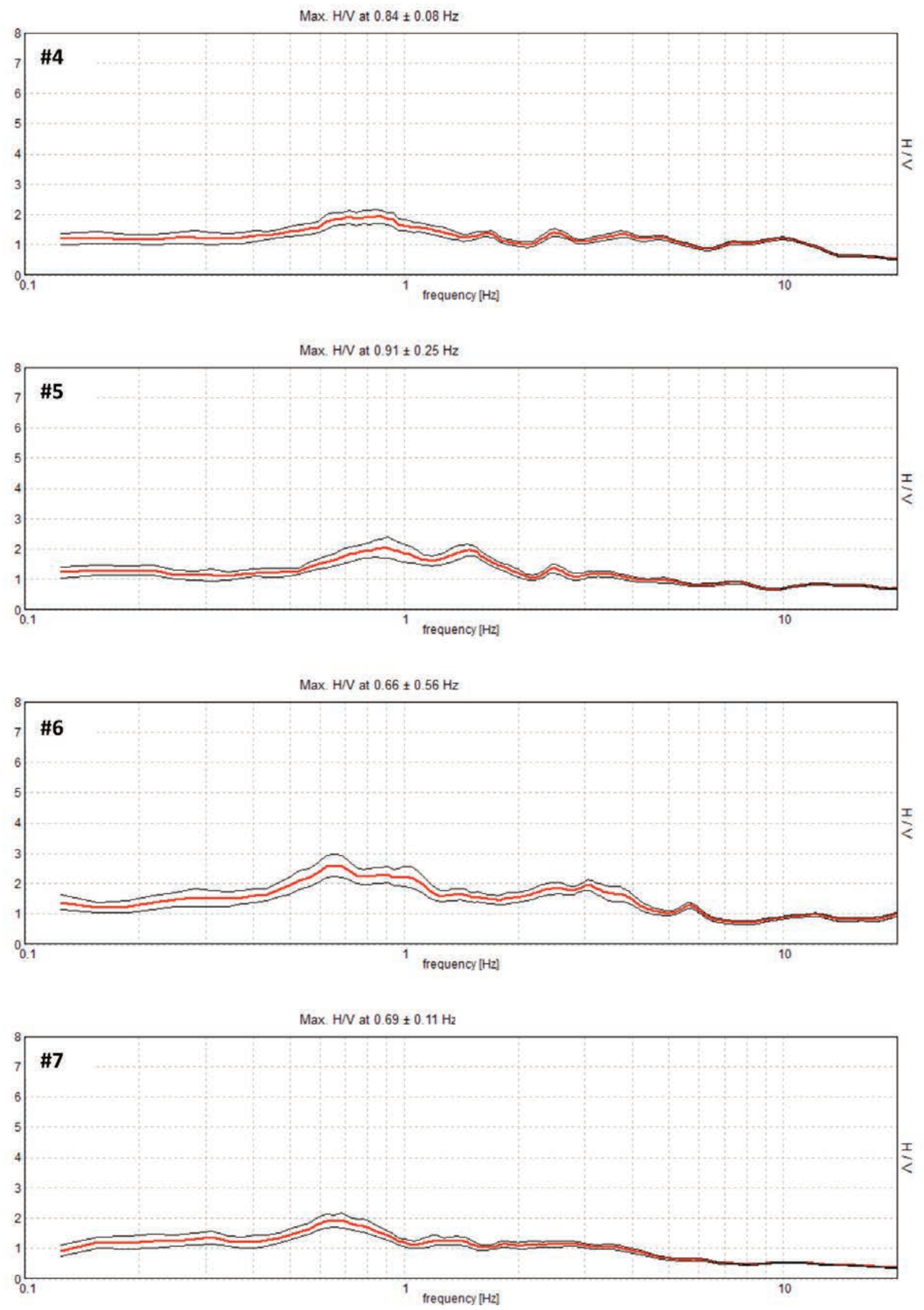

FIGURE S4. HVSR curves for the Salvatore dei Greci area (\#16). Red curve = mean spectral ratio, black curves = standard deviation. 

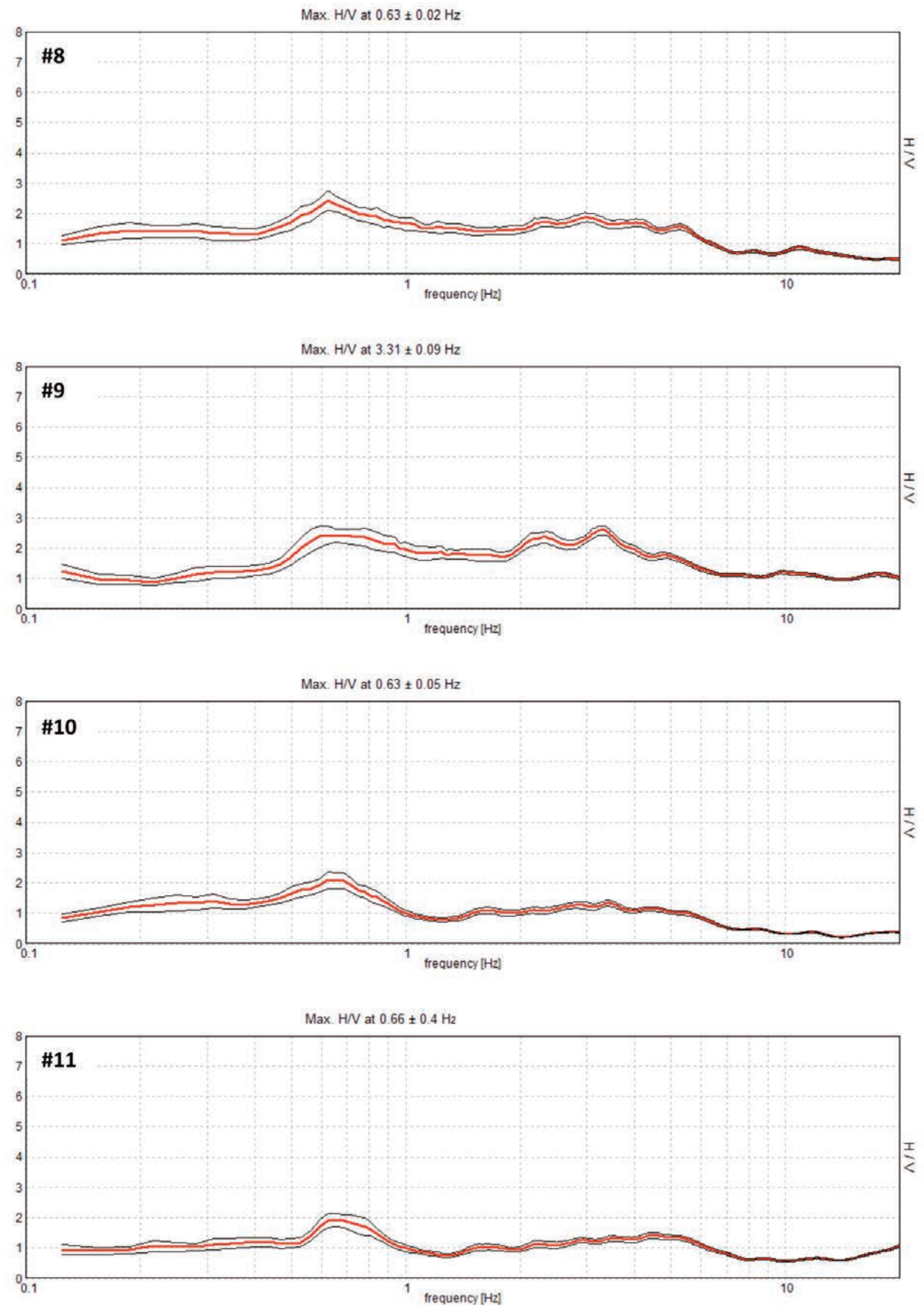

FIGURE S4. HVSR curves for the Salvatore dei Greci area (\#16). Red curve = mean spectral ratio, black curves = standard deviation. 

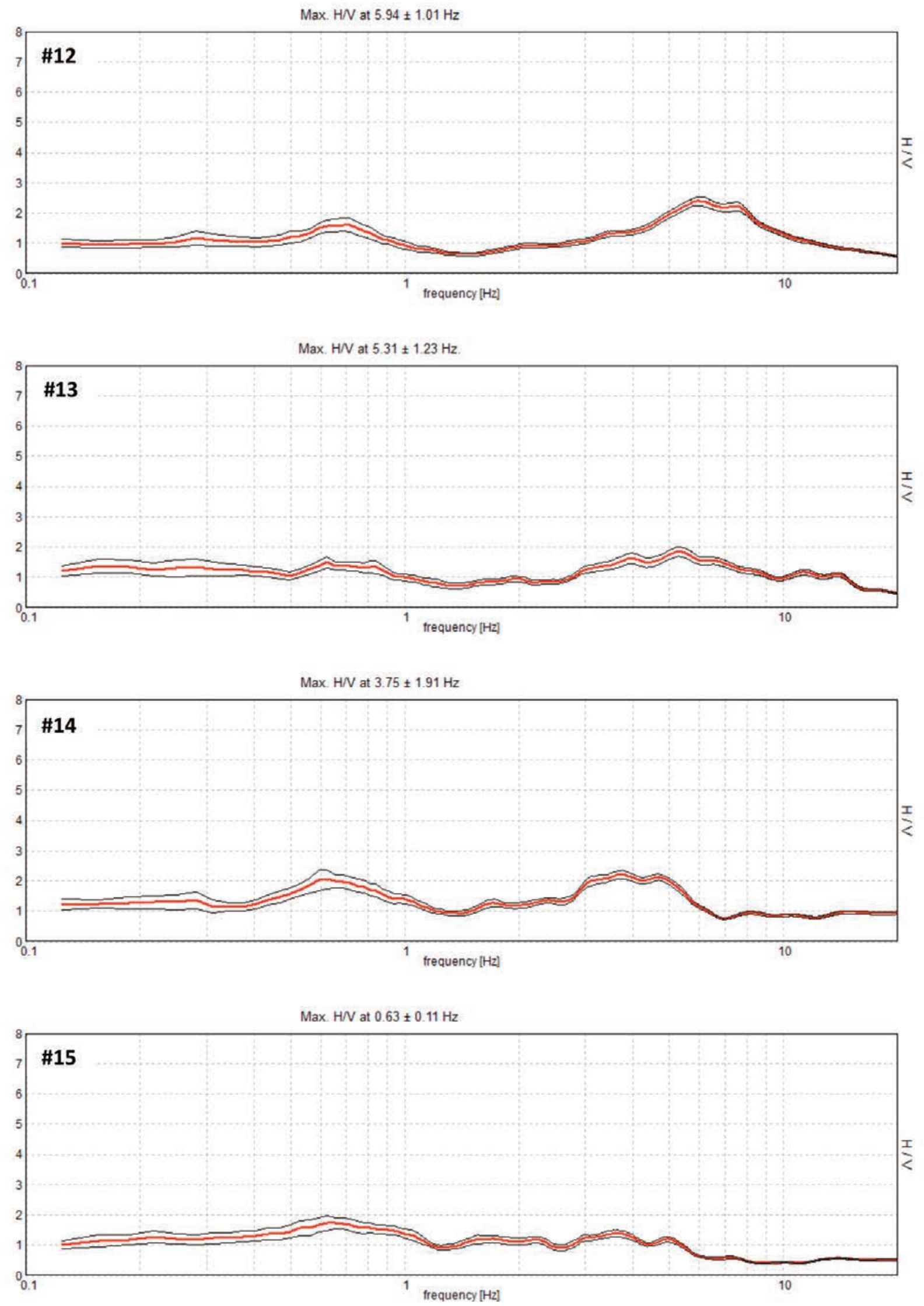

FIGURE S4. HVSR curves for the Salvatore dei Greci area (\#16). Red curve = mean spectral ratio, black curves = standard deviation. 
Max. $\mathrm{H} N$ at $0.69 \pm 0.3 \mathrm{~Hz}$

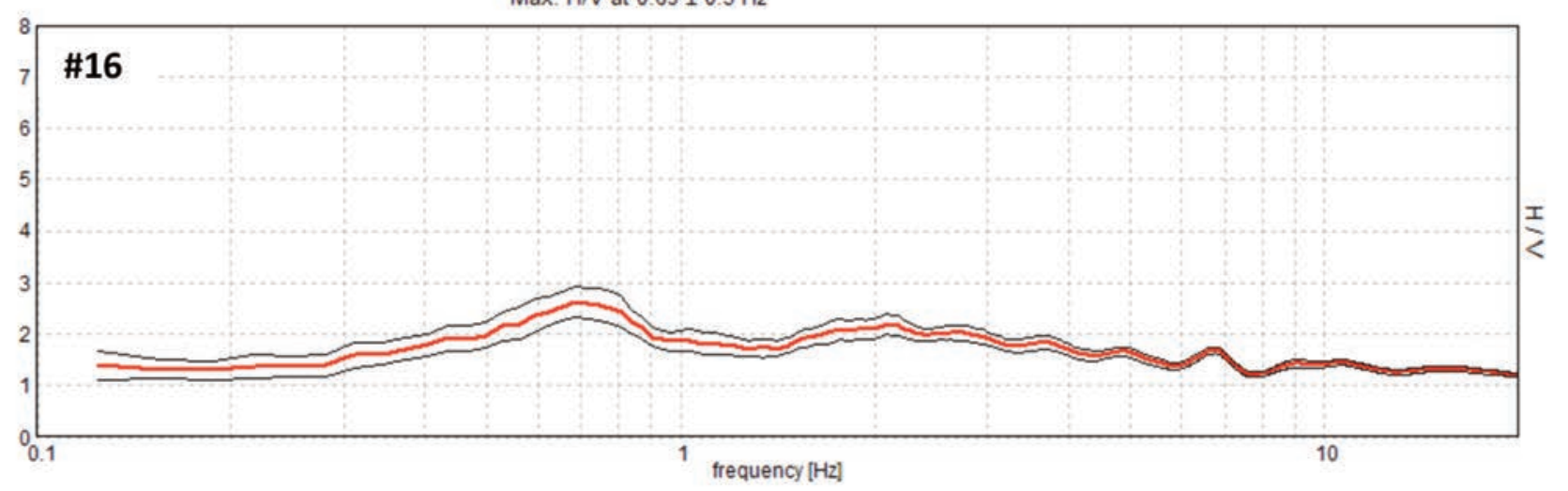

FIGURE S4. HVSR curves for the Salvatore dei Greci area (\#16). Red curve = mean spectral ratio, black curves $=$ standard deviation. 


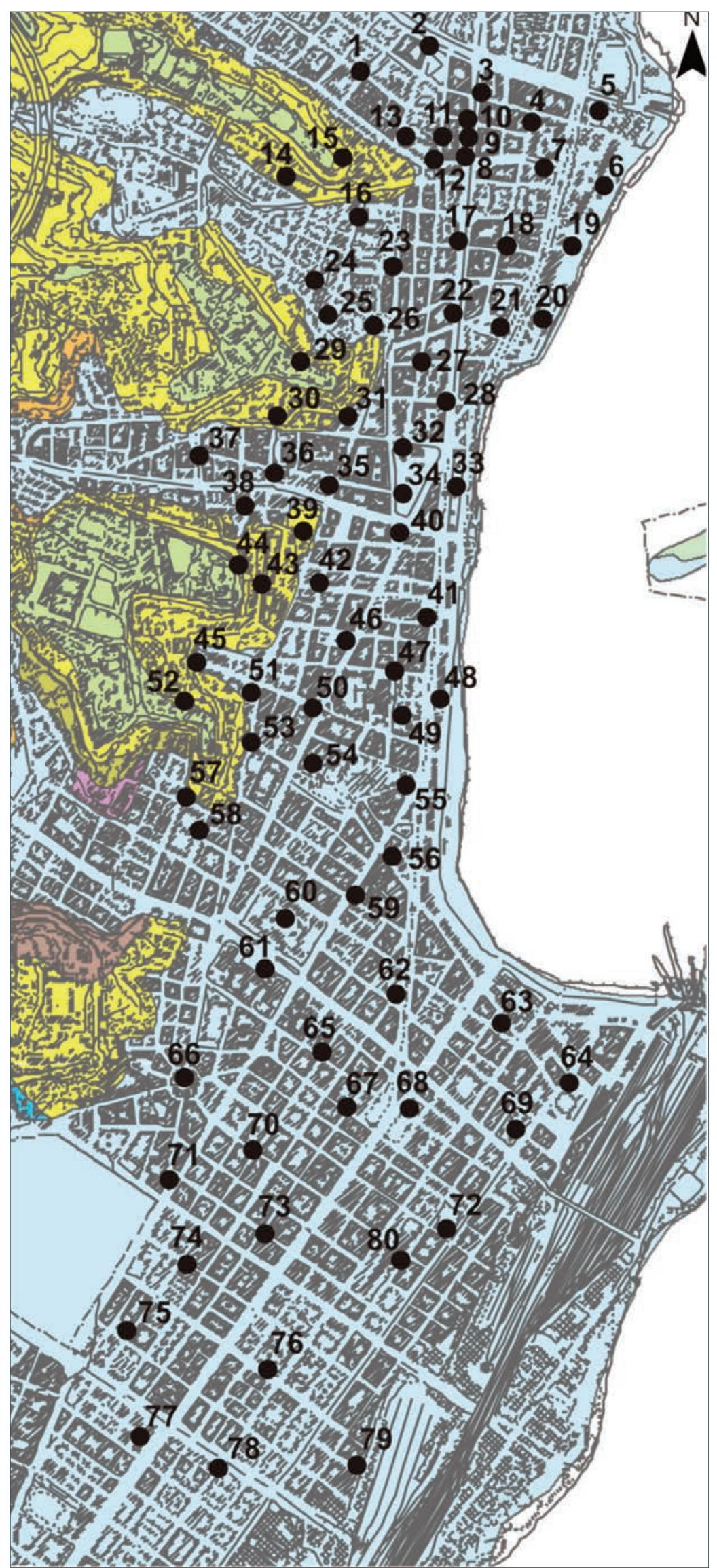

FIGURE S5. HVSR measurement points in the Historical centre sector. 

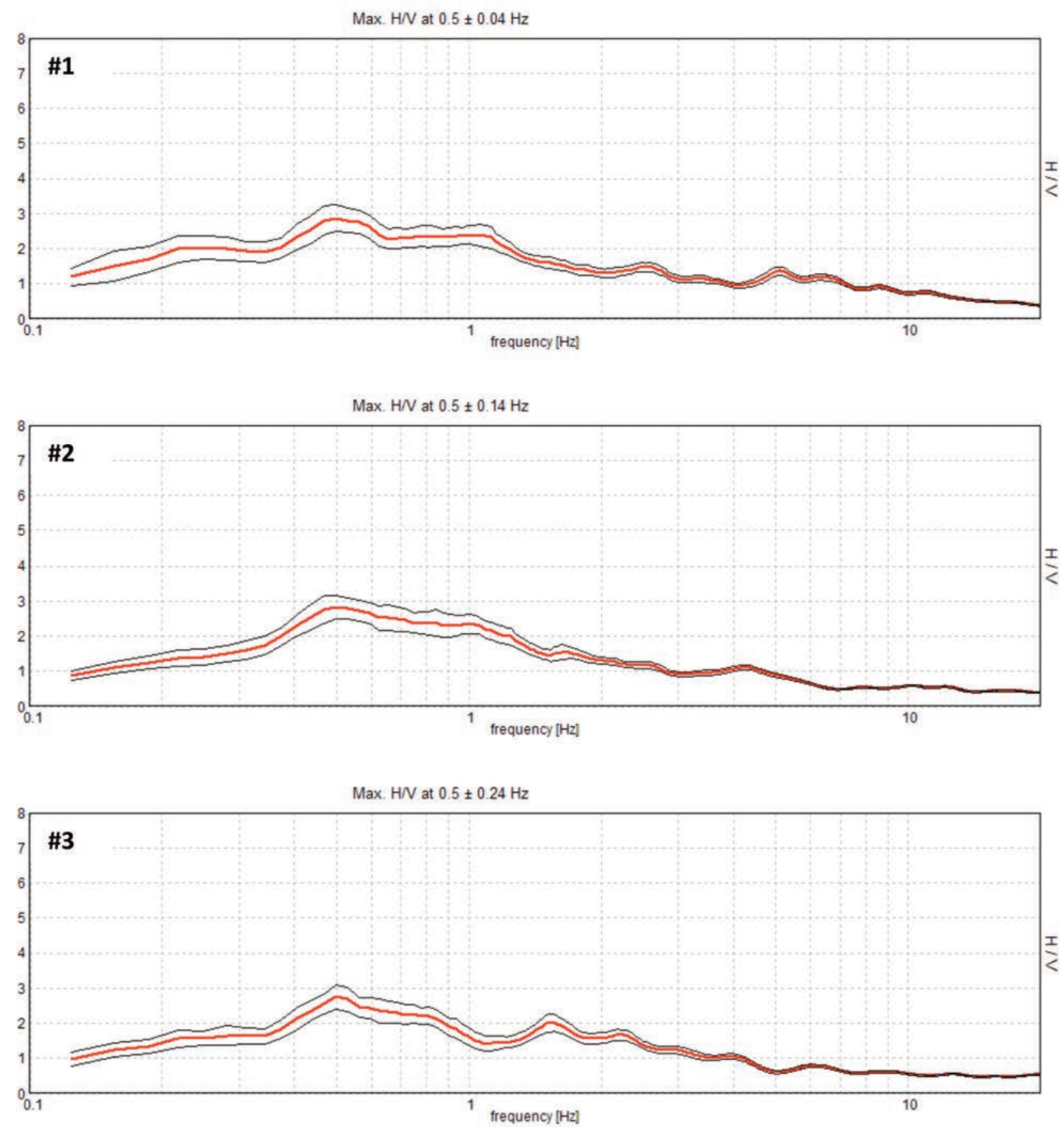

FIGURE S6. HVSR curves for the Historical Center area (\#80). Red curve = mean spectral ratio, black curves = standard deviation. 

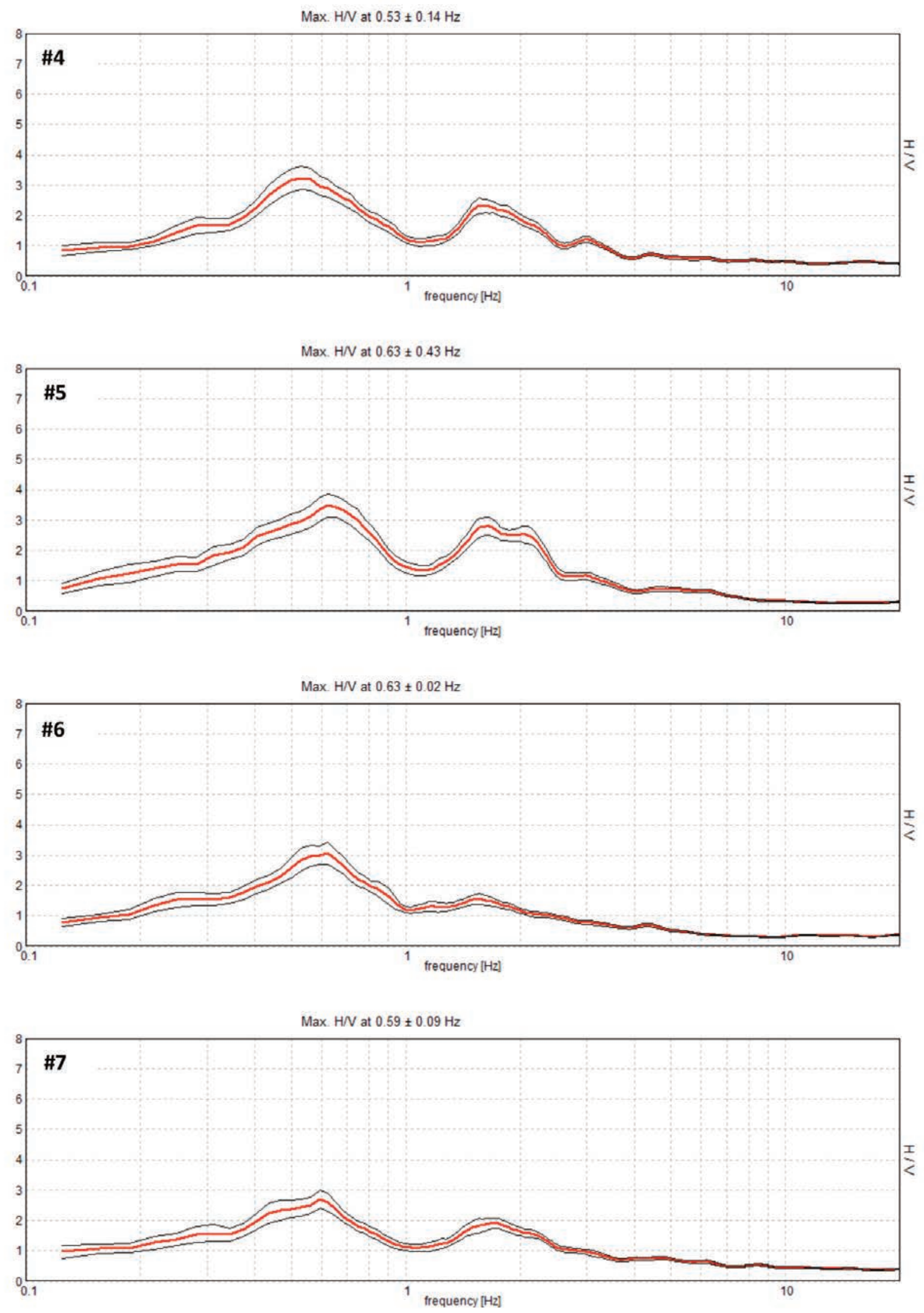

FIGURE S6. HVSR curves for the Historical Center area $(\# 80)$. Red curve $=$ mean spectral ratio, black curves $=$ standard deviation. 

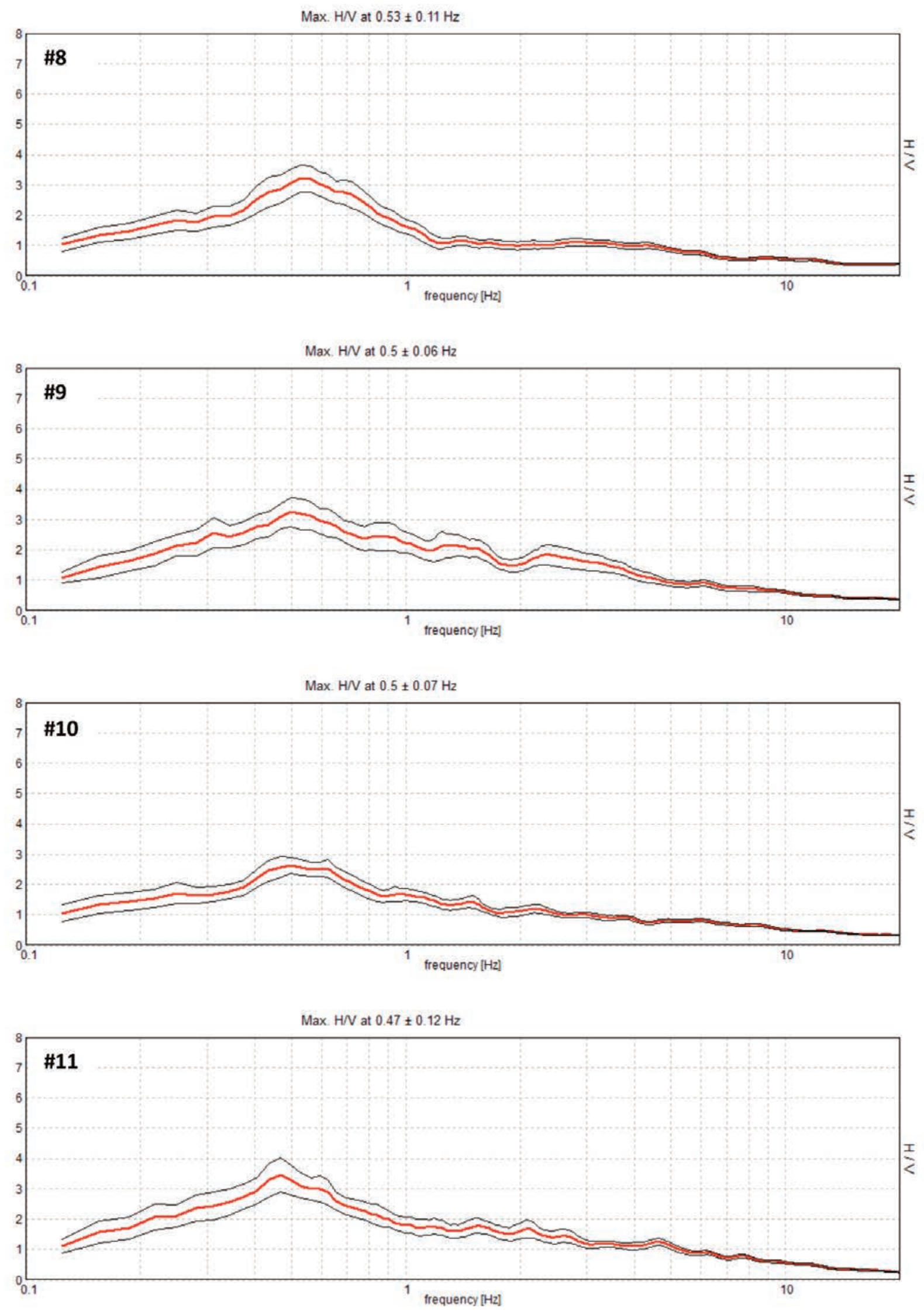

FIGURE S6. HVSR curves for the Historical Center area $(\# 80)$. Red curve $=$ mean spectral ratio, black curves $=$ standard deviation 

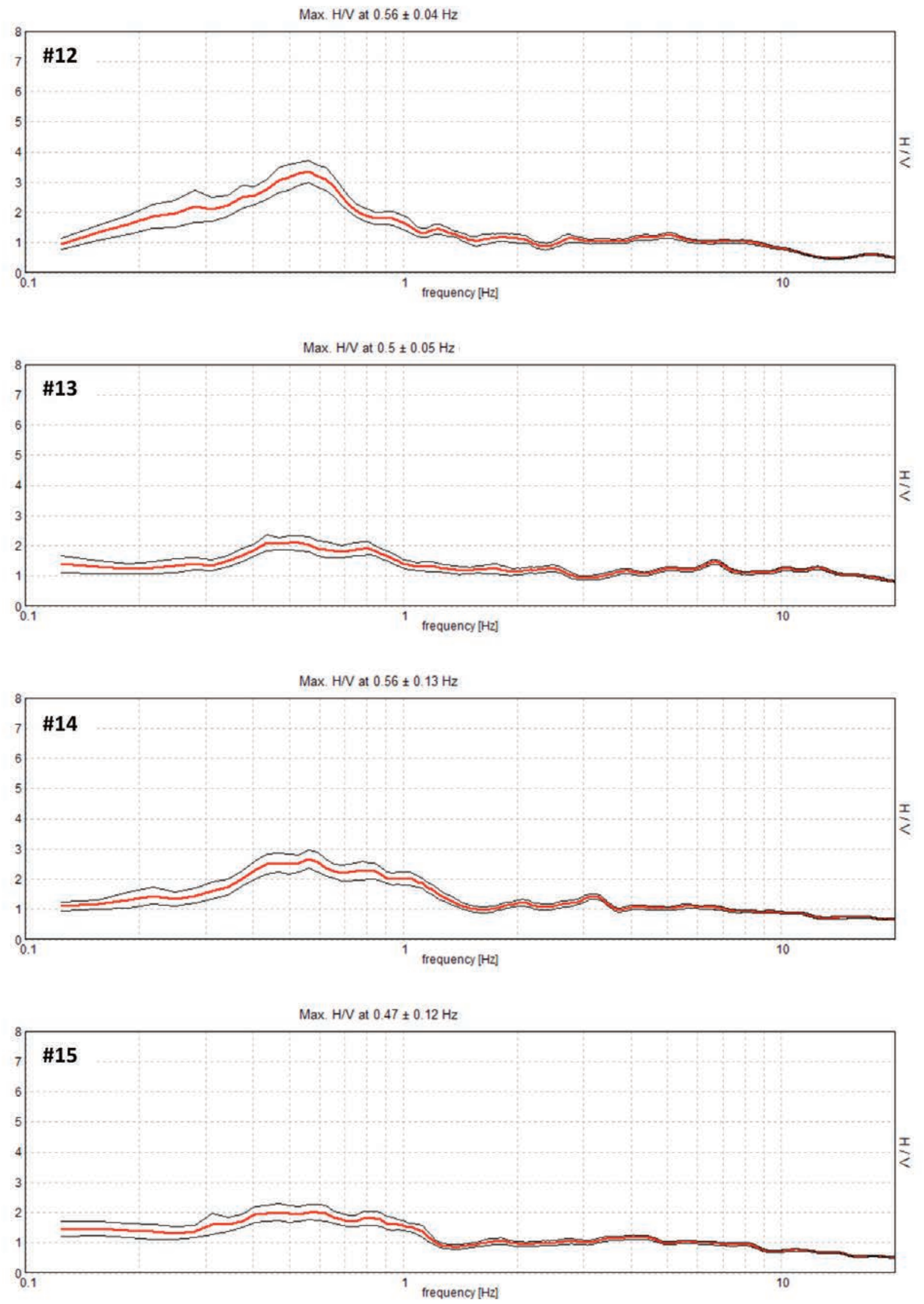

FIGURE S6. HVSR curves for the Historical Center area $(\# 80)$. Red curve $=$ mean spectral ratio, black curves $=$ standard deviation. 

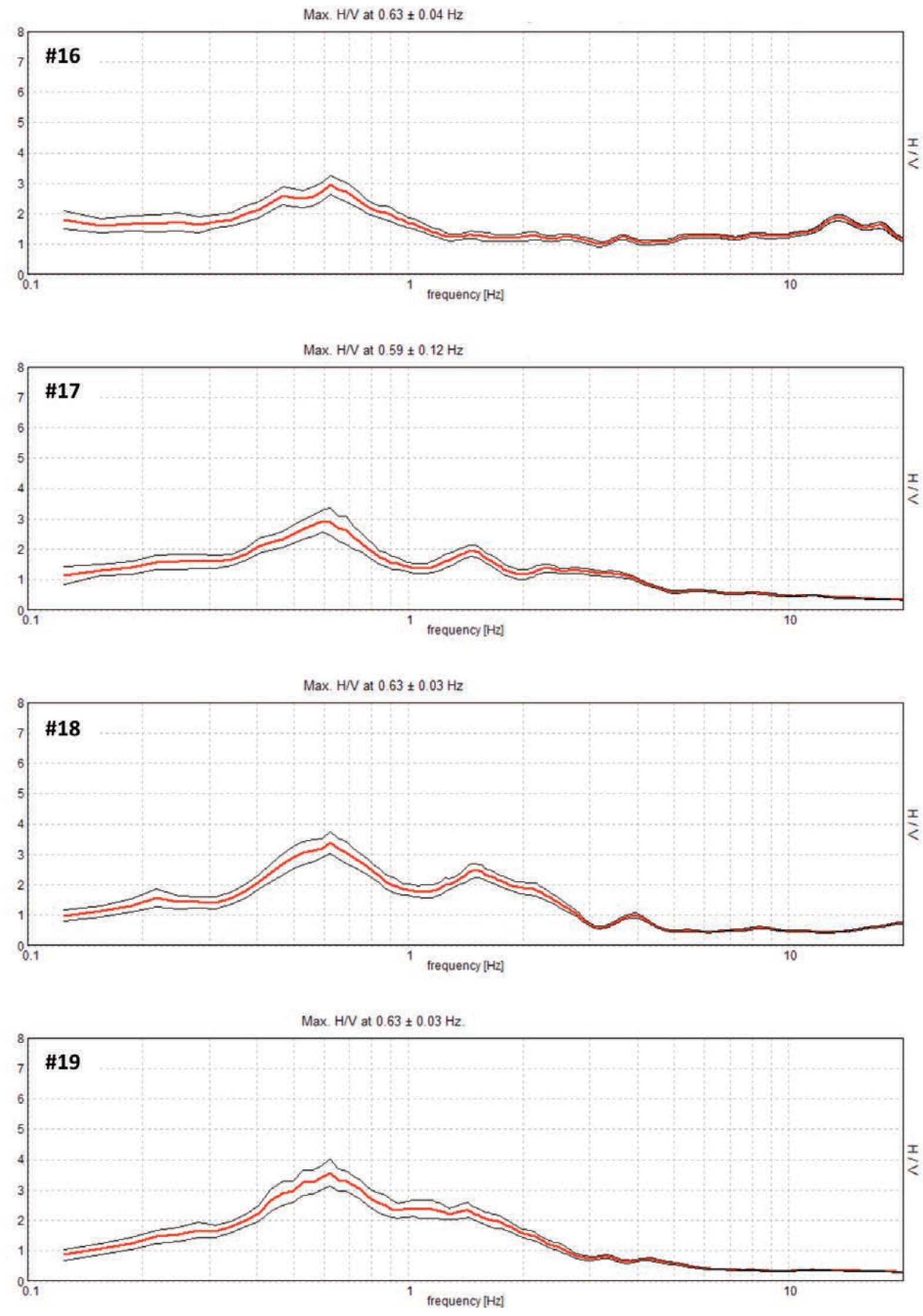

FIGURE S6. HVSR curves for the Historical Center area $(\# 80)$. Red curve $=$ mean spectral ratio, black curves $=$ standard deviation 

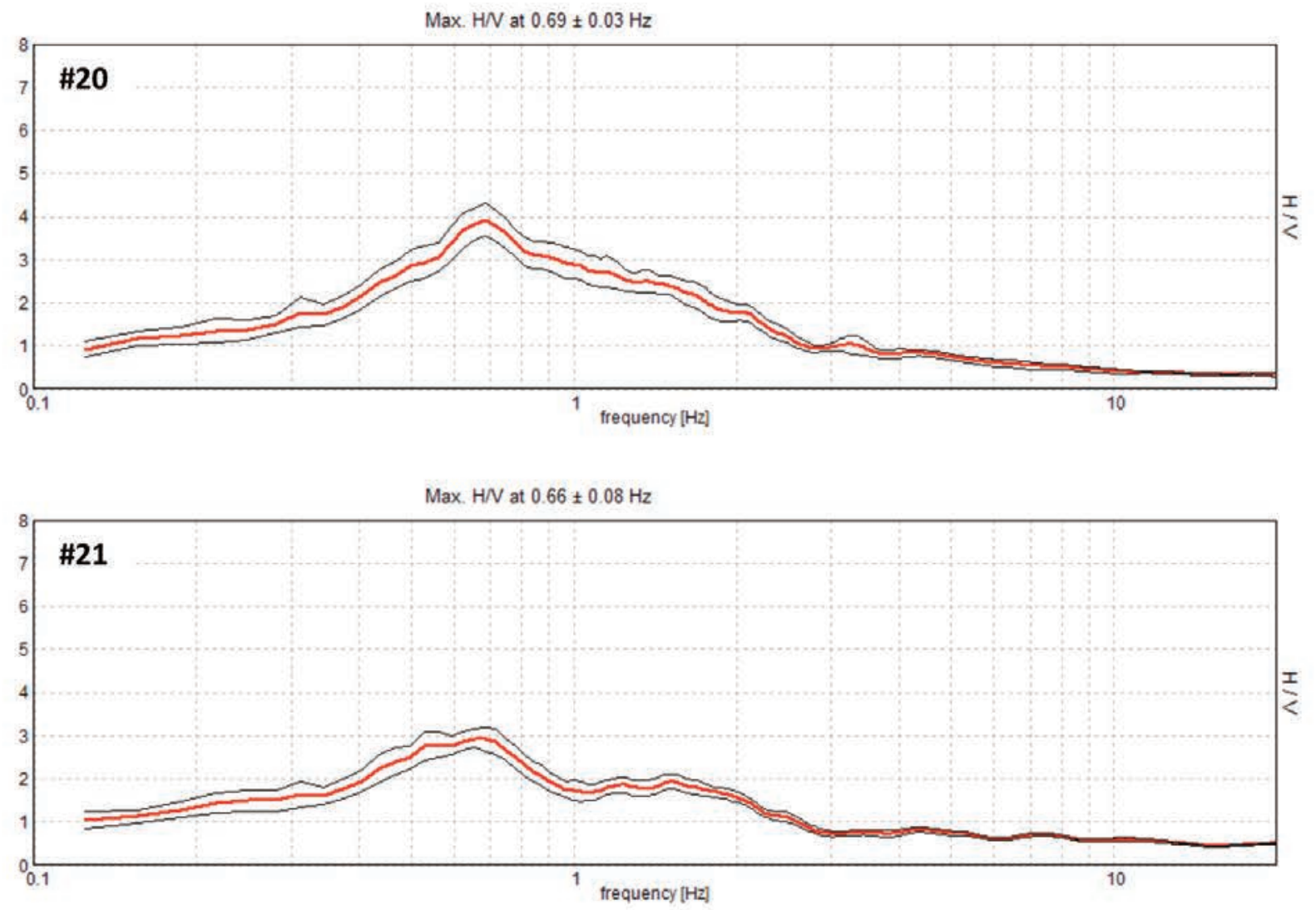

Max. $\mathrm{H} / \mathrm{V}$ at $0.63 \pm 0.03 \mathrm{~Hz}$

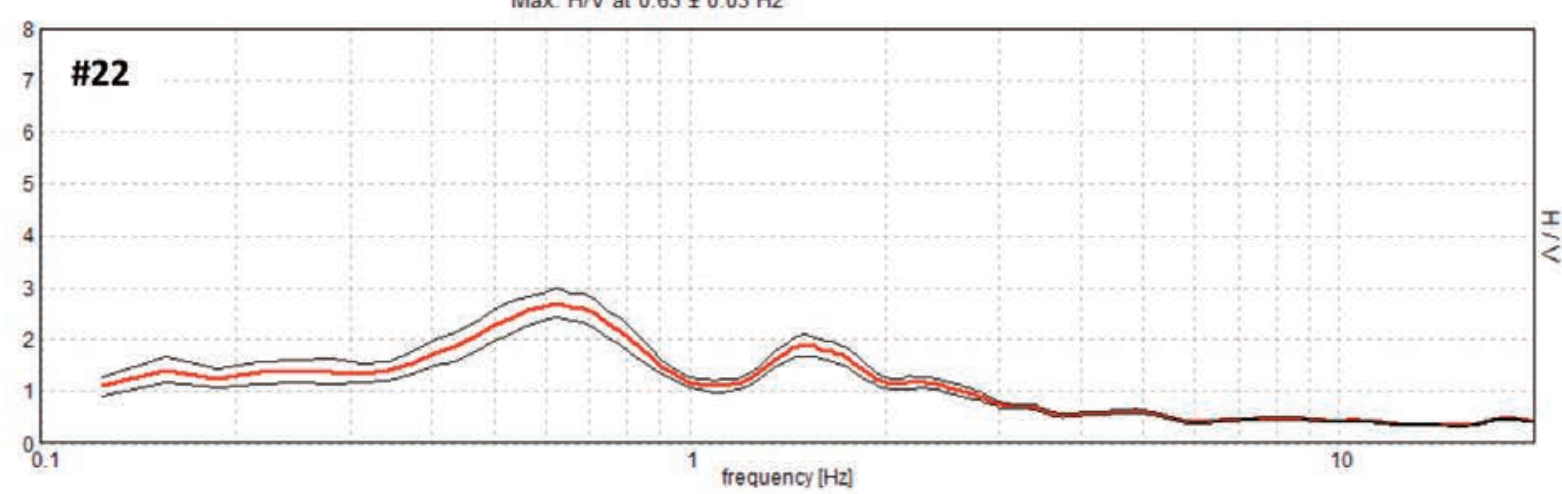

Max. $\mathrm{H} / \mathrm{V}$ at $0.63 \pm 0.07 \mathrm{~Hz}$

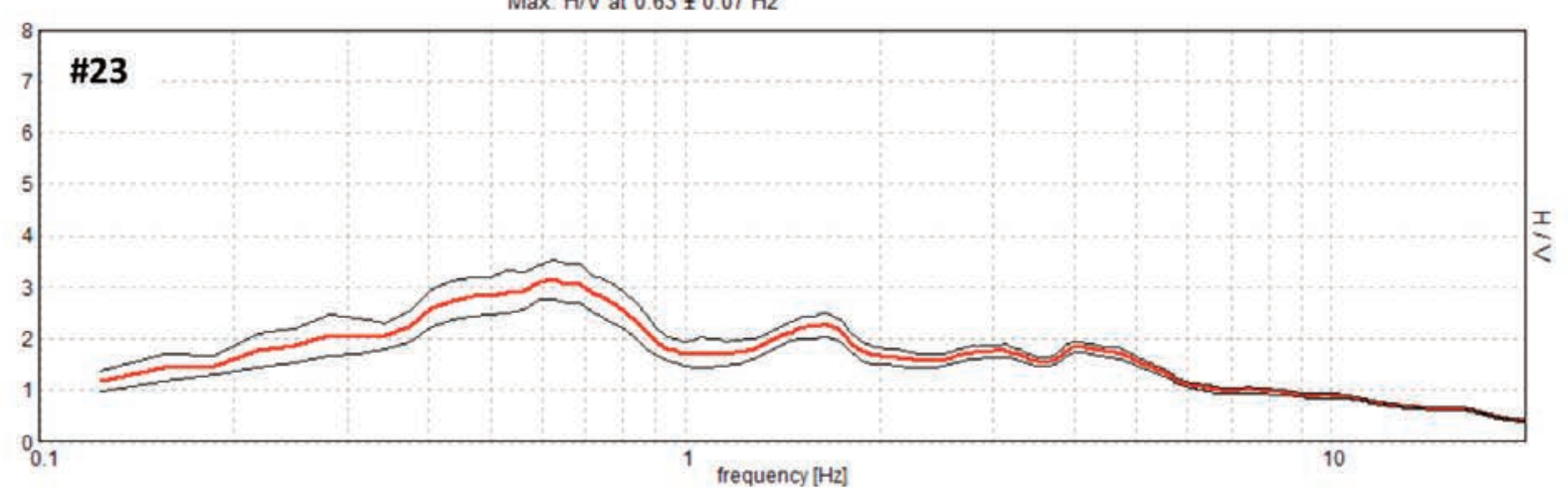

FIGURE S6. HVSR curves for the Historical Center area $(\# 80)$. Red curve $=$ mean spectral ratio, black curves $=$ standard deviation. 

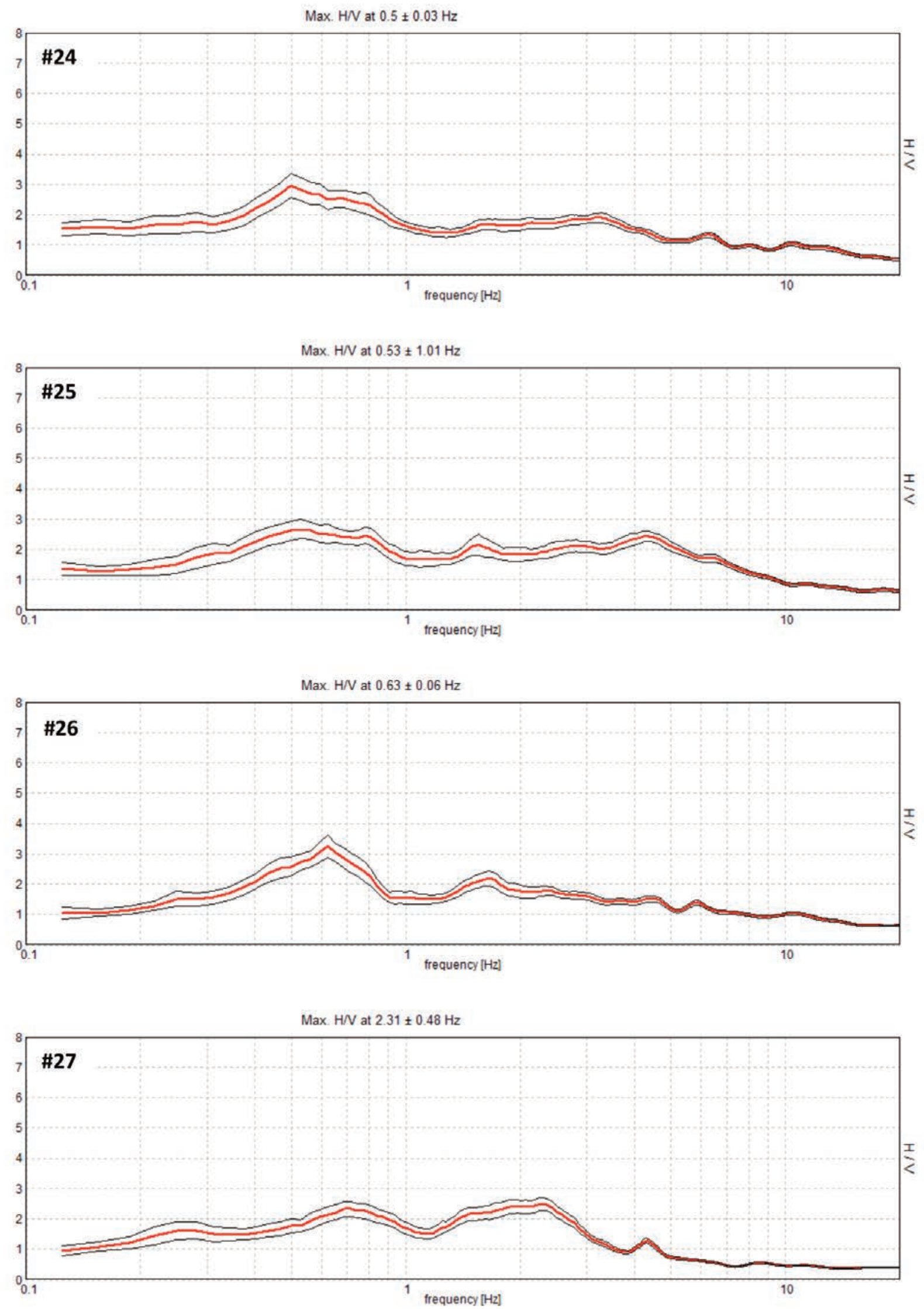

FIGURE S6. HVSR curves for the Historical Center area $(\# 80)$. Red curve $=$ mean spectral ratio, black curves $=$ standard deviation 

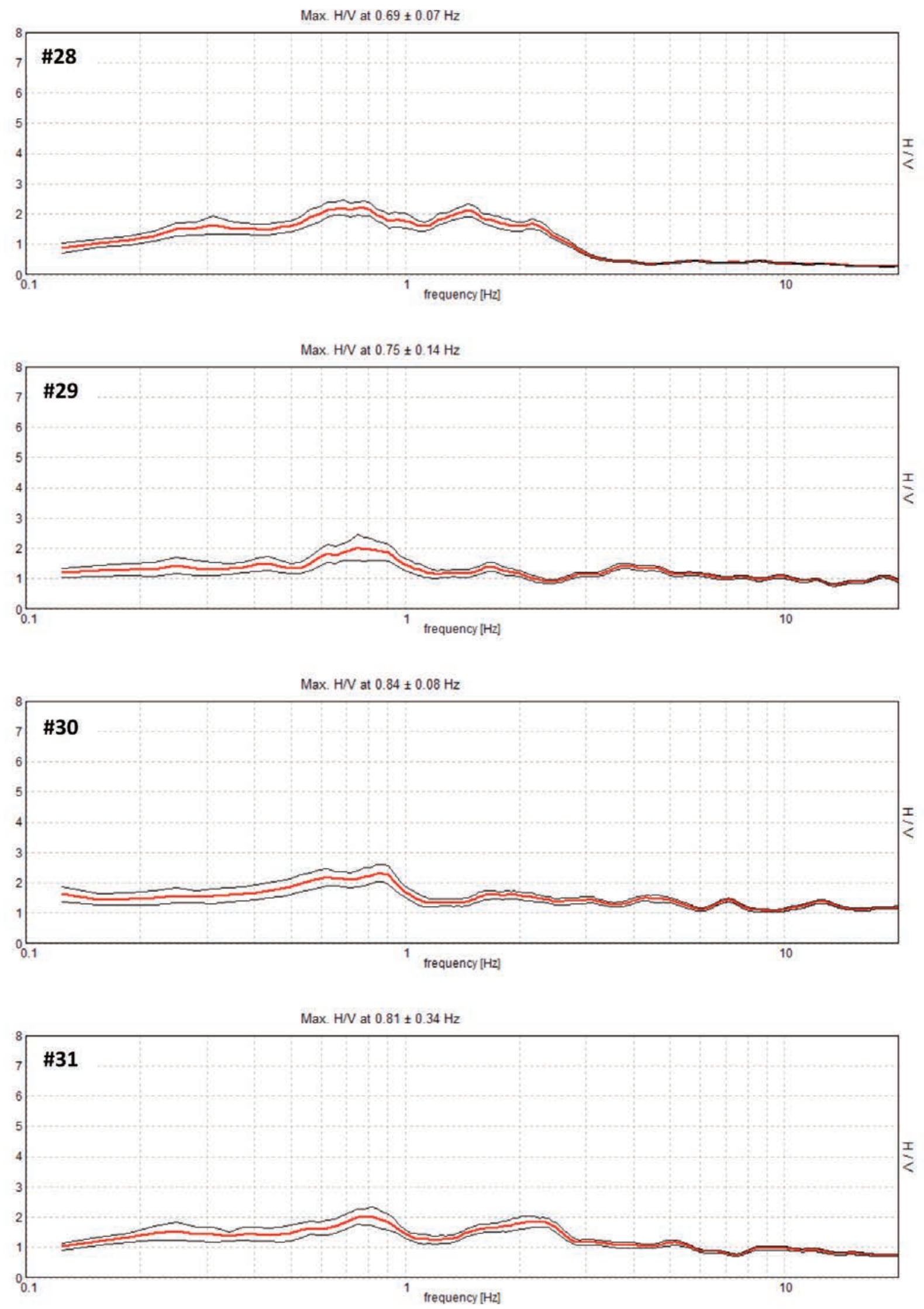

FIGURE S6. HVSR curves for the Historical Center area $(\# 80)$. Red curve $=$ mean spectral ratio, black curves $=$ standard deviation. 

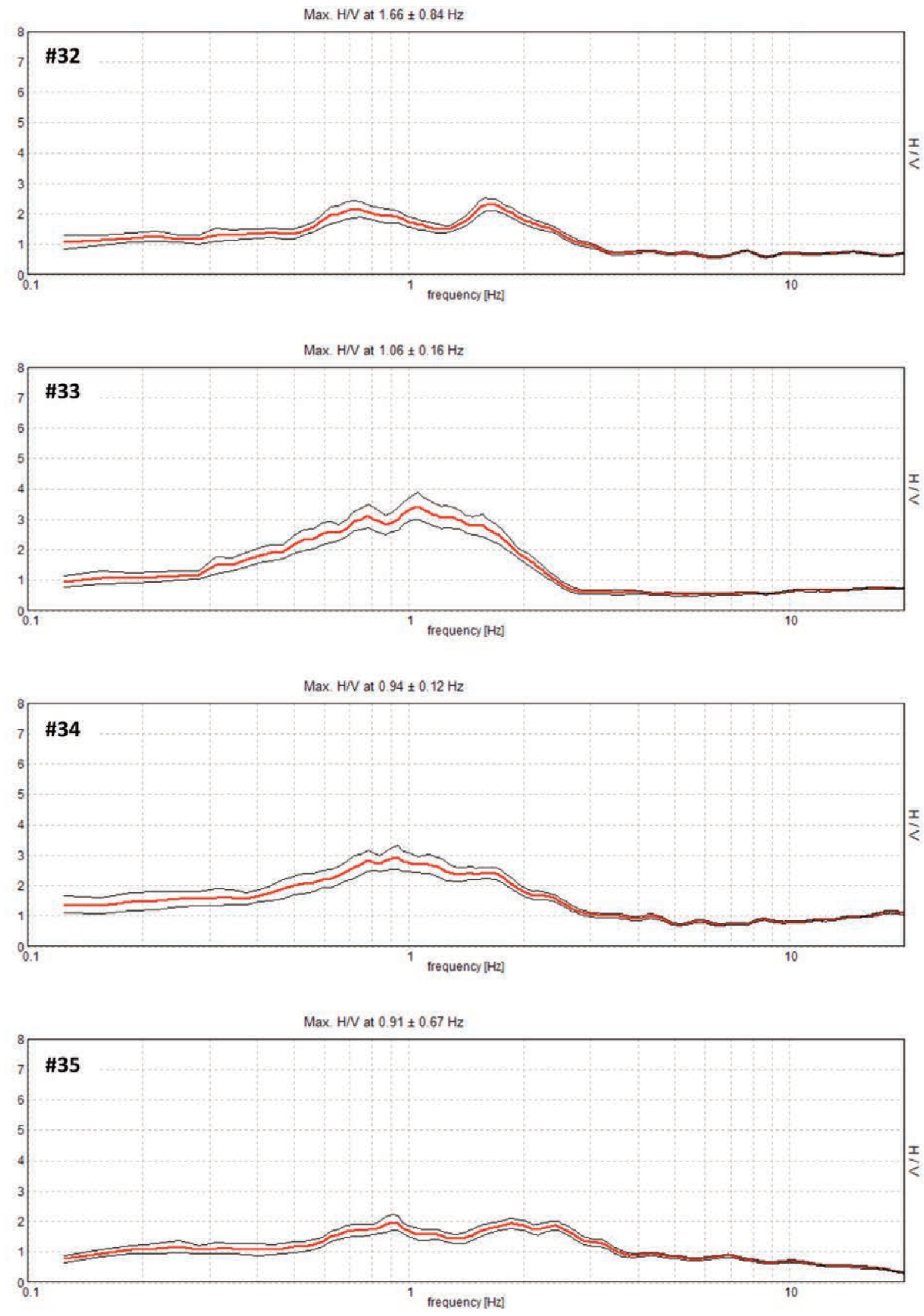

FIGURE S6. HVSR curves for the Historical Center area $(\# 80)$. Red curve $=$ mean spectral ratio, black curves $=$ standard deviation 

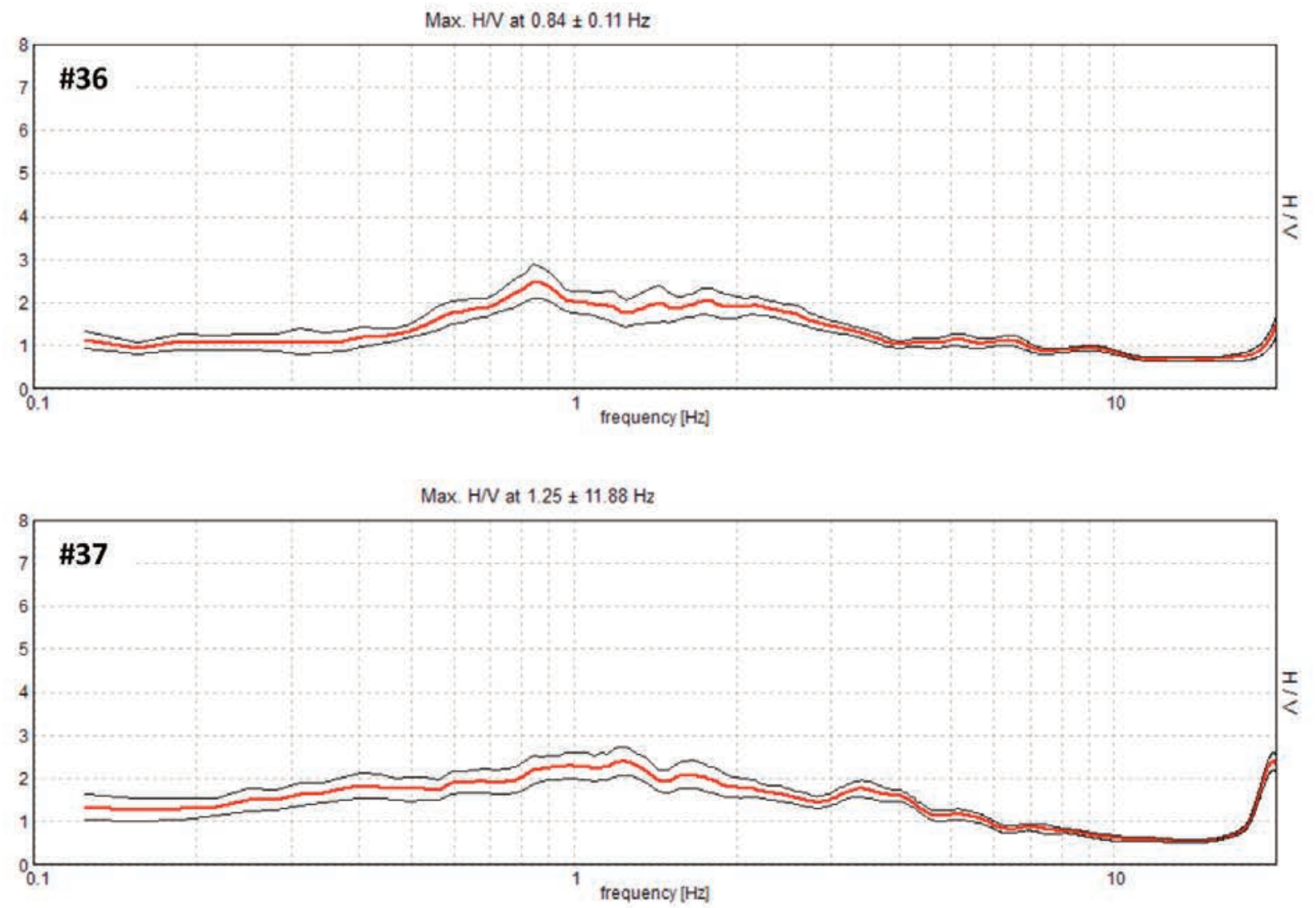

Max. $\mathrm{H} / \mathrm{V}$ at $4.97 \pm 1.11 \mathrm{~Hz}$

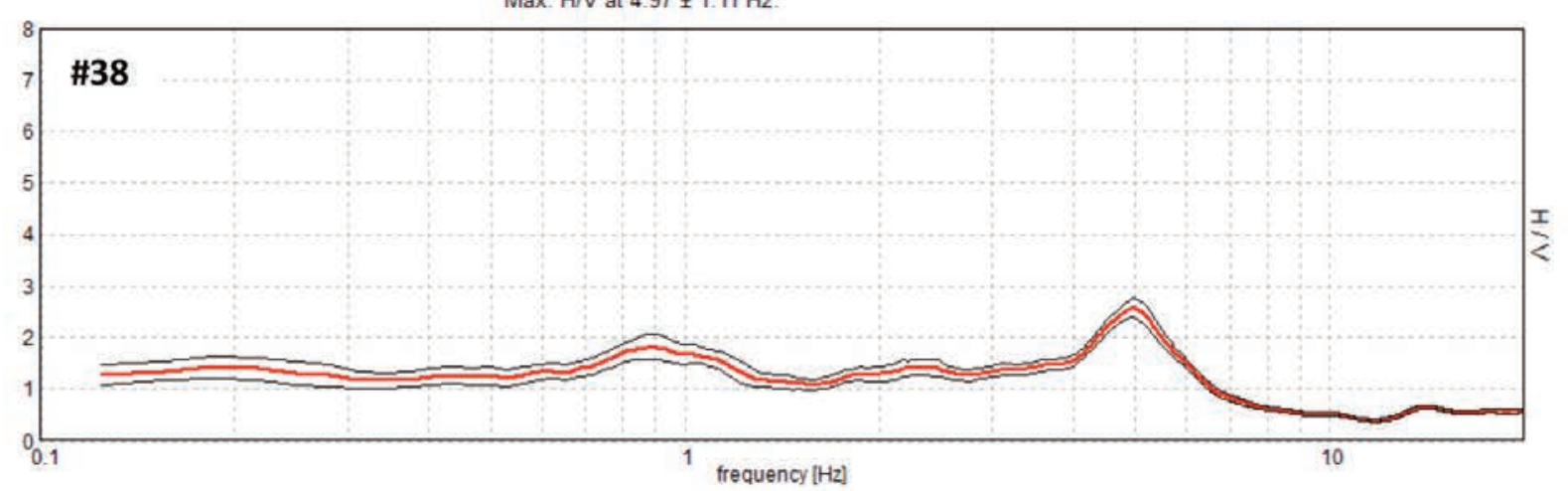

Max. $\mathrm{H} / \mathrm{V}$ at $0.94 \pm 0.03 \mathrm{~Hz}$

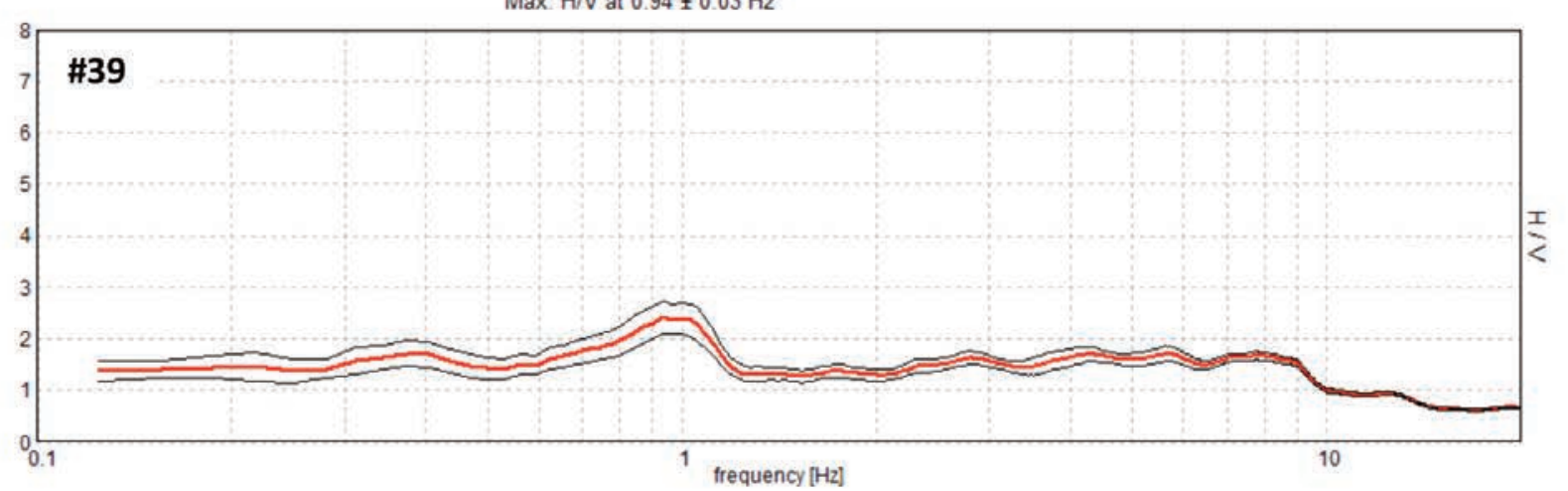

FIGURE S6. HVSR curves for the Historical Center area $(\# 80)$. Red curve $=$ mean spectral ratio, black curves $=$ standard deviation. 

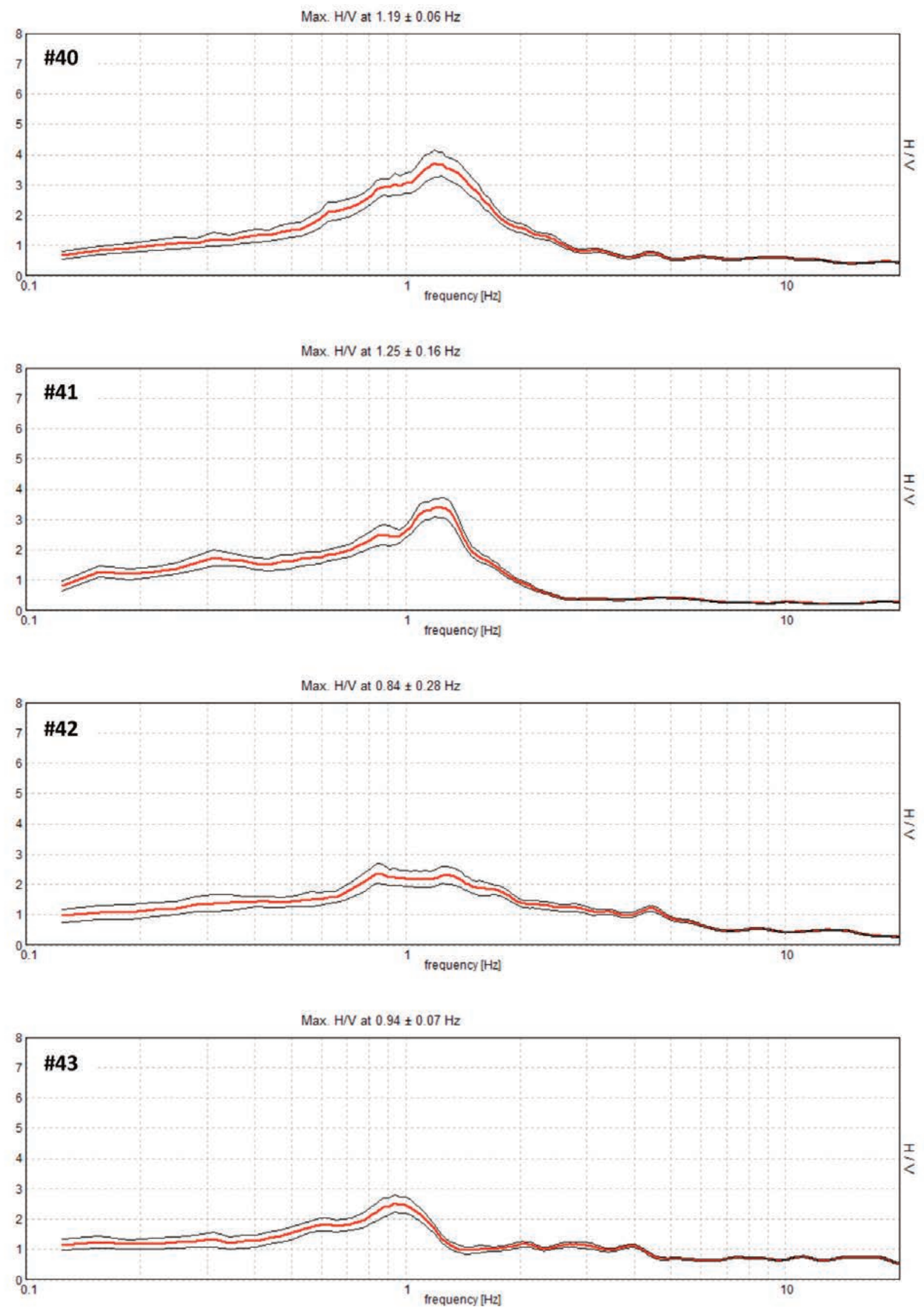

FIGURE S6. HVSR curves for the Historical Center area $(\# 80)$. Red curve $=$ mean spectral ratio, black curves $=$ standard deviation 

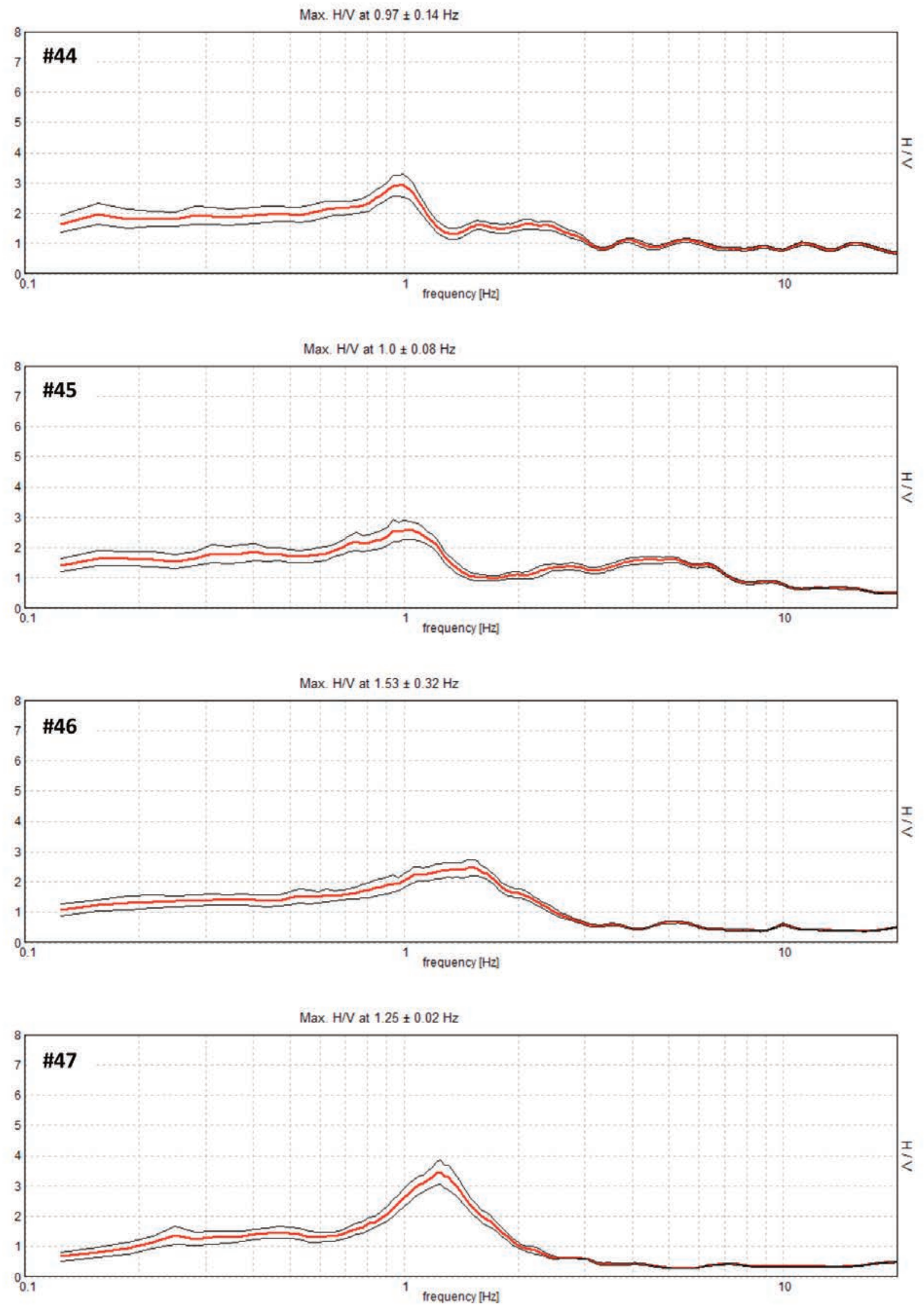

FIGURE S6. HVSR curves for the Historical Center area $(\# 80)$. Red curve $=$ mean spectral ratio, black curves $=$ standard deviation. 

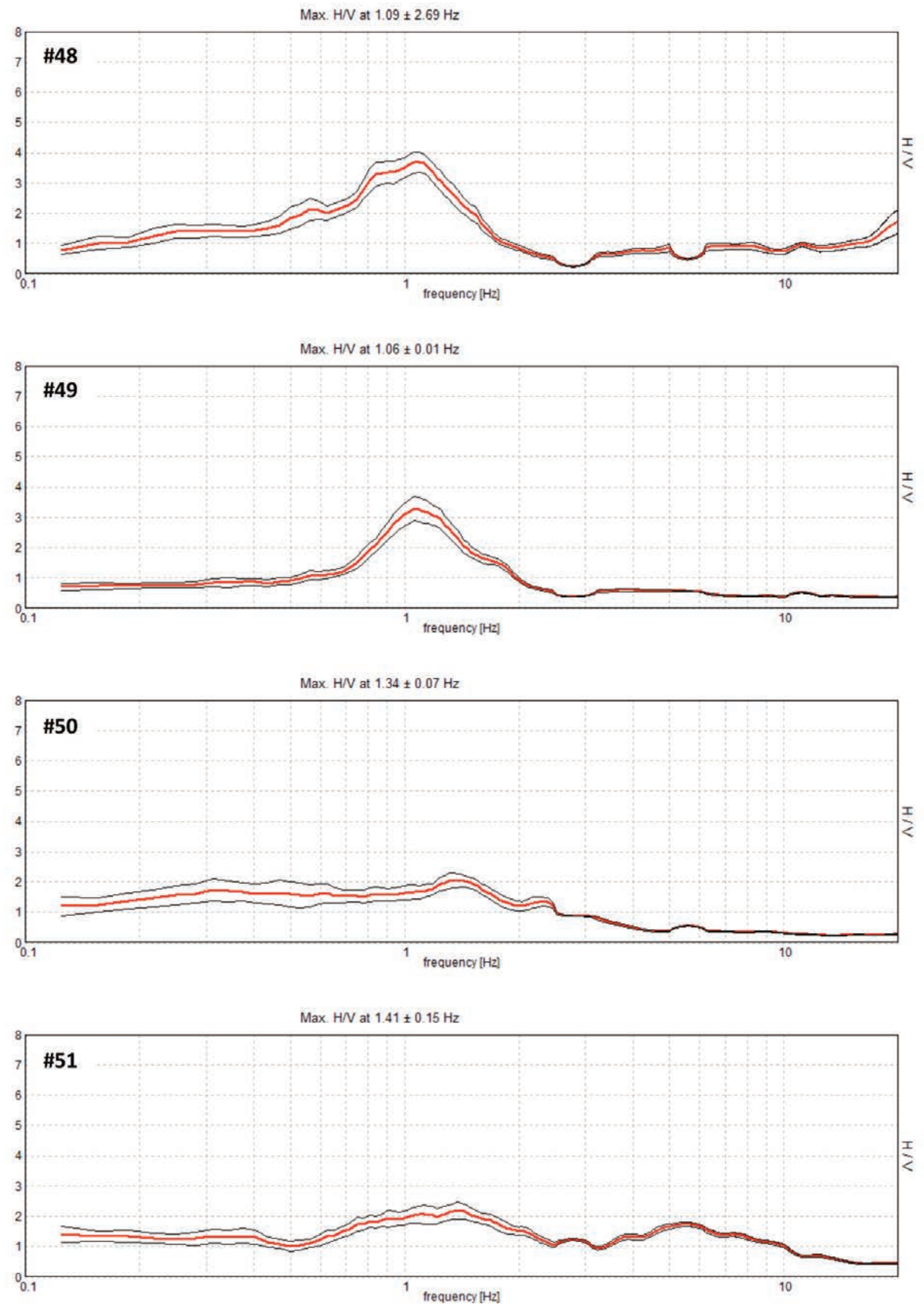

FIGURE S6. HVSR curves for the Historical Center area $(\# 80)$. Red curve $=$ mean spectral ratio, black curves $=$ standard deviation 

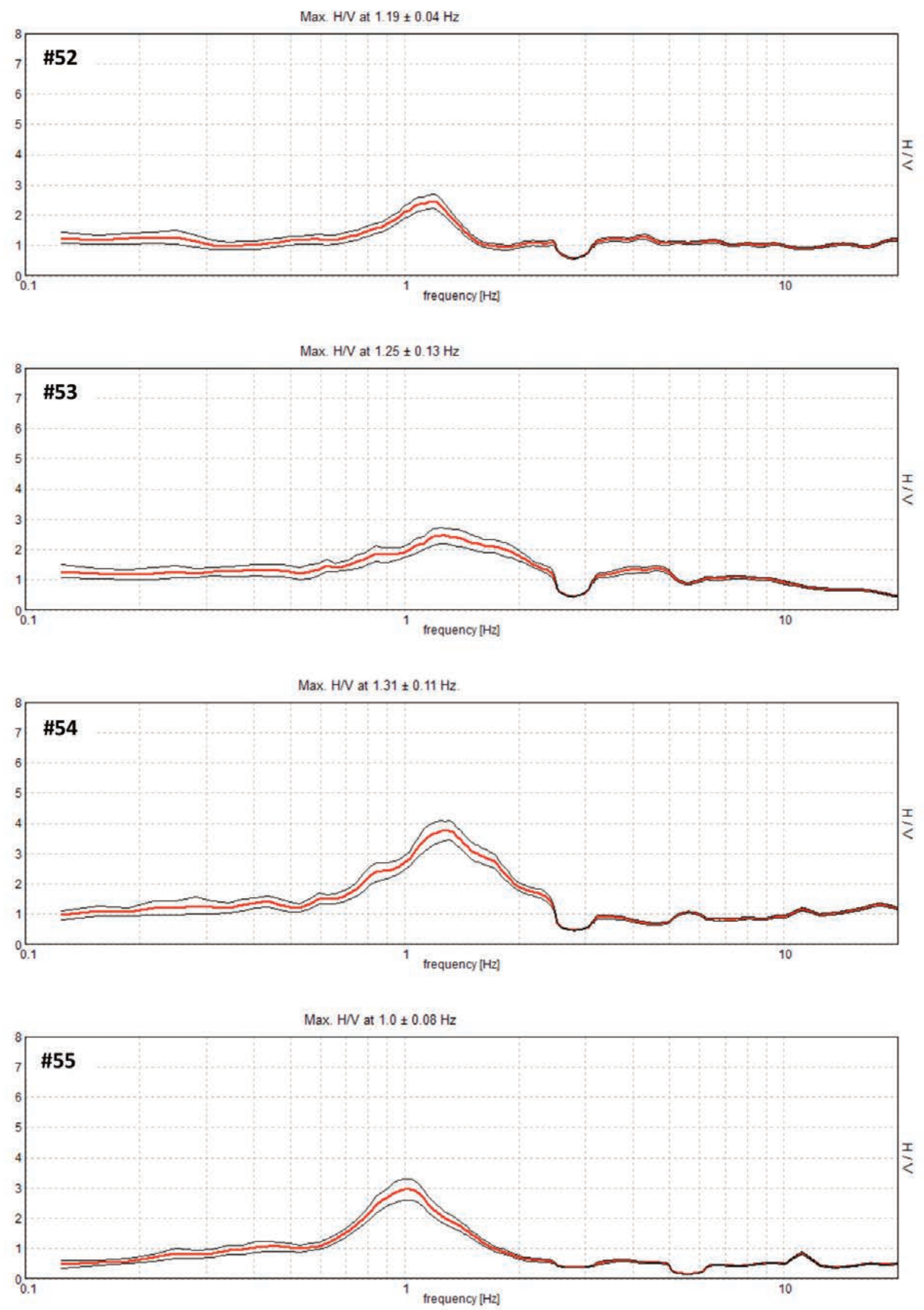

FIGURE S6. HVSR curves for the Historical Center area $(\# 80)$. Red curve $=$ mean spectral ratio, black curves $=$ standard deviation. 

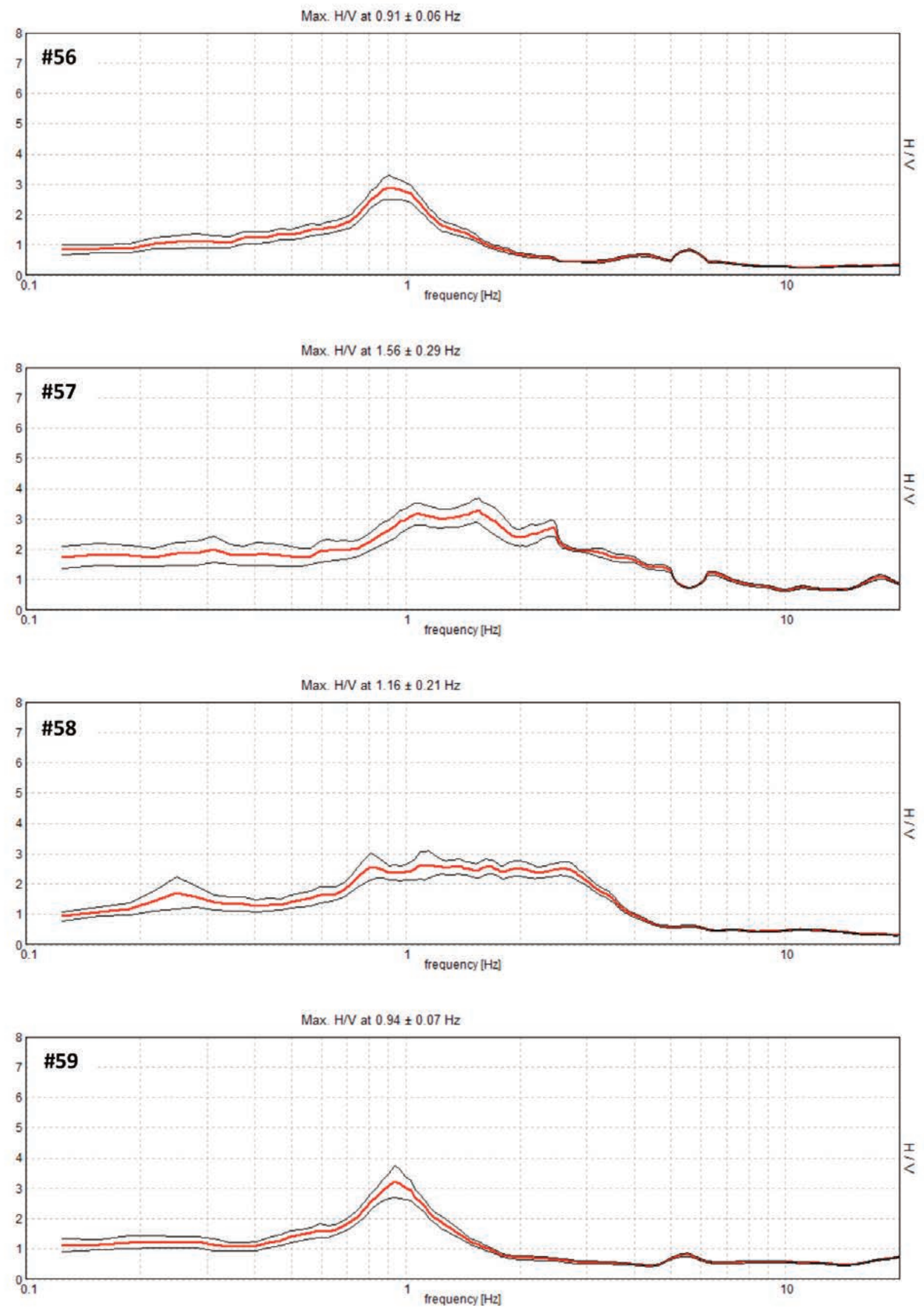

FIGURE S6. HVSR curves for the Historical Center area $(\# 80)$. Red curve $=$ mean spectral ratio, black curves $=$ standard deviation 

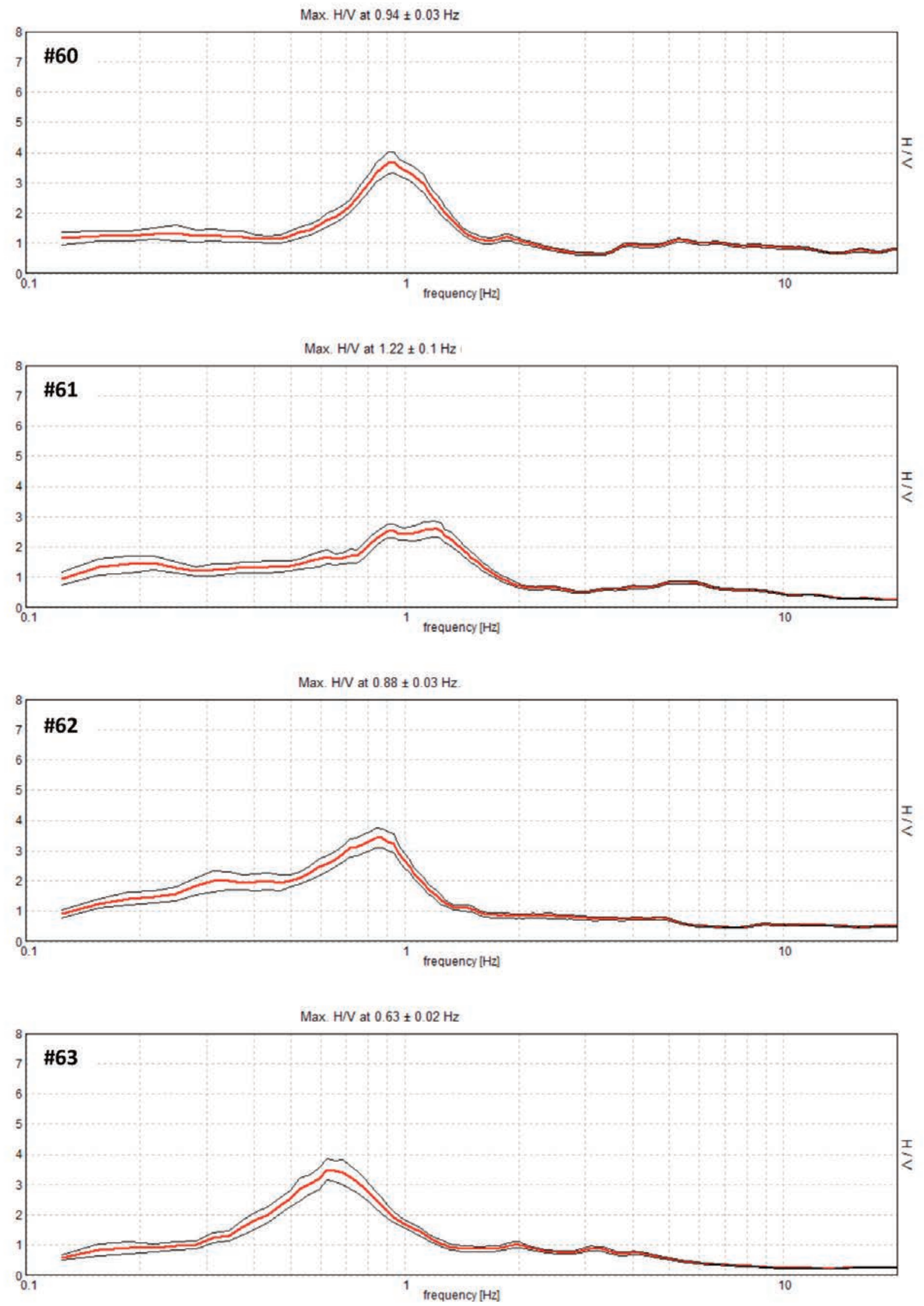

FIGURE S6. HVSR curves for the Historical Center area $(\# 80)$. Red curve $=$ mean spectral ratio, black curves $=$ standard deviation. 

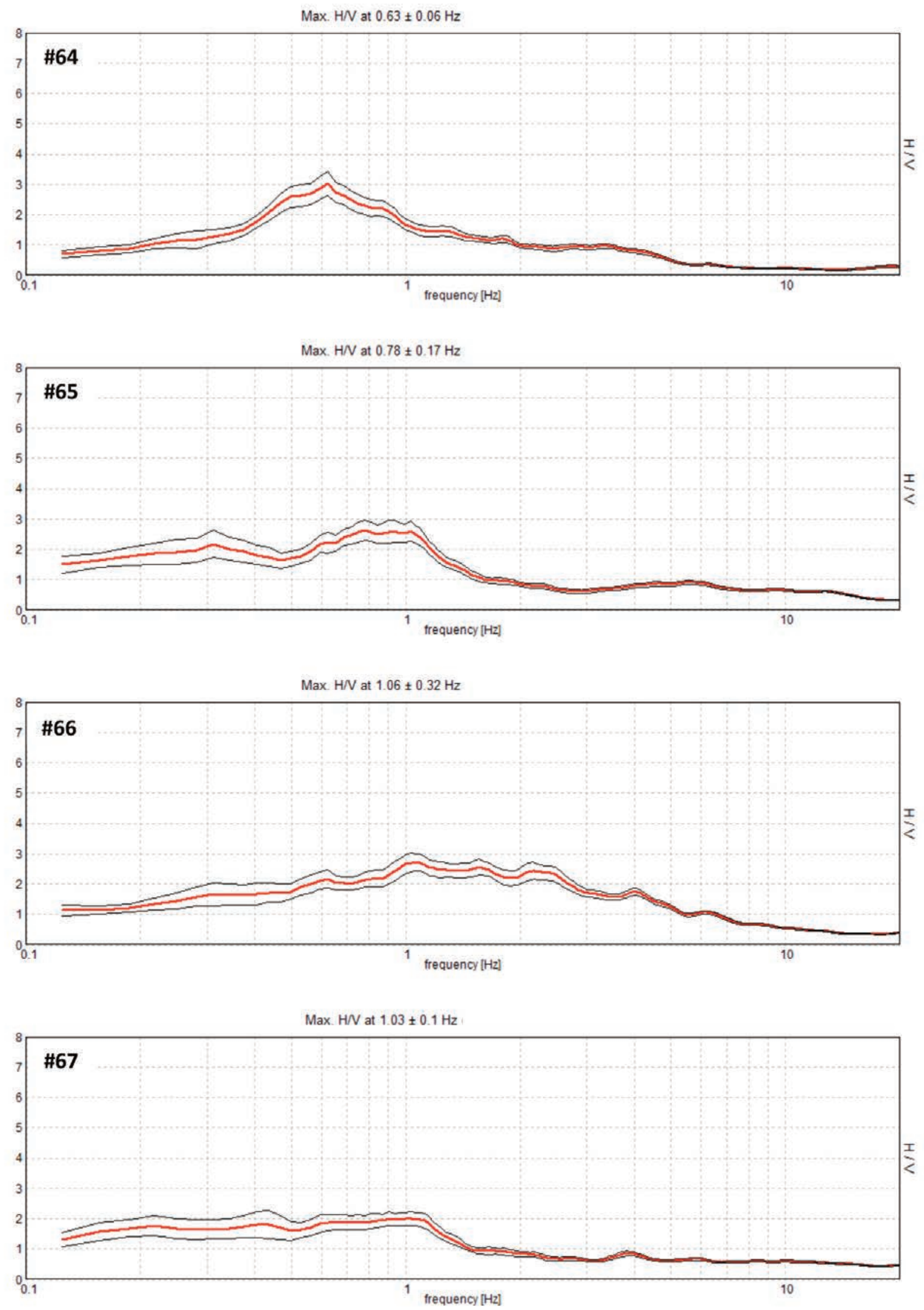

FIGURE S6. HVSR curves for the Historical Center area $(\# 80)$. Red curve $=$ mean spectral ratio, black curves $=$ standard deviation 

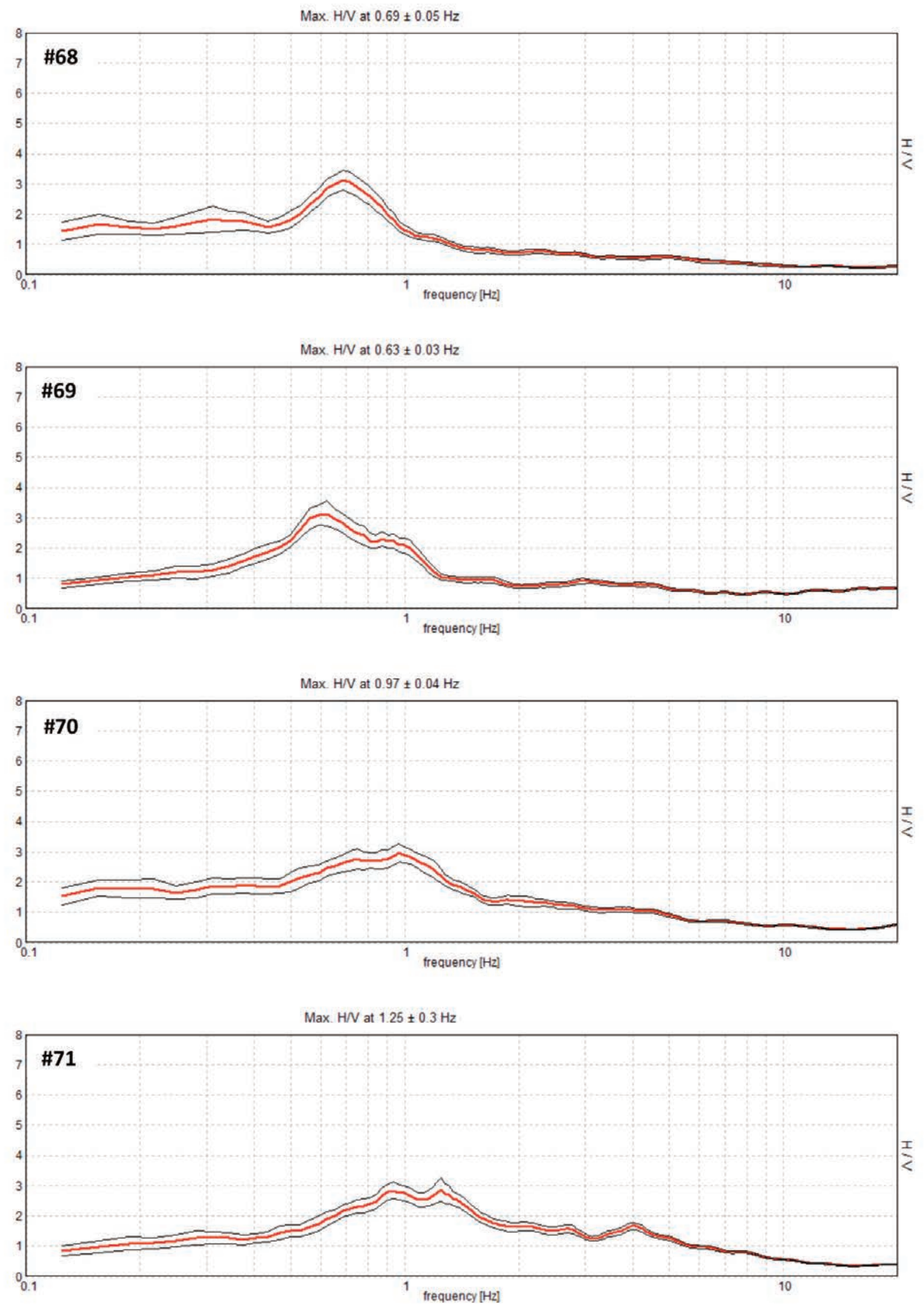

FIGURE S6. HVSR curves for the Historical Center area $(\# 80)$. Red curve $=$ mean spectral ratio, black curves $=$ standard deviation. 

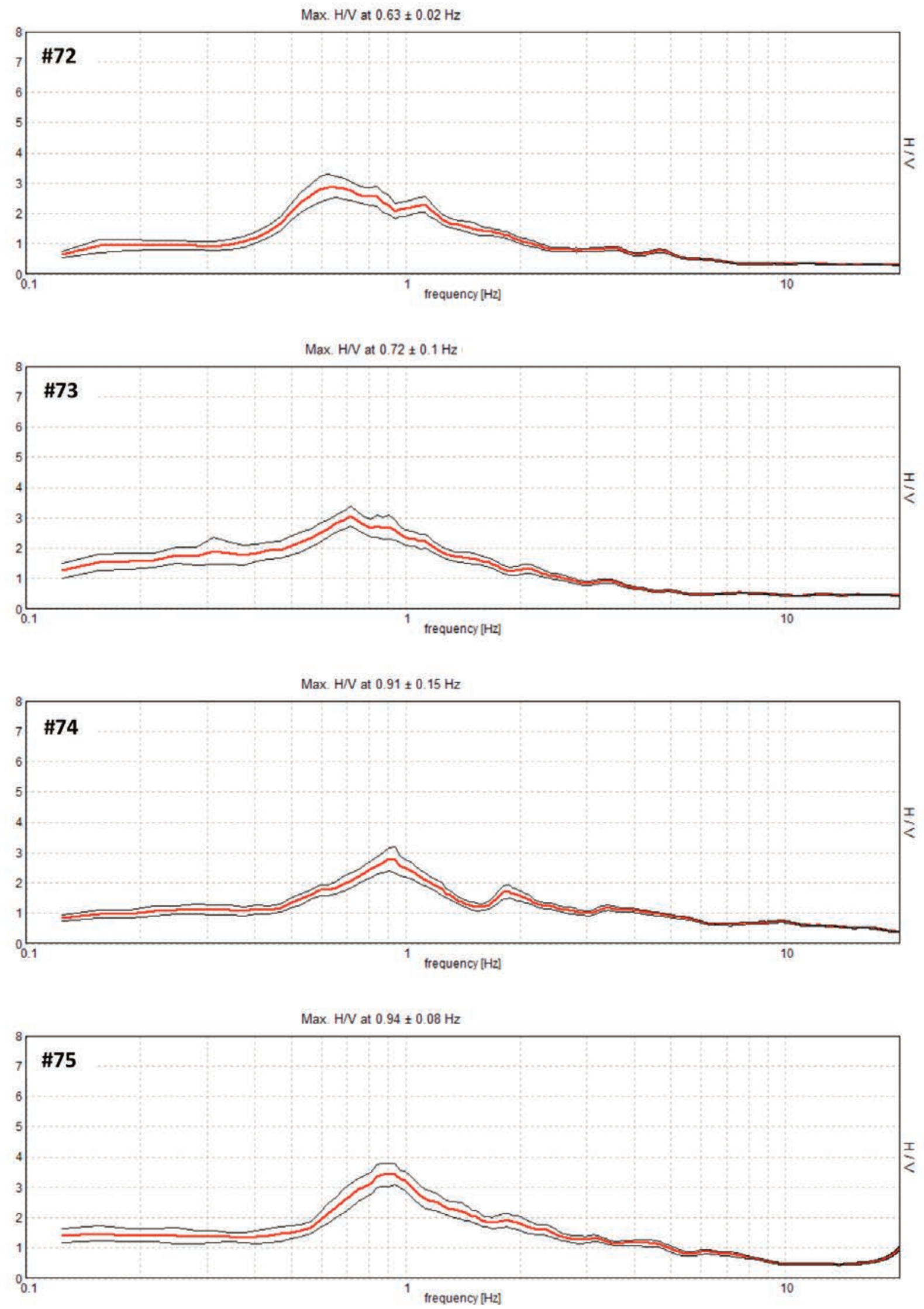

FIGURE S6. HVSR curves for the Historical Center area $(\# 80)$. Red curve $=$ mean spectral ratio, black curves $=$ standard deviation 

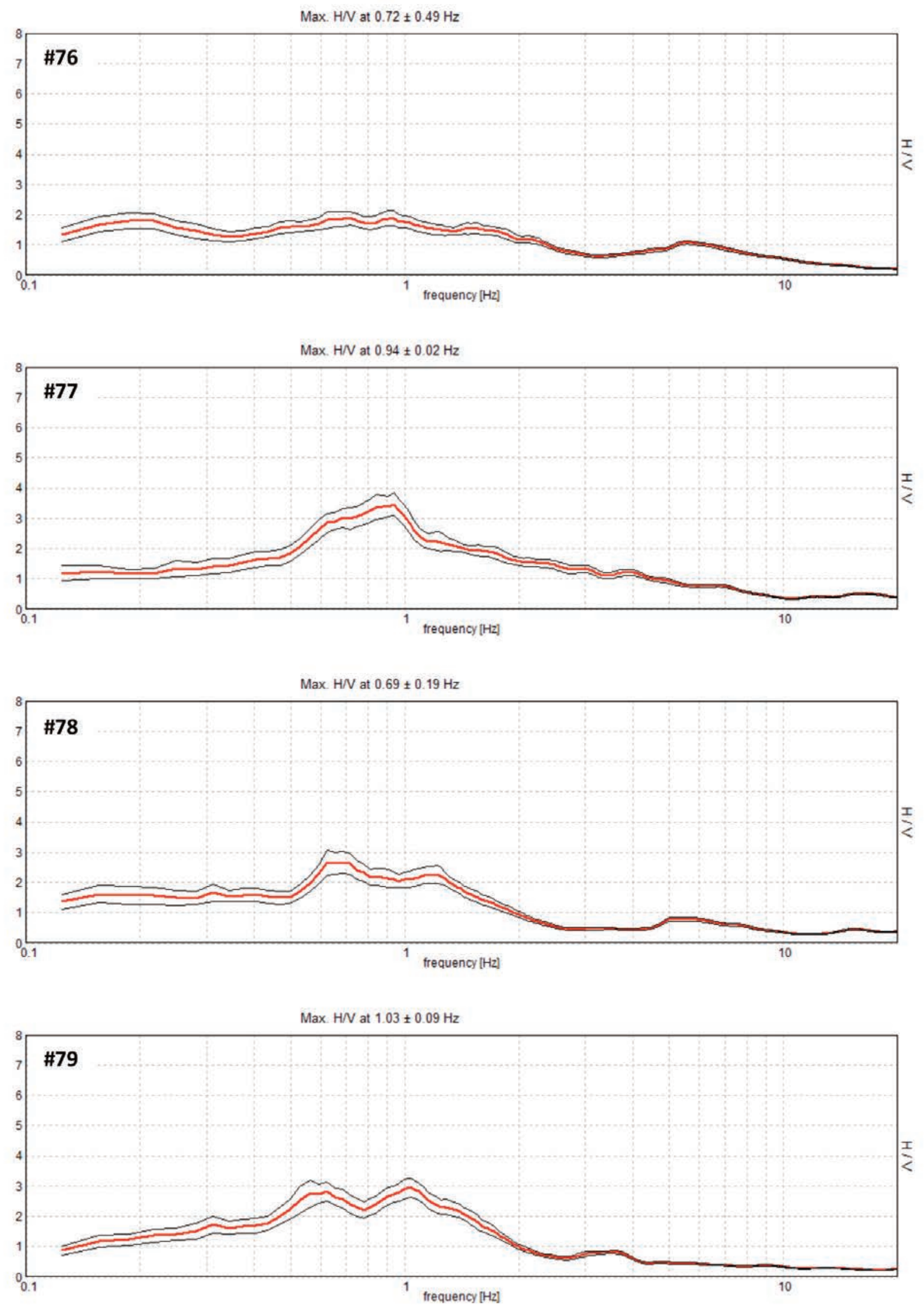

FIGURE S6. HVSR curves for the Historical Center area $(\# 80)$. Red curve $=$ mean spectral ratio, black curves $=$ standard deviation. 
SCOLARO ET AL.

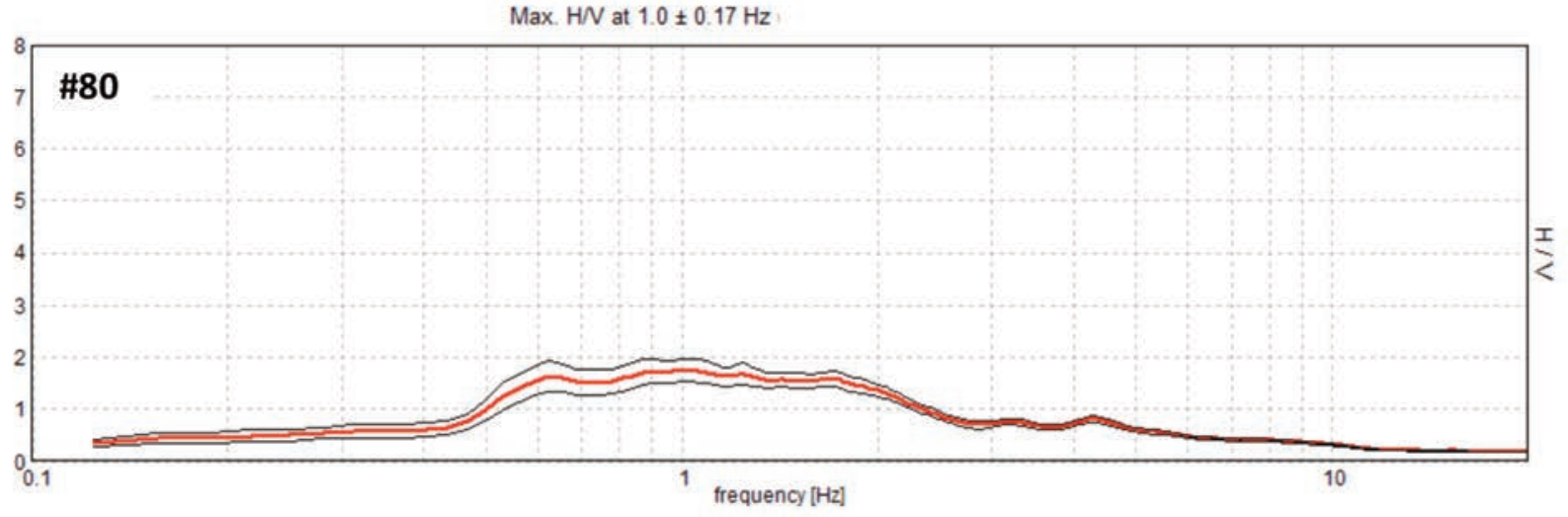

FIGURE S6. HVSR curves for the Historical Center area $(\# 80)$. Red curve $=$ mean spectral ratio, black curves $=$ standard deviation. 


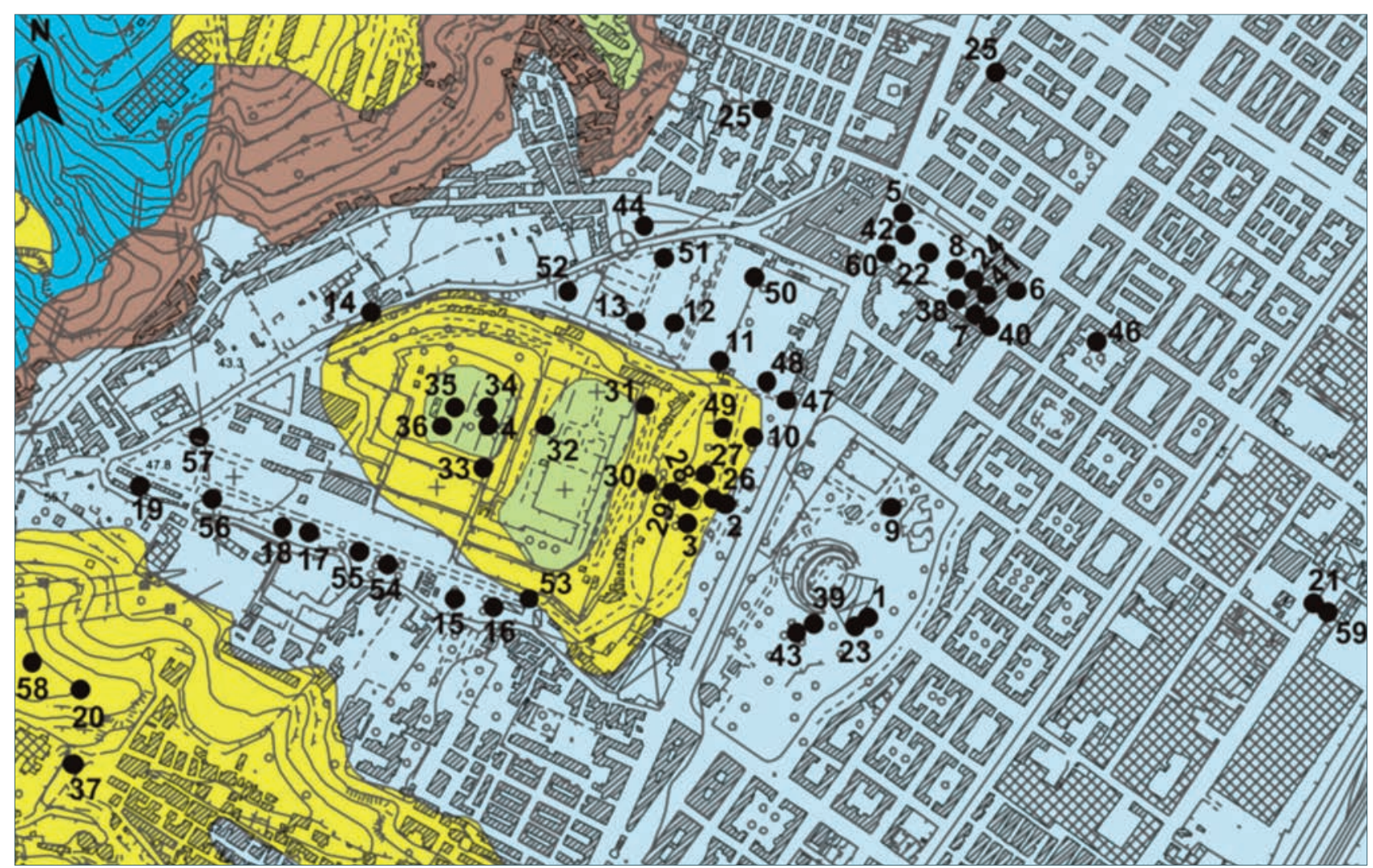

FIGURE S7. HVSR measurement points in the monumental cemetery sector. 

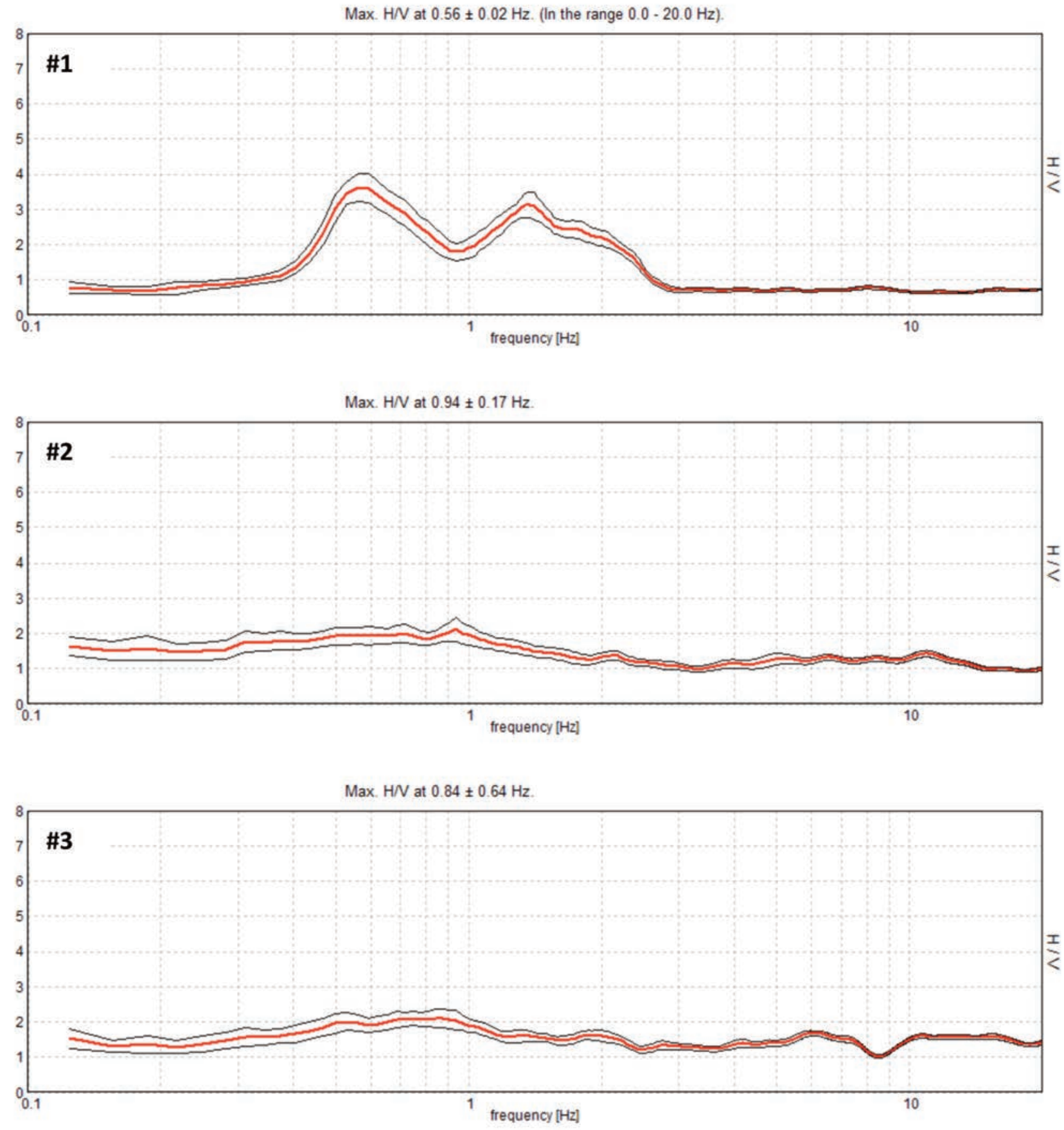

FIGURE S8. HVSR curves for the Monumental Cemetery area (\#60). Red curve = mean spectral ratio, black curves = standard deviation. 

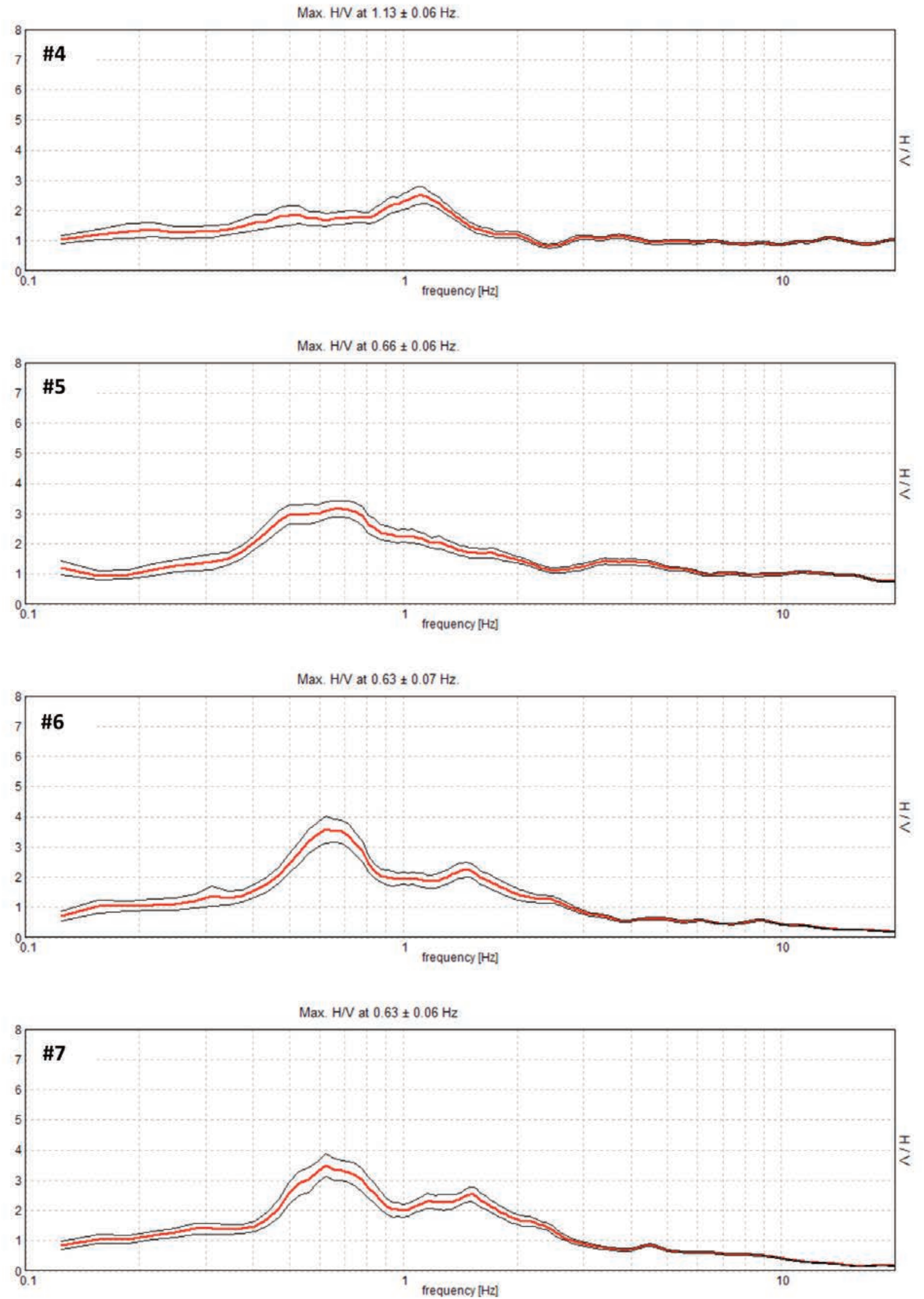

FIGURE S8. HVSR curves for the Monumental Cemetery area (\#60). Red curve = mean spectral ratio, black curves = standard deviation. 

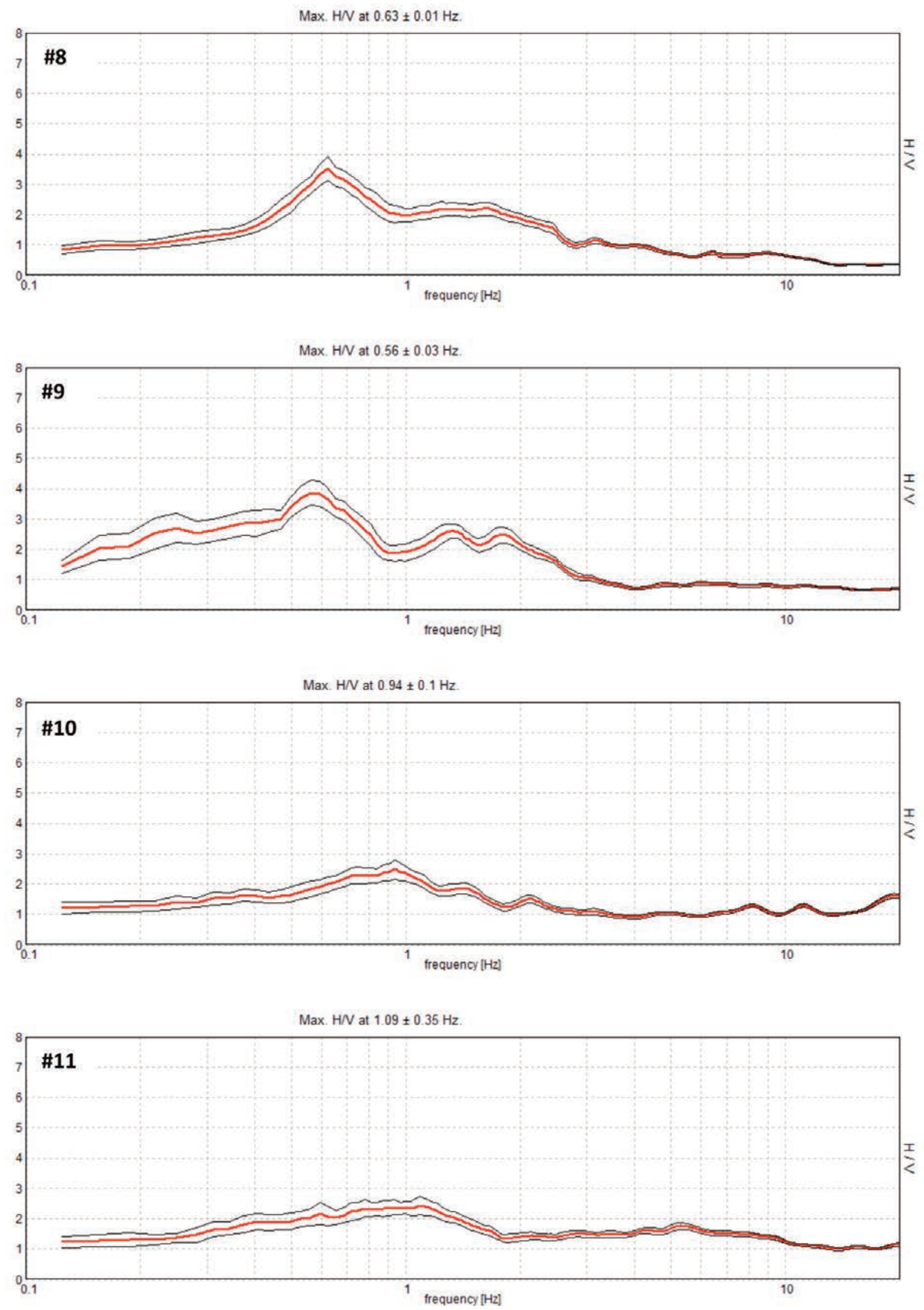

FIGURE S8. HVSR curves for the Monumental Cemetery area (\#60). Red curve = mean spectral ratio, black curves = standard deviation. 

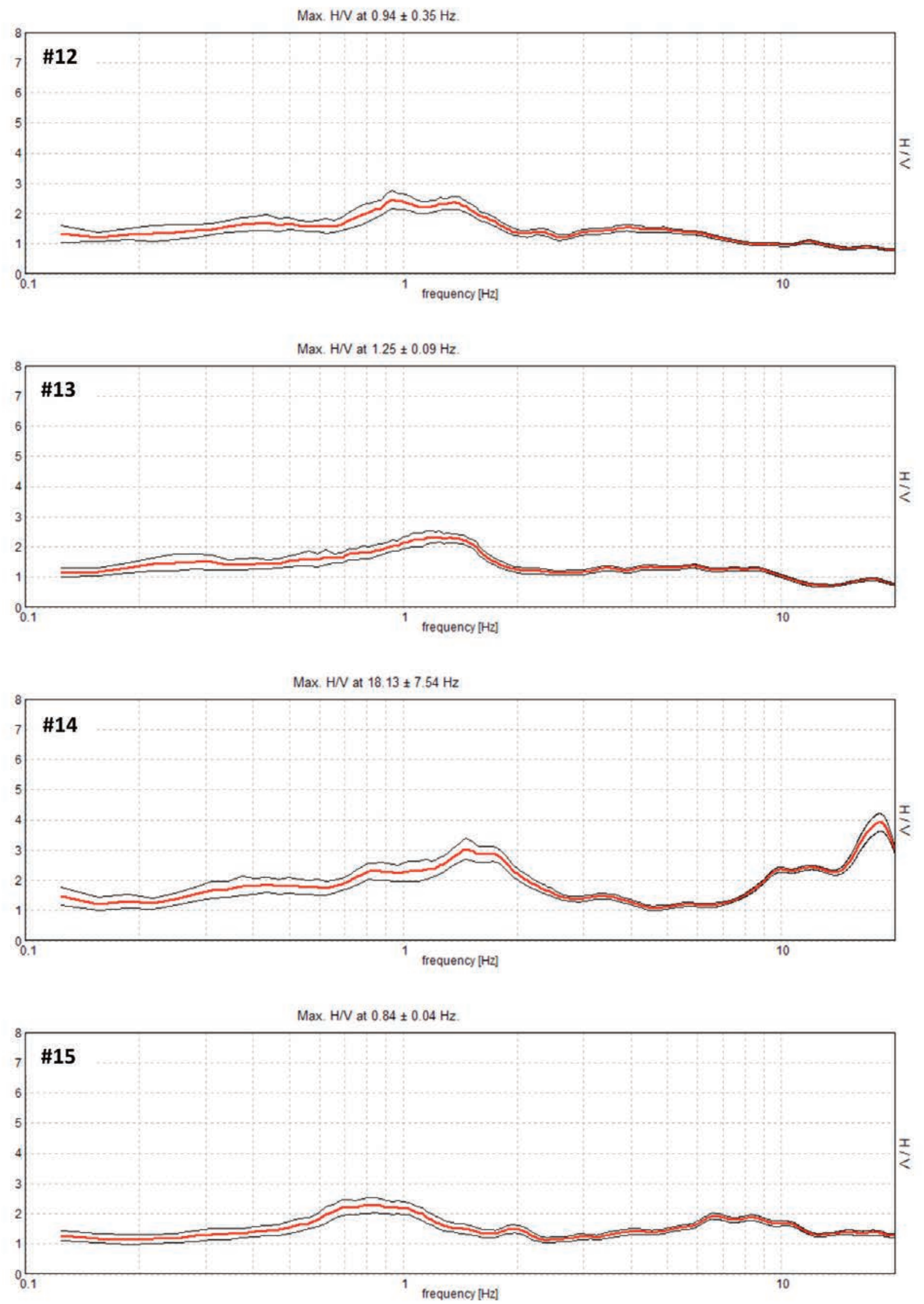

FIGURE S8. HVSR curves for the Monumental Cemetery area (\#60). Red curve $=$ mean spectral ratio, black curves $=$ standard deviation. 


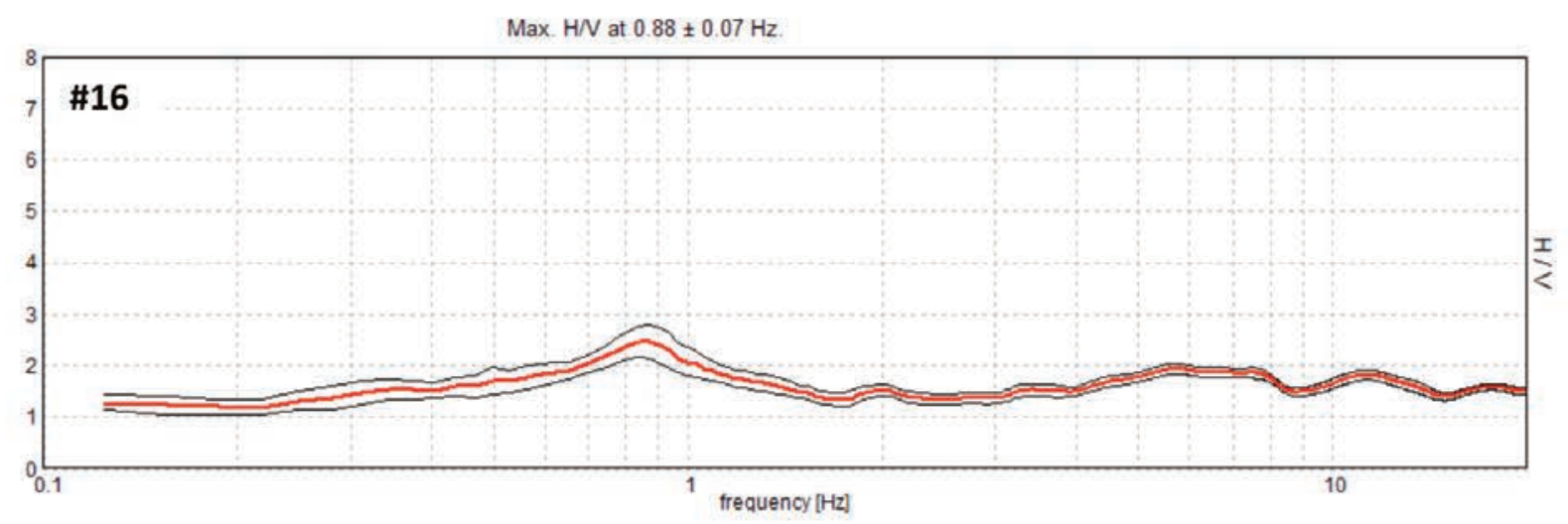

Max. $\mathrm{H} / \mathrm{N}$ at $19.06 \pm 2.33 \mathrm{~Hz}$

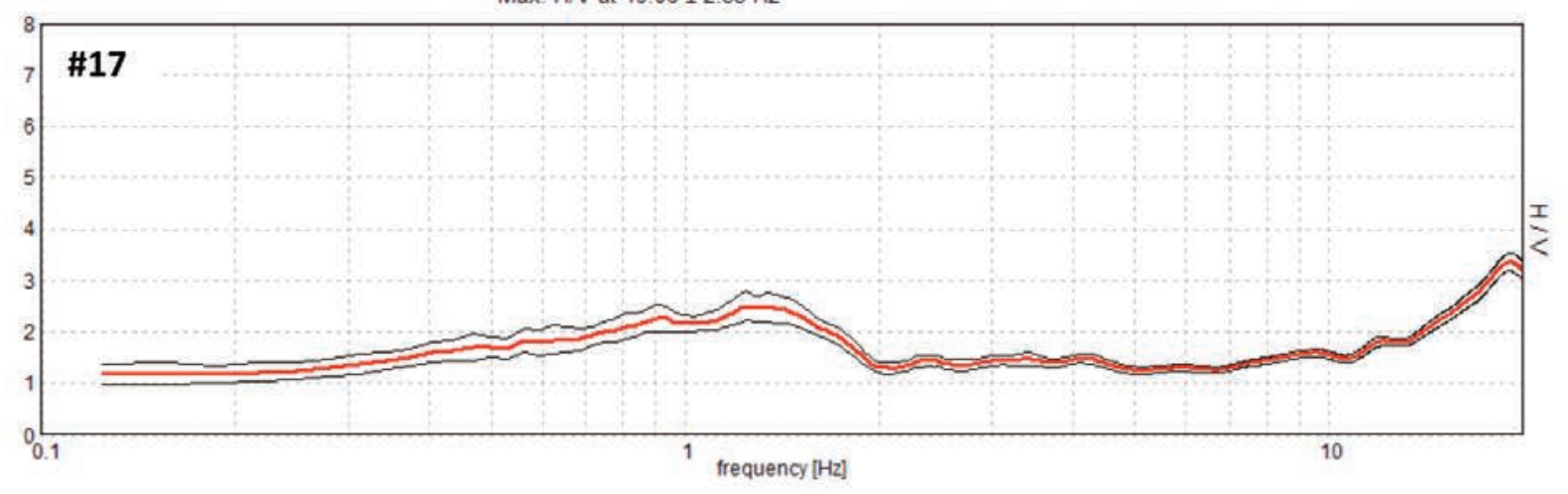

$\operatorname{Max} . \mathrm{H} / \mathrm{N}$ at $17.81 \pm 3.06 \mathrm{~Hz}$

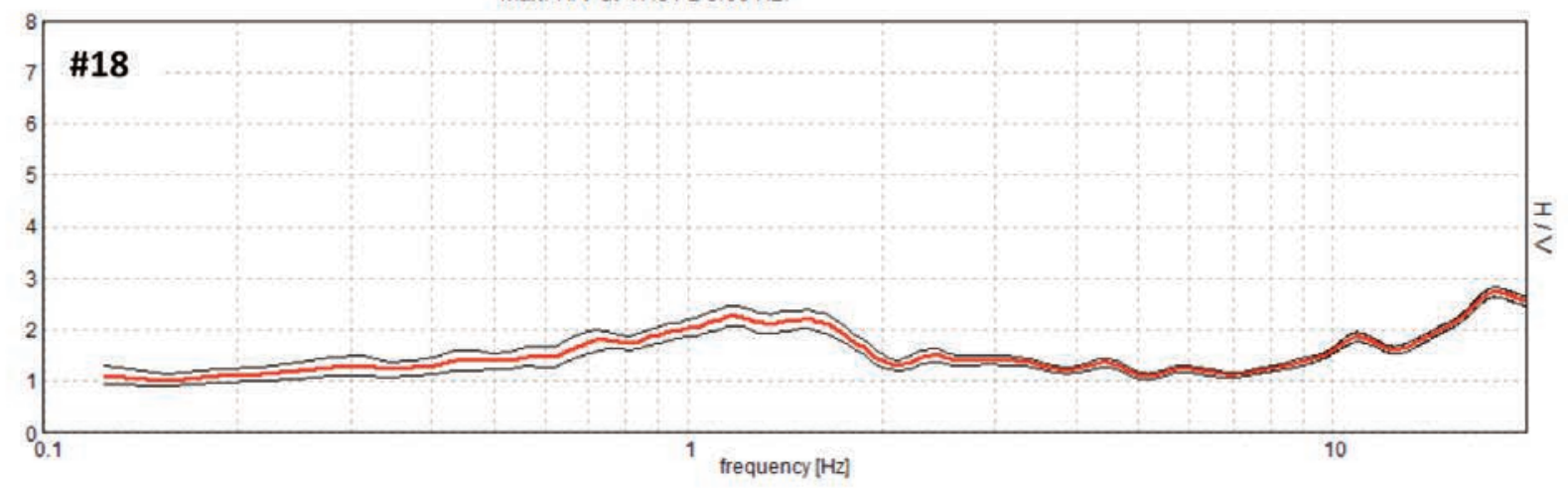

Max. $\mathrm{H} / \mathrm{N}$ at $1.97 \pm 0.2 \mathrm{~Hz}$

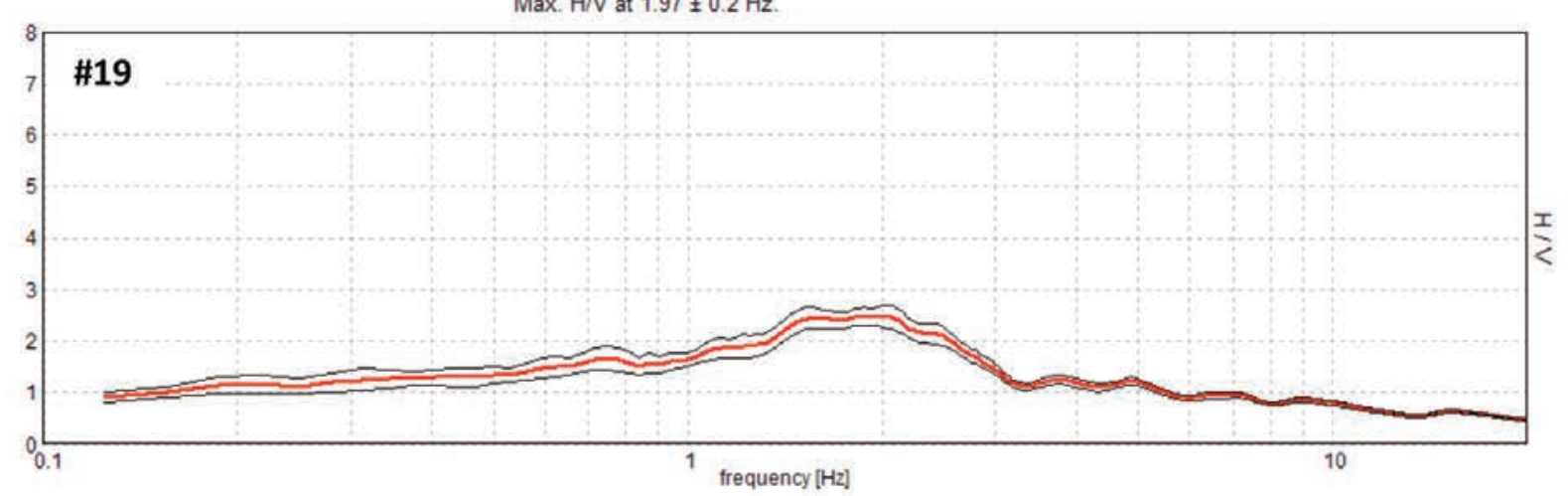

FIGURE S8. HVSR curves for the Monumental Cemetery area (\#60). Red curve $=$ mean spectral ratio, black curves $=$ standard deviation. 

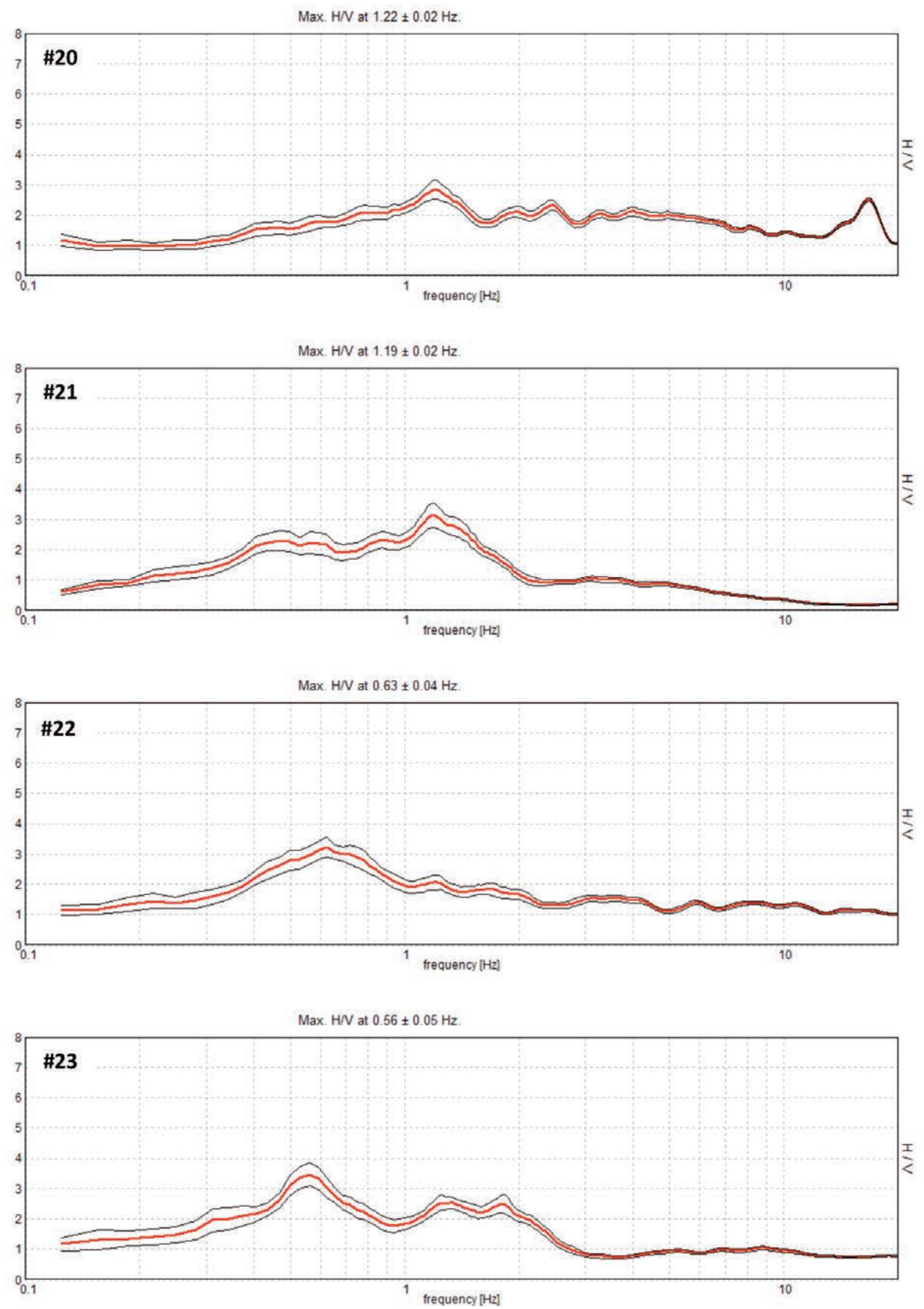

FIGURE S8. HVSR curves for the Monumental Cemetery area (\#60). Red curve = mean spectral ratio, black curves = standard deviation. 

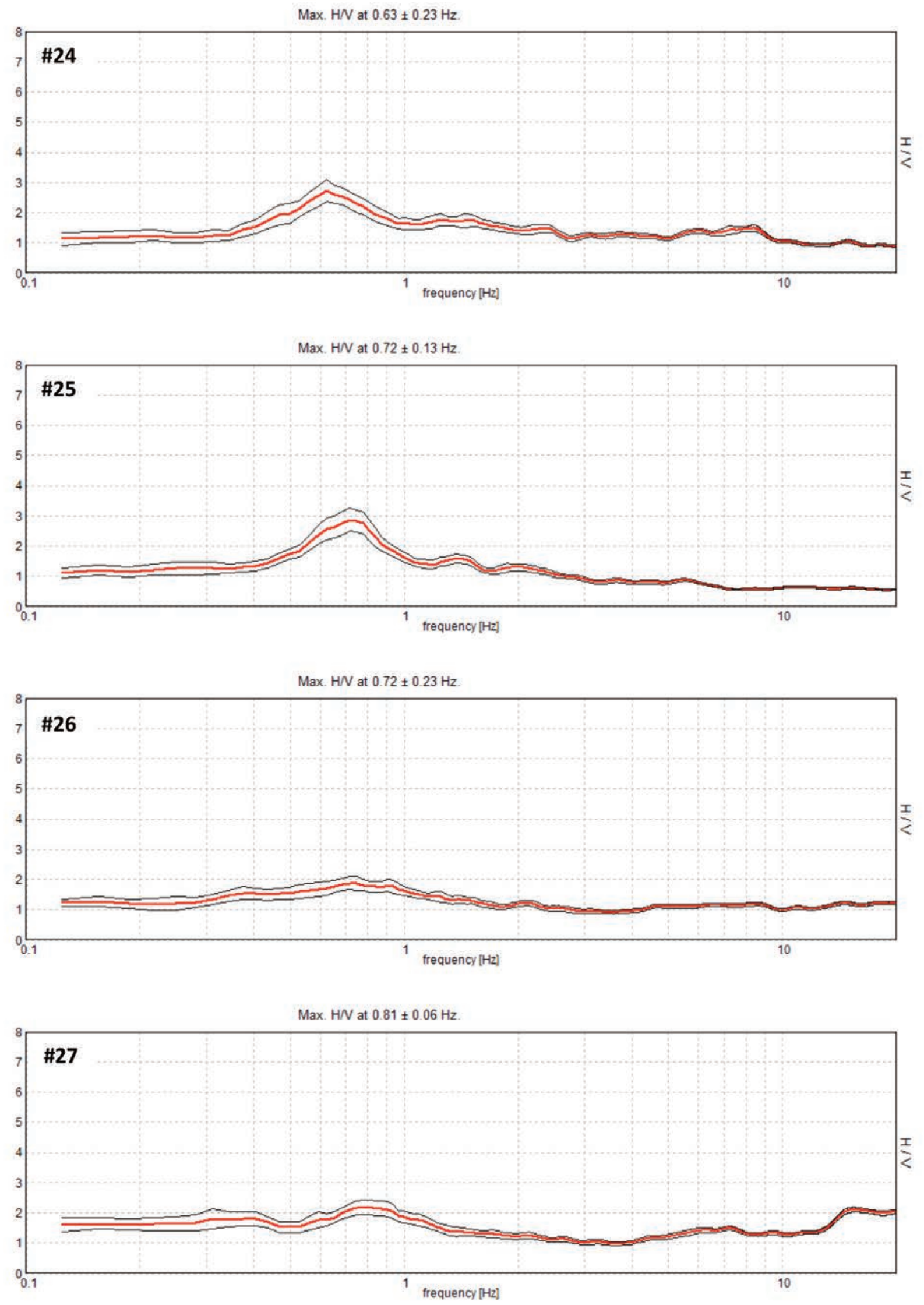

FIGURE S8. HVSR curves for the Monumental Cemetery area (\#60). Red curve = mean spectral ratio, black curves = standard deviation. 

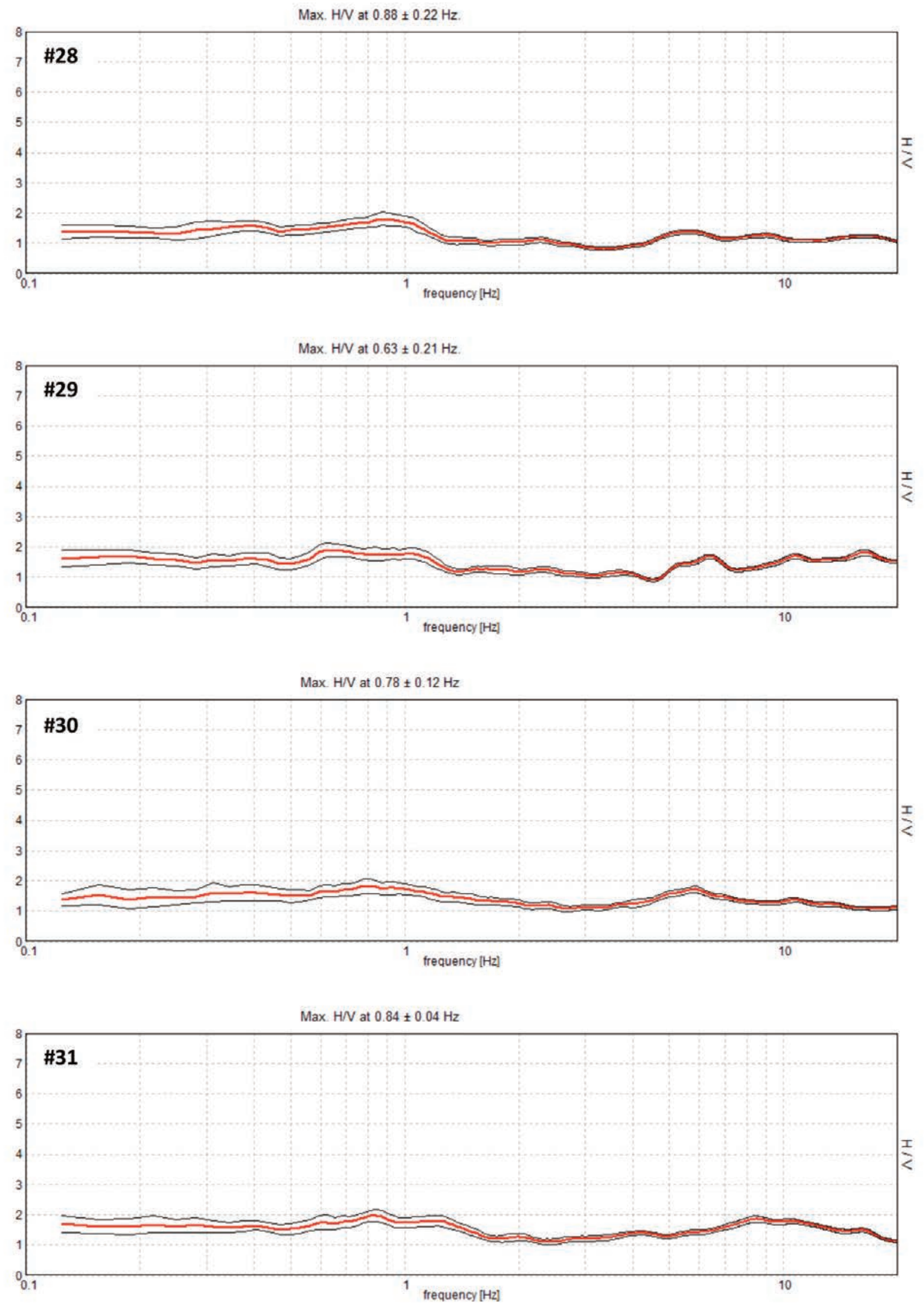

FIGURE S8. HVSR curves for the Monumental Cemetery area (\#60). Red curve = mean spectral ratio, black curves = standard deviation. 


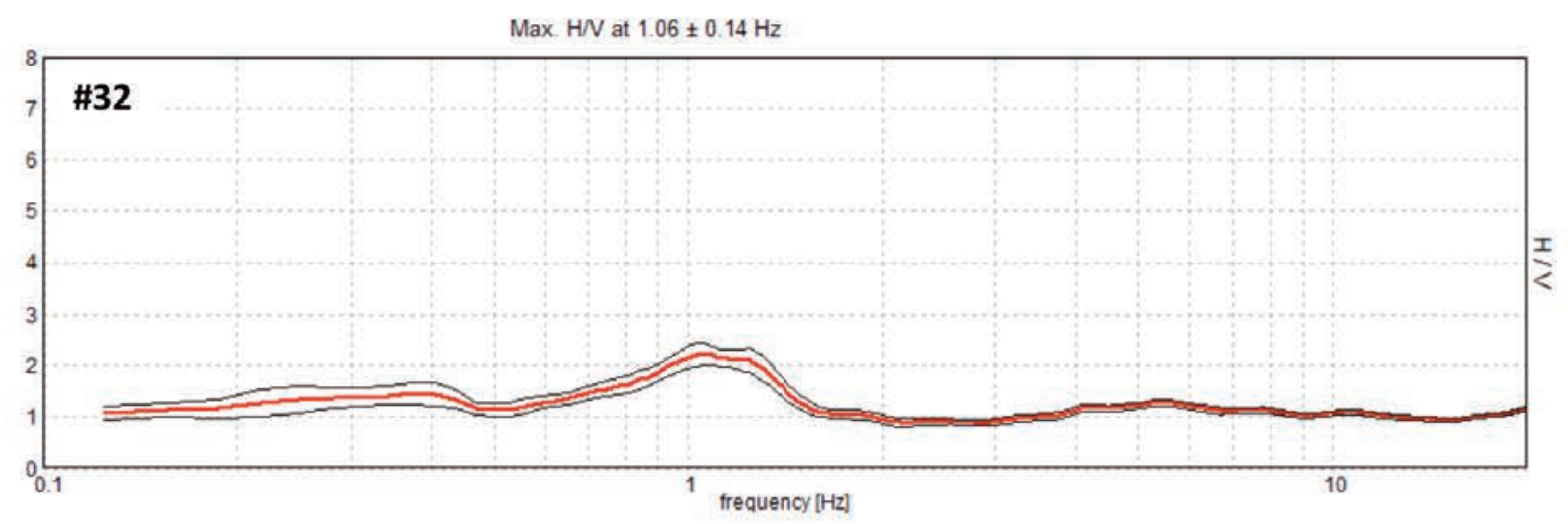

Max. $\mathrm{H} / \mathrm{V}$ at $1.0 \pm 0.15 \mathrm{~Hz}$

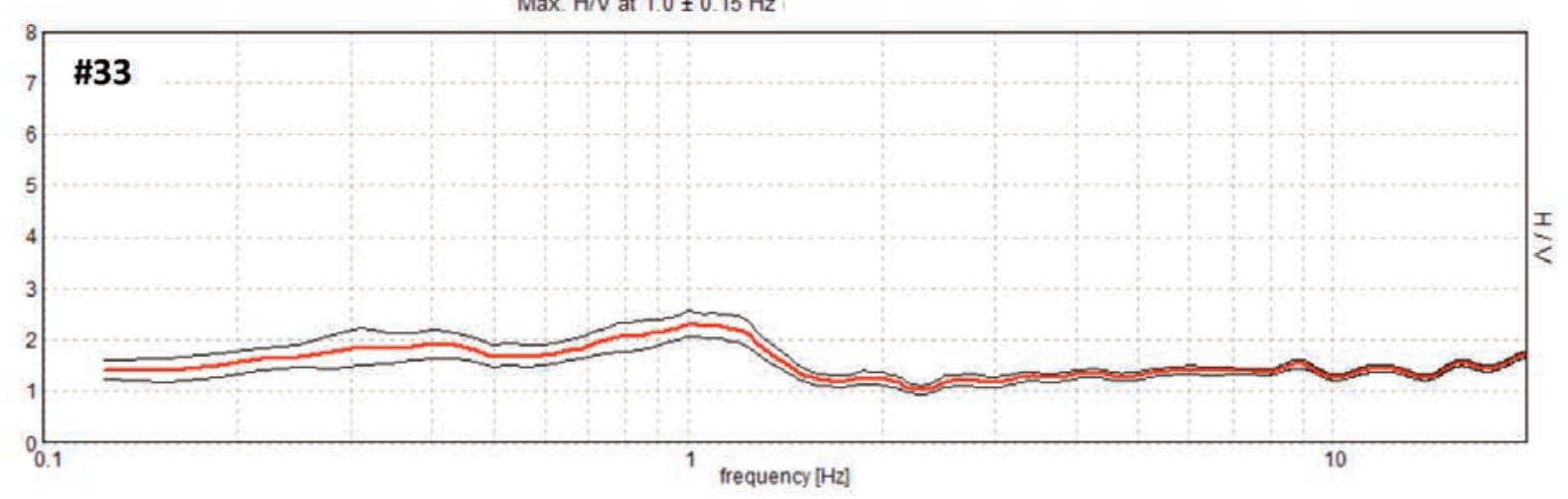

Max. $\mathrm{H} / \mathrm{N}$ at $1.19 \pm 0.06 \mathrm{~Hz}$

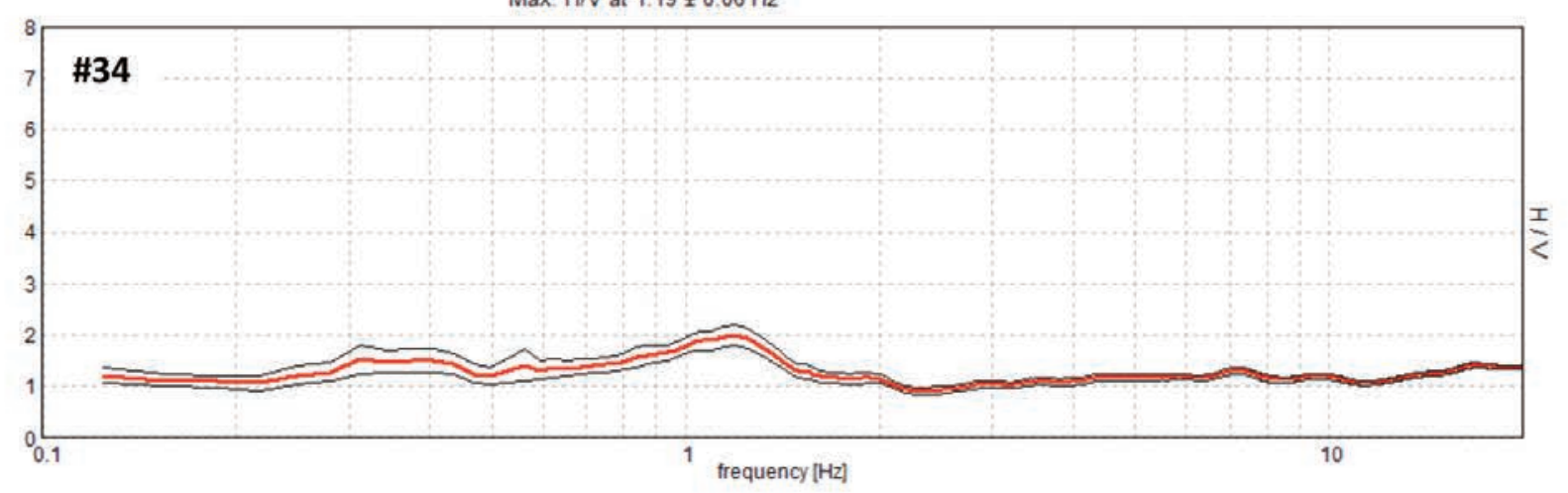

Max. $\mathrm{H} / \mathrm{N}$ at $1.25 \pm 0.16 \mathrm{~Hz}$

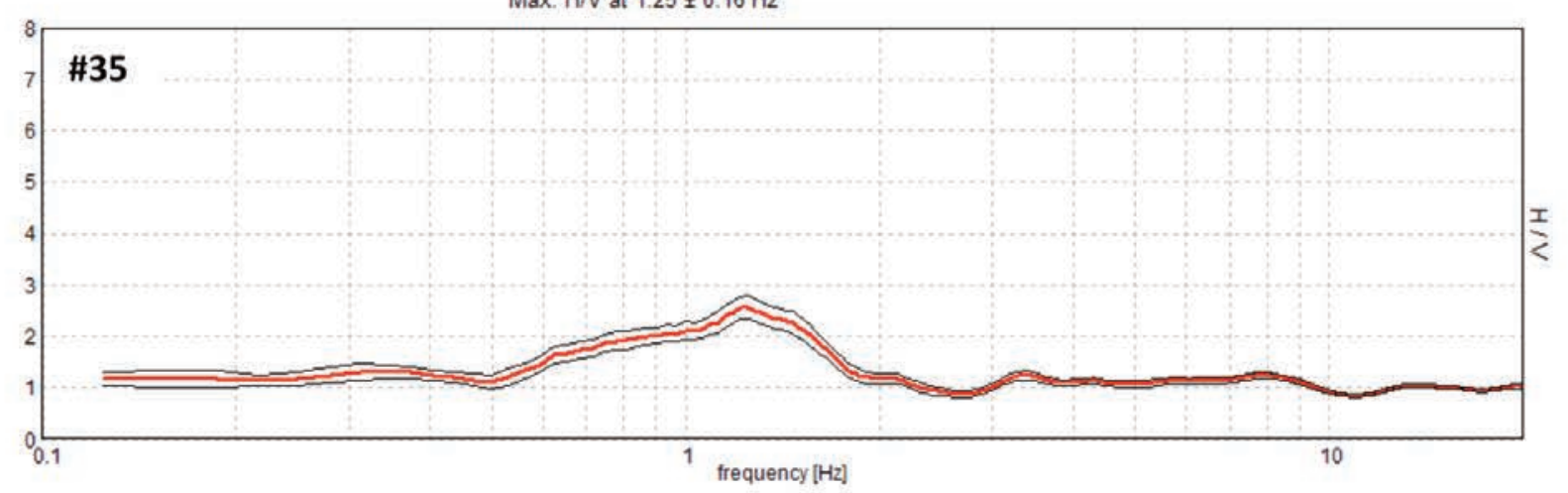

FIGURE S8. HVSR curves for the Monumental Cemetery area (\#60). Red curve = mean spectral ratio, black curves = standard deviation. 

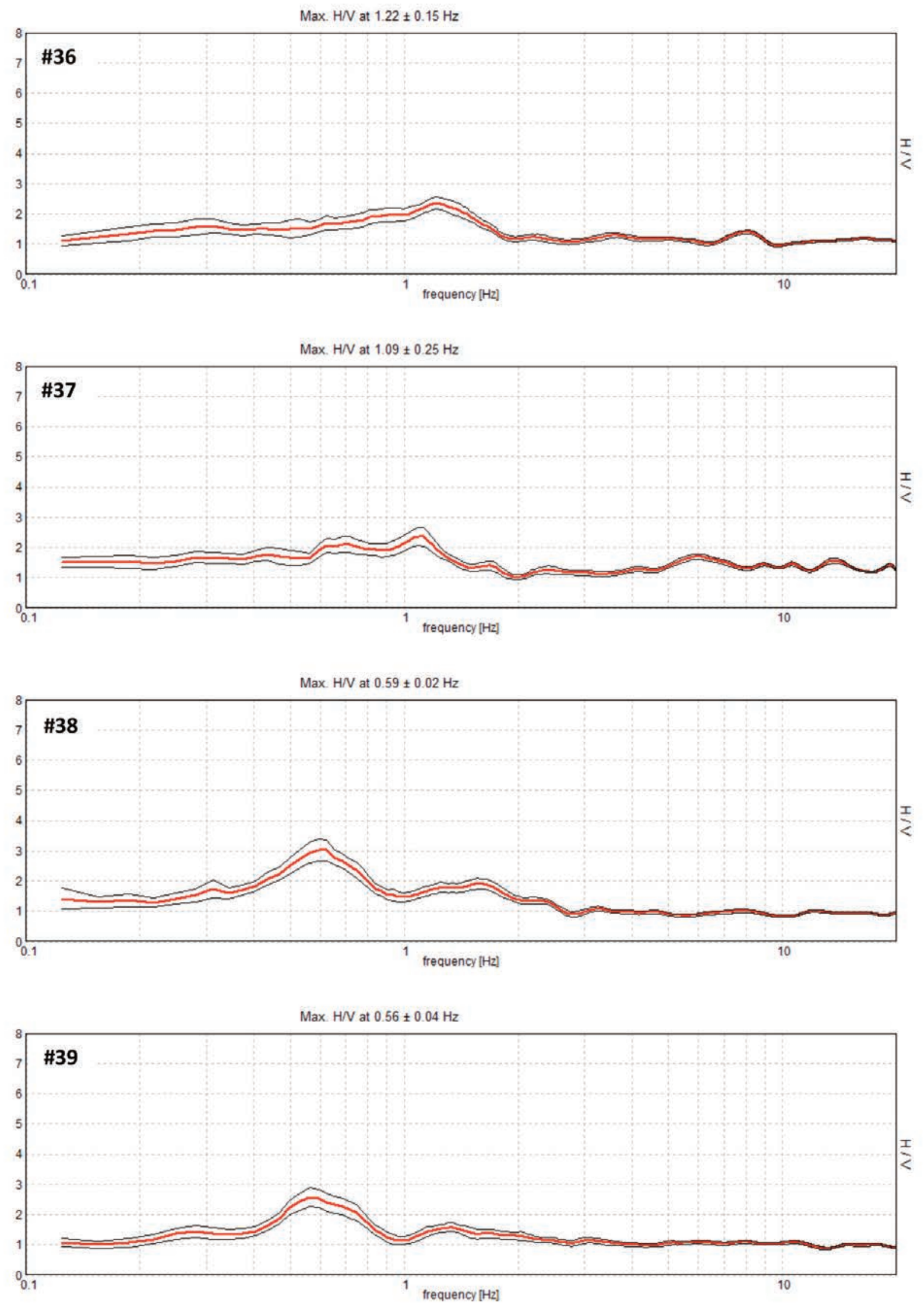

FIGURE S8. HVSR curves for the Monumental Cemetery area (\#60). Red curve = mean spectral ratio, black curves = standard deviation. 

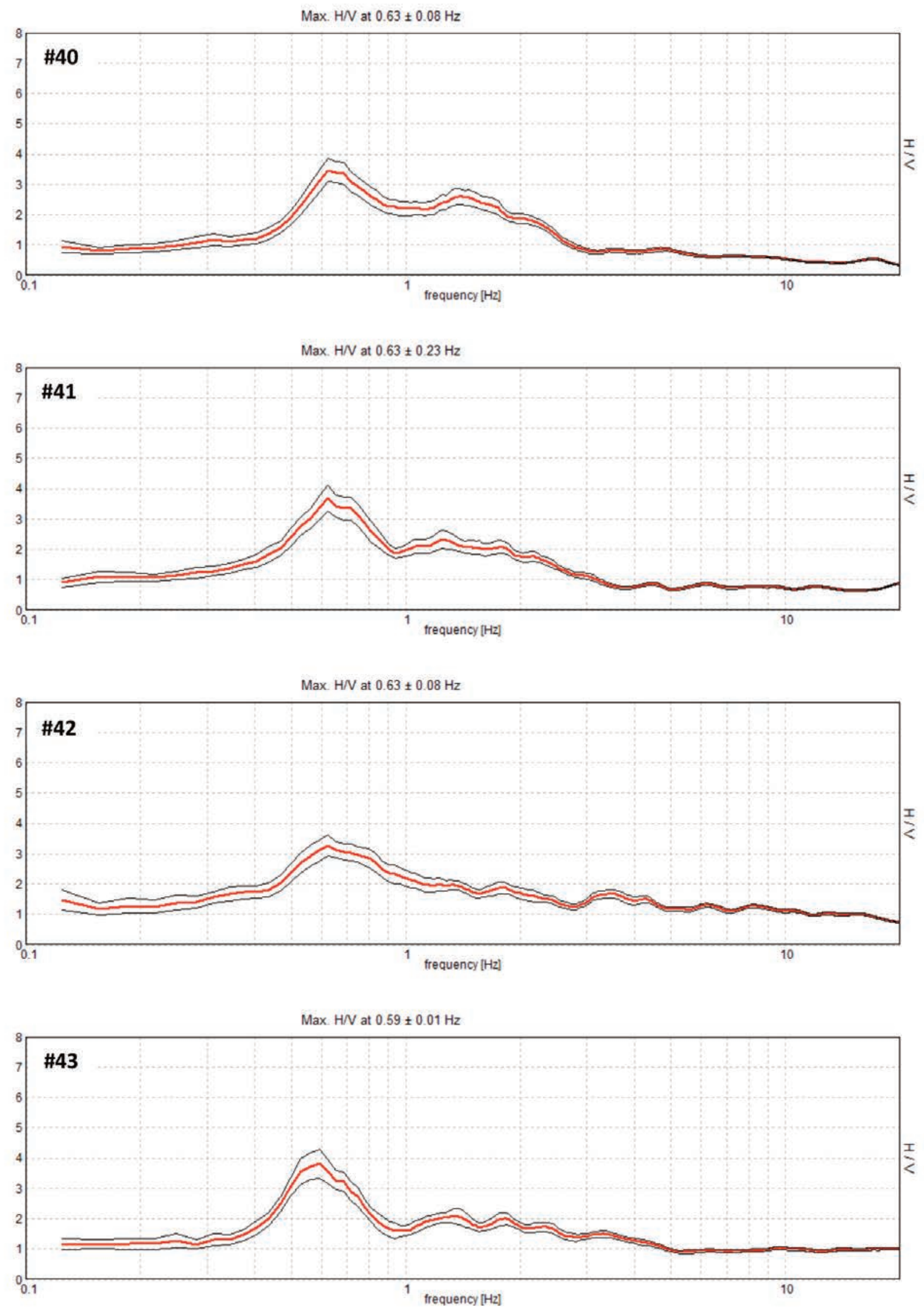

FIGURE S8. HVSR curves for the Monumental Cemetery area (\#60). Red curve = mean spectral ratio, black curves = standard deviation. 

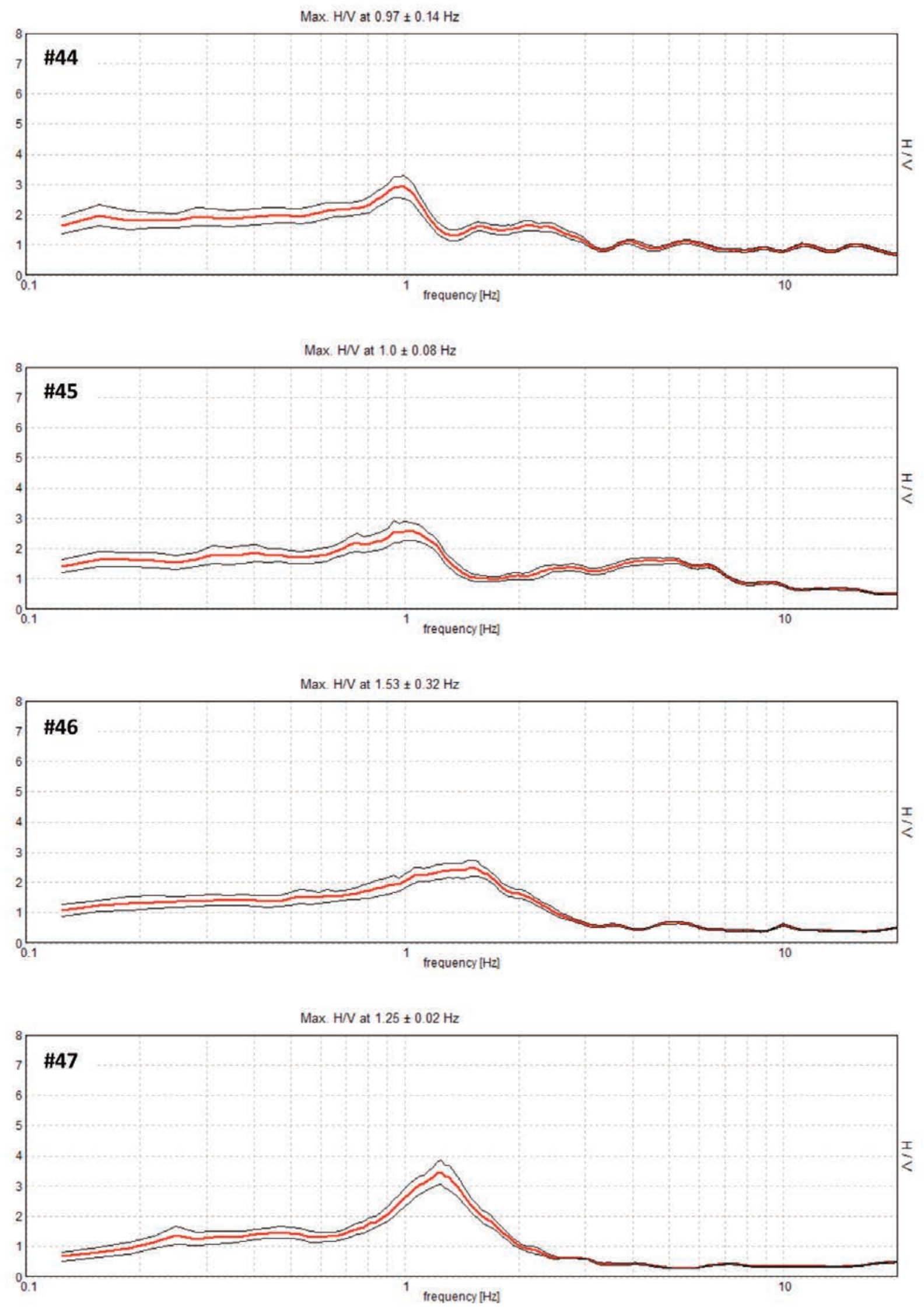

FIGURE S8. HVSR curves for the Monumental Cemetery area (\#60). Red curve = mean spectral ratio, black curves = standard deviation. 

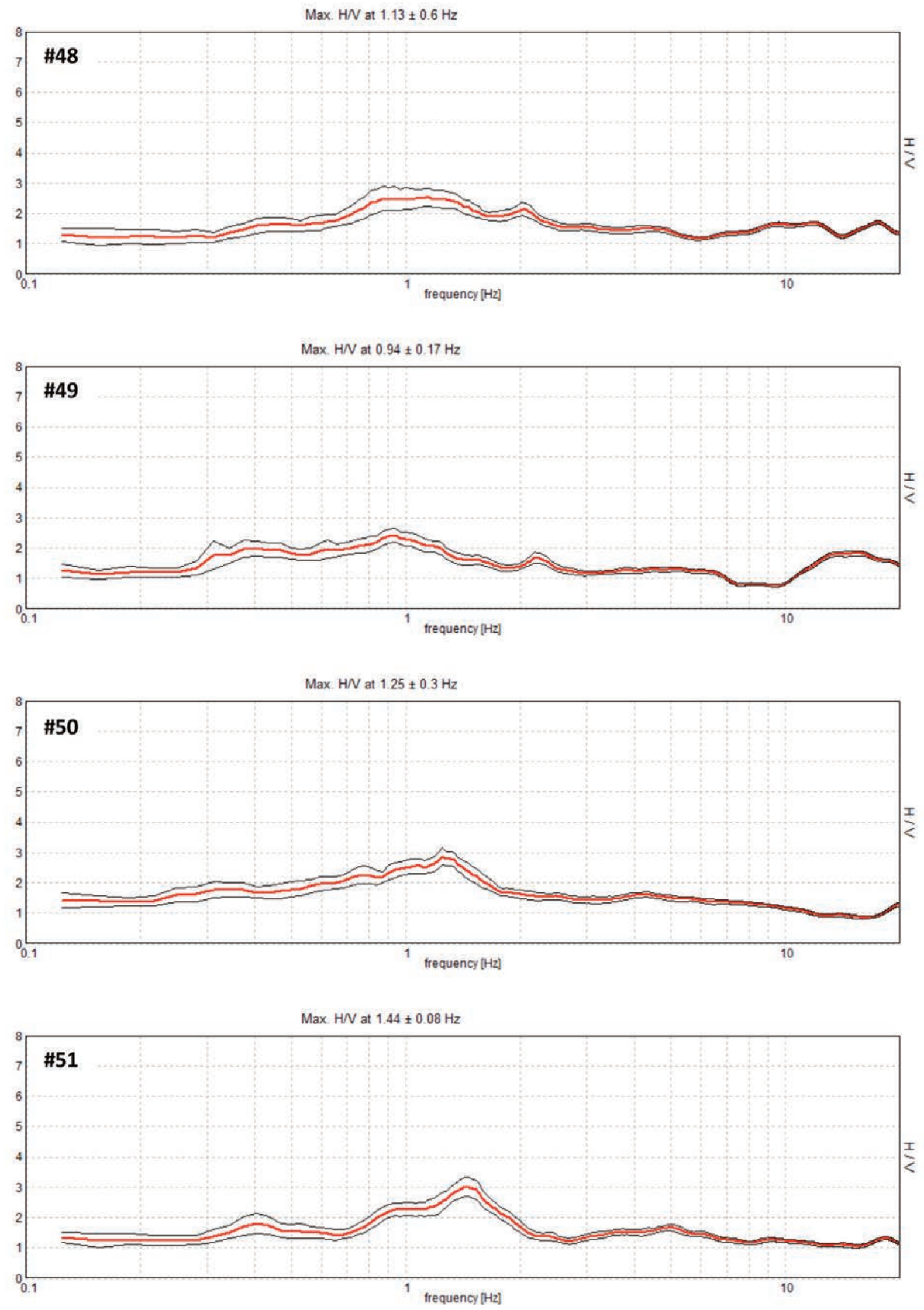

FIGURE S8. HVSR curves for the Monumental Cemetery area (\#60). Red curve = mean spectral ratio, black curves = standard deviation. 

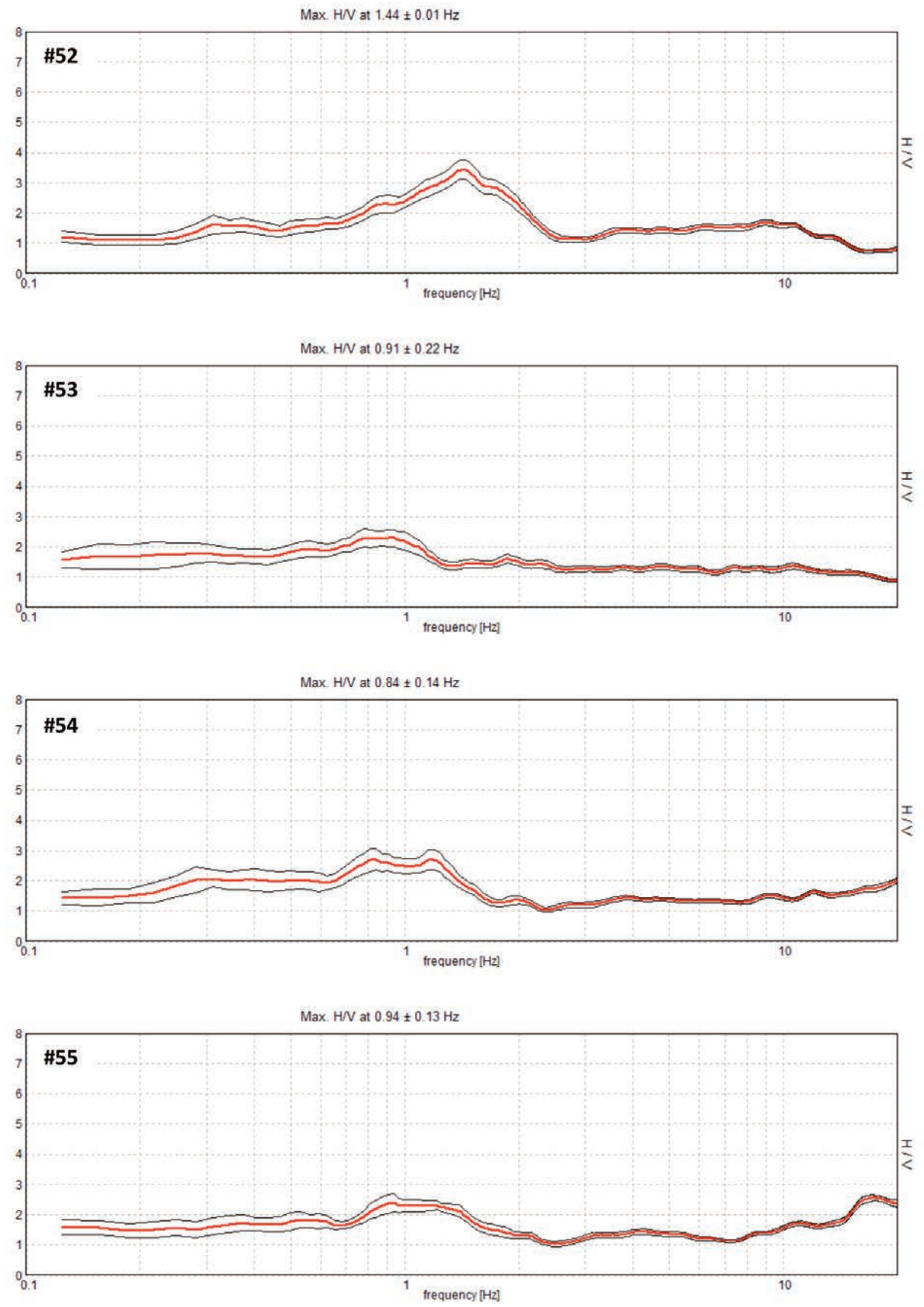

FIGURE S8. HVSR curves for the Monumental Cemetery area (\#60). Red curve = mean spectral ratio, black curves = standard deviation. 

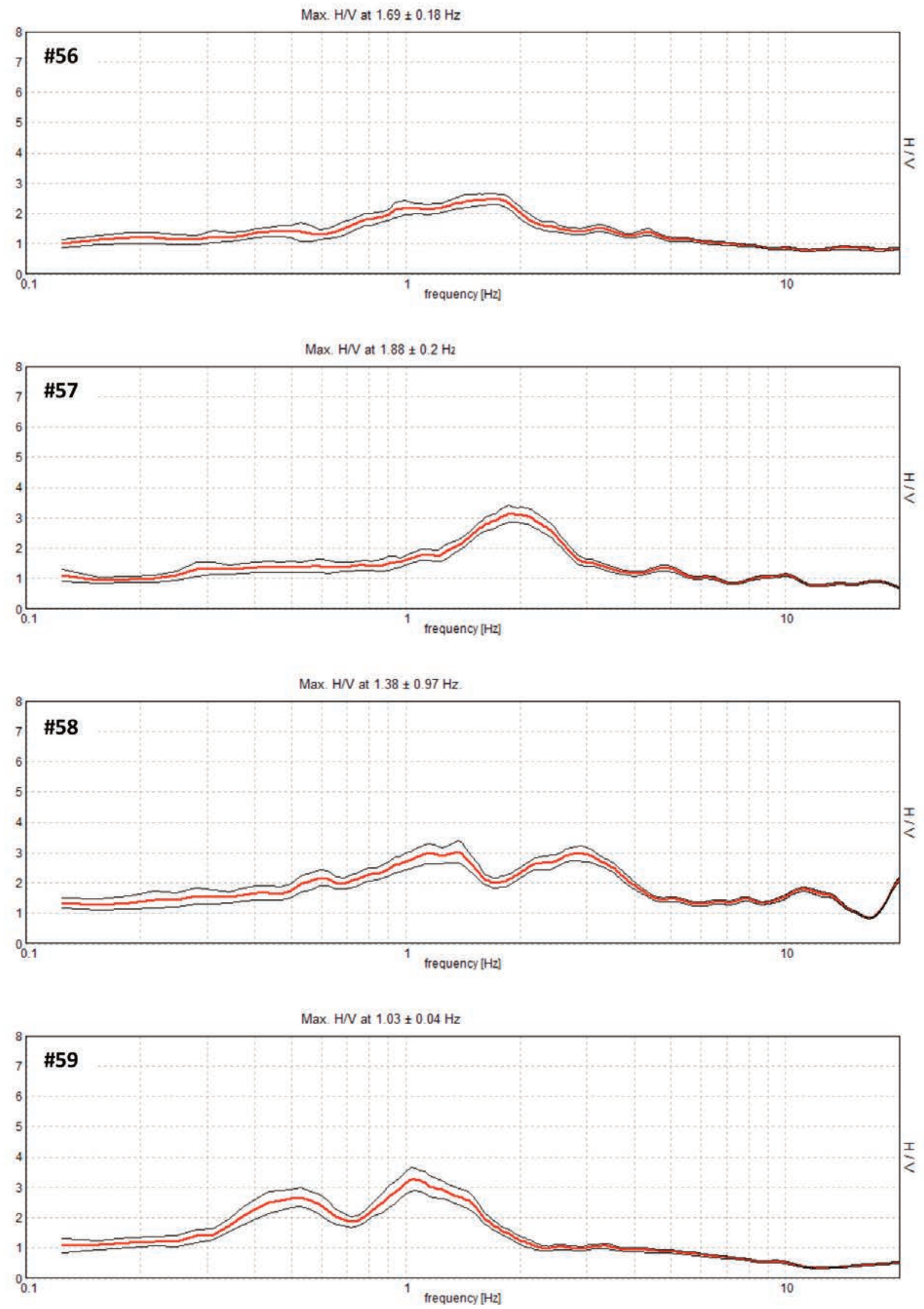

FIGURE S8. HVSR curves for the Monumental Cemetery area (\#60). Red curve = mean spectral ratio, black curves = standard deviation. 


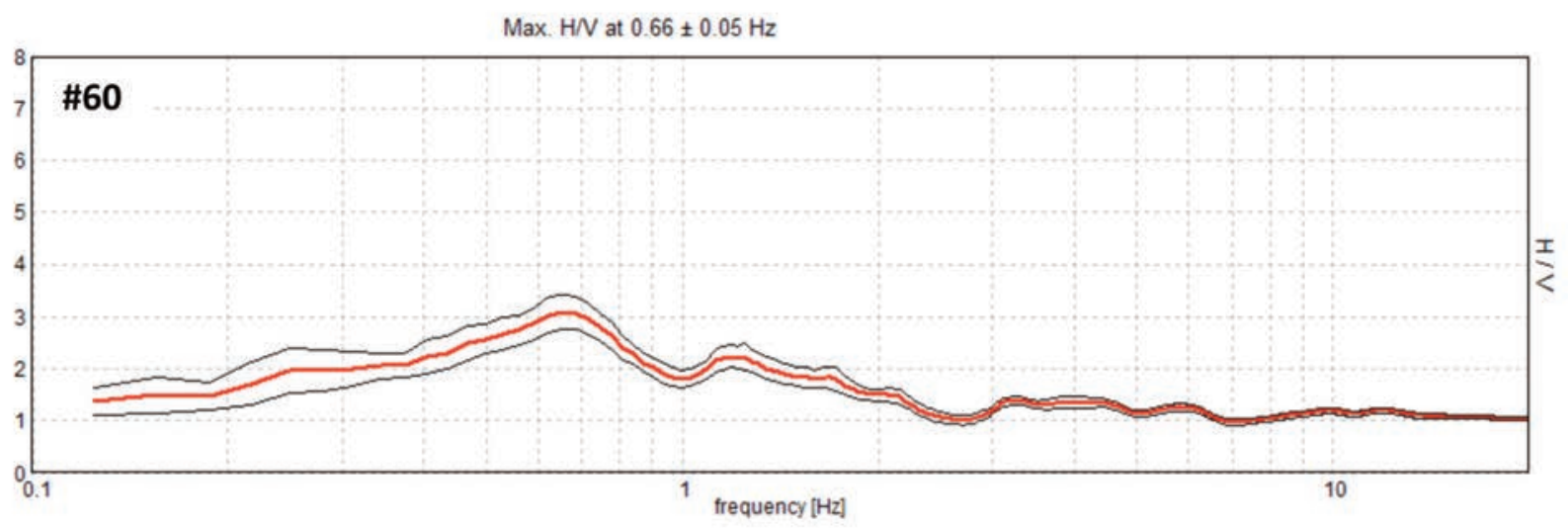

FIGURE S8. HVSR curves for the Monumental Cemetery area (\#60). Red curve $=$ mean spectral ratio, black curves $=$ standard deviation. 